RÓZSA JUHOS*

\title{
MÖGLICHE FUNKTIONEN DER MITTELALTERLICHEN HEILIGEN GRÄBER
}

Possible Functions of Medieval Holy Sepulchres. In Western Christianity, the tomb of Christ and the Church of the Holy Sepulchre in Jerusalem not only served as an influential architectural precedent throughout the Middle Ages, but also became a defining element of the Good Friday and Easter liturgies. Liturgical sources inform us that in some parts of the Latin Church, beginning in the second half of the tenth century, it was customary on Good Friday to place the Cross and/or the consecrated Host from Holy Thursday into the sepulchrum, the symbolic tomb of Christ. The Crucifix and the Sacrament would be removed from the sepulchre at dawn on Easter Sunday, and the empty tomb became the semantic centre of the Easter ceremony, as evidence of the Resurrection. Sculptural representations of the Holy Sepulchre from as early as the thirteenth century have survived, and it is possible to deduce that they were used to fulfil the function of the sepulchrum during the ceremonies of Holy Week. Liturgical texts do not usually make reference to figural Holy Sepulchres, so they cannot be used as direct sources for this purpose, although they do help us to understand liturgical sepulchres and to determine the role they performed in the liturgical space. The sepulchre was, on the one hand, a tool used in liturgical practice, and the ceremony itself defined the object, its status and its interpretation. A deeper examination of the activities carried out during the Triduum Sacrum, meanwhile, may enable us to determine the active role of the Holy Sepulchre, as an image, as part of the ceremony and for the duration of the ceremony. The use of sepulchres was not limited to liturgical or ritual practice, for certain examples remained visible at other times of the year, and may have provided an opportunity for the images to be used for individual devotion. The unrelated written and material sources may, in the final analysis, lend us the chance to identify the conceptual functions of the liturgical-ritual Holy Sepulchre and the Holy Sepulchre as an image.

Keywords: Holy Sepulchre, Good Friday and Easter liturgies, devotional practices, functions of images in the Middle Ages

\section{EINLEITUNG}

Das Grab Christi in Jerusalem ist ein zentrales Thema und ein architektonisches Urbild der christlichen Kunst und des Christenglaubens. Die nach dem Vorbild der Grabeskirche erbauten Friedhofs-, Tauf- oder Gedenkkapellen, deren Tituli sich oft auf das Vorbild bezogen, ${ }^{1}$ sind seit dem 9. Jahrhundert bekannt, verbreiteten sich aber besonders ab dem 11. Jahrhundert infolge der Kreuzzüge. Vom 11. Jahrhundert an erschienen Kopien des Heiligen Grabs auch im Inne-

\footnotetext{
* Rózsa Juhos PhD student, Doctoral School of Philosophical Sciences, Eötvös Loránd University, Faculty of Arts and Humanities, Institute of Art History; e-mail: juhos.rozsa@gmail.com
}

ren der Kirchen (Abb. 1-2). Heiliges Grab nennt man nicht nur die eigenständigen Baueinheiten, sondern auch die vom 13. Jahrhundert üblich gewordenen plastischen figuralen Kompositionen in architektonischem Rahmen, die Figuren aus den Szenen von Christus im Grab, der Auferstehung oder in einigen Fällen der Grablegung enthalten ${ }^{2}$ (Abb. 3a). Dieser Aufsatz erörtert die Gruppe von Heiliggrab-Kompositionen, die in den vom 10. Jahrhundert gebräuchlichen Zeremonien der westlichen christlichen Liturgie beim sog. sepulchrum, dem symbolischen Grab Christi, eine Rolle spielten. Man legte am Karfreitag, nach der Missa praesanctificatorum und der Kreuzverehrung (adoratio crucis) symbolisch das Kruzifix und/oder 


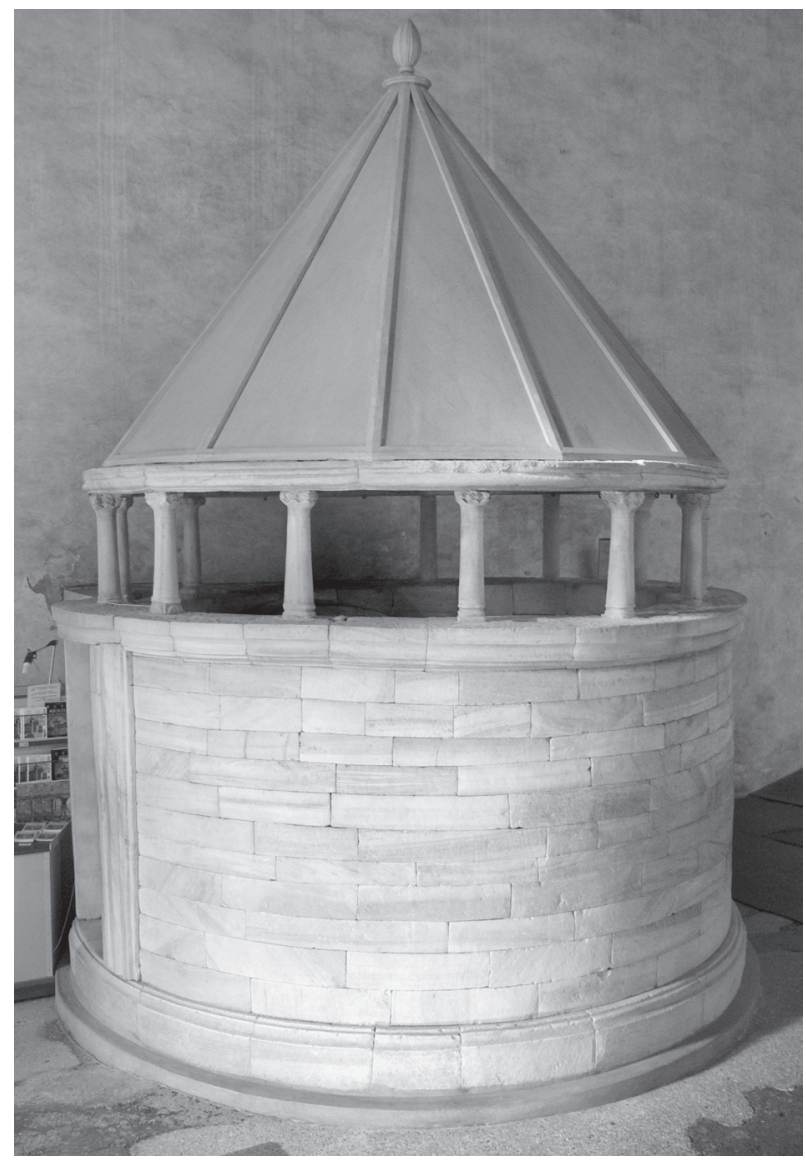

Abb. 1. Aquileia, Basilika, Nachbau des Heiligen Grabes in Jerusalem, 11. Jahrhundert

(Foto: https://commons.wikimedia.org/wiki/File:Aquileia_ Basilica_-_Heiliges_Grab.jpg)

die am Gründonnerstag geweihte Hostie zu Grabe. Dieser Ritus wird in den liturgischen Quellen depositio crucis oder depositio hostiae genannt. In der Osternacht entnahm man in der elevatio meist insgeheim den Depositionsgegenstand oder die Gegenstände, und man brachte ihn/sie auf den Hochaltar oder den Seitenaltar, möglicherweise in die Sakristei zurück. In der Matutin fand der Ostertropus visitatio sepulchri statt, der sich als Gespräch zwischen den drei Marien und dem Engel am leeren Grab abspielte, und begann mit der Frage „Quem quaeritis?“ (Wen sucht ihr?). Die frühesten bekannten Vorschriften bezüglich der Riten des Triduum Sacrum finden sich in der um 973 vom Aethelwold, dem Bischof von Winchester, zusammengestellten Regularis Concordia. Hier erscheinen die depositio und die elevatio des Kruzifixes. Das früheste Beispiel der symbolischen Grablegung der Hostie geht aus der Biografie des heiligen Ulrich, des Bischofs von Augsburg (†973), hervor. Nach ihr war dieser Ritus in der zweiten Hälfte des 10. Jahrhunderts schon gebräuchlich. Die Rituale waren bis zu den Bestre-

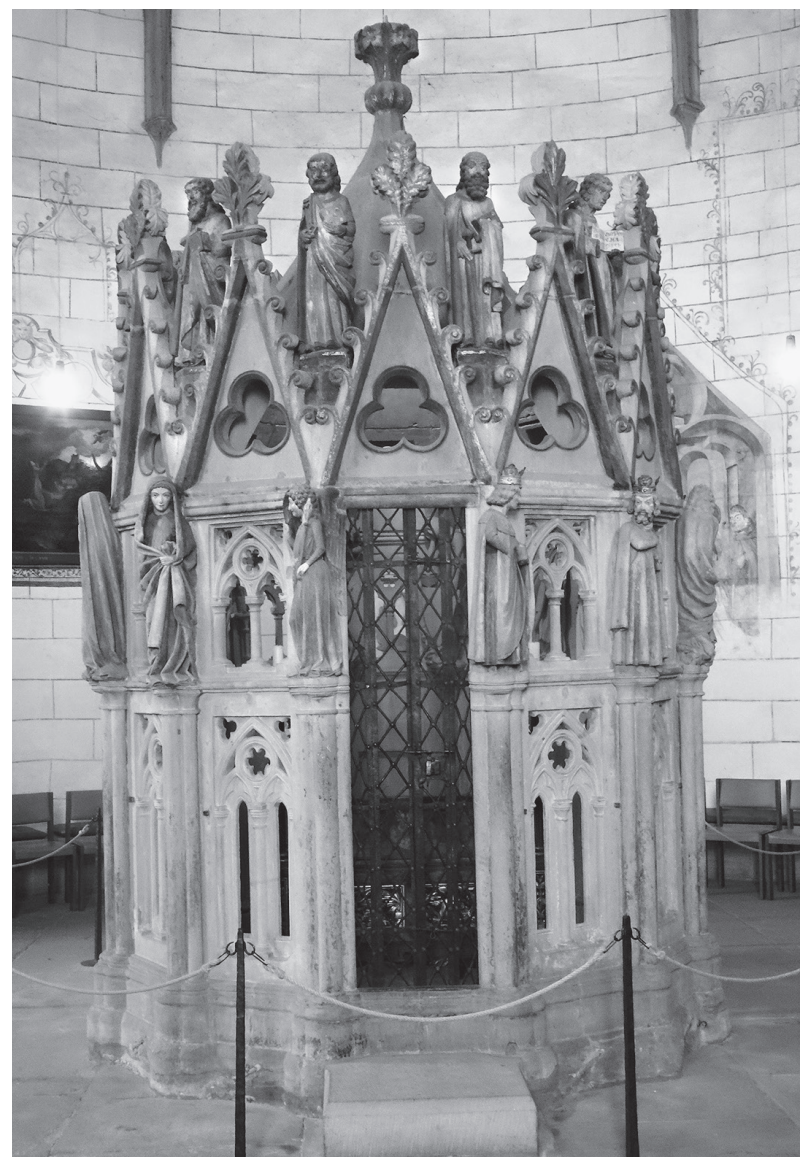

Abb. 2. Konstanz, Münster, Mauritiusrotunda, um 1260 (Foto: Pál Lôvei)

bungen zur Vereinheitlichung der Liturgie nach dem Konzil von Trient - und vielerorts auch danach - recht verbreitet, obwohl sie nie verbindlich vorgeschrieben waren. Nicht nur die verschiedenen HeiliggrabTypen, sondern auch die Bildtypen der depositio, wie die Abbildung des Leichnams Christi oder die vom Kreuz abnehmbare Christusgestalt, deren bewegliche Arme an den Körper angelegt werden konnten, ${ }^{3}$ bildeten sich bis zum 13. Jahrhundert heraus.

Der genaue Gebrauch der einzelnen HeiliggrabBauten ist generell in keiner zeitgenössischen Schriftquelle dokumentiert. Um die Art ihrer Benutzung nachzuvollziehen, müsste man gleichzeitig auch die liturgische Handlung rekonstruieren, wozu jedoch keine ausreichenden Informationen verfügbar sind. Die liturgischen Quellen informieren nur selten über den genauen Ablauf eines Rituals und verraten nicht viel über den sepulchrum genannten Gegenstand, in den die Hostie oder das Kruzifix gelegt wurde. Erforscht werden können daher nur die formalen und strukturalen Eigenheiten der Heiliggrab-Bauten. Eine 


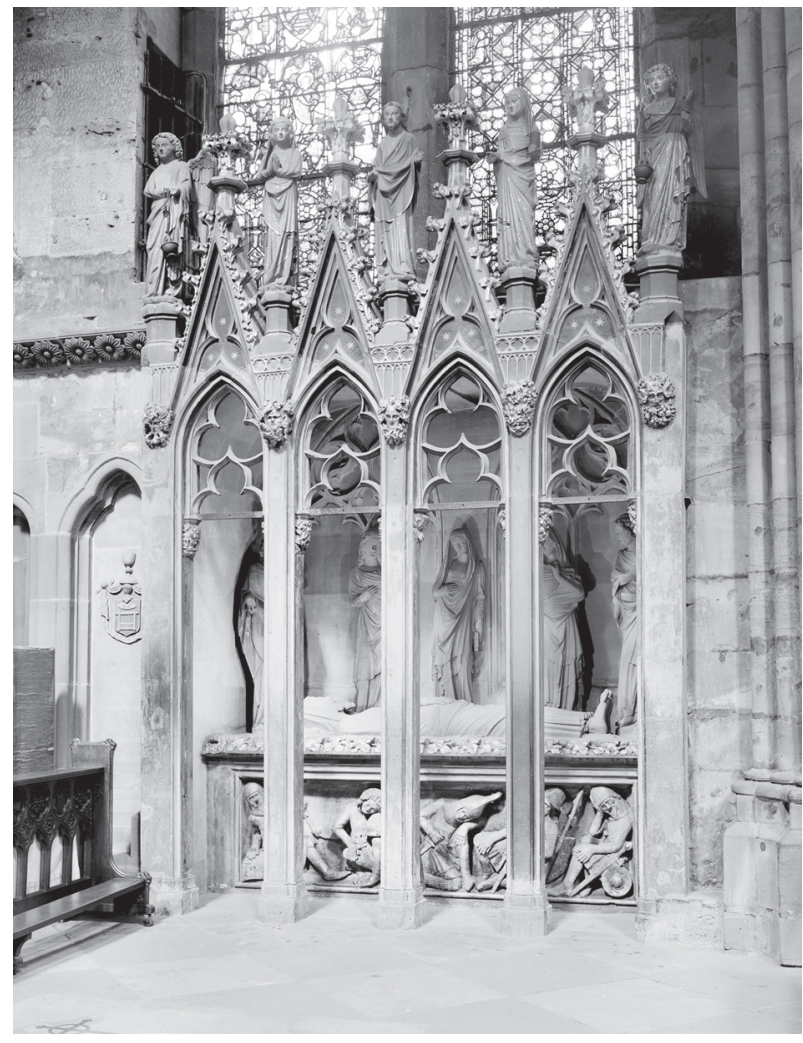

Abb. 3a. Freiburg im Breisgau, Münster, Heiliges Grab, um 1330 (Foto: Helga Schmidt-Glassner, Bildarchiv Foto Marburg: http://www.bildindex.de/document/ obj20564472)

mögliche Veränderung der Funktion wird also aus der Typengeschichte abgeleitet und die Schriftquellen illustrieren bloß die allgemeine Bestimmung des Kontextes. Eine Ausnahme bildet die Arbeit von Neil C. Brook, der anhand von Quellentexten versuchte, Heiliggrab-Typen zu unterscheiden, welche sich aber schwerlich mit den bekannten Heiliggrab-Formen in Einklang bringen lassen. ${ }^{4}$ Zwei Möglichkeiten bestehen: Einerseits kann man die einzelnen Gegenstände als primäre Quellen der Funktion untersuchen, andererseits können die mit ihnen unmittelbar nicht zusammenhängenden Schriftquellen ermittelt werden. Diese können uns gewissermaßen darüber Auskunft geben, welche Ansprüche die damalige Liturgie an Heilige Gräber stellte. Will man jedoch die beiden Möglichkeiten ins Verhältnis setzen, muss man umsichtig vor-

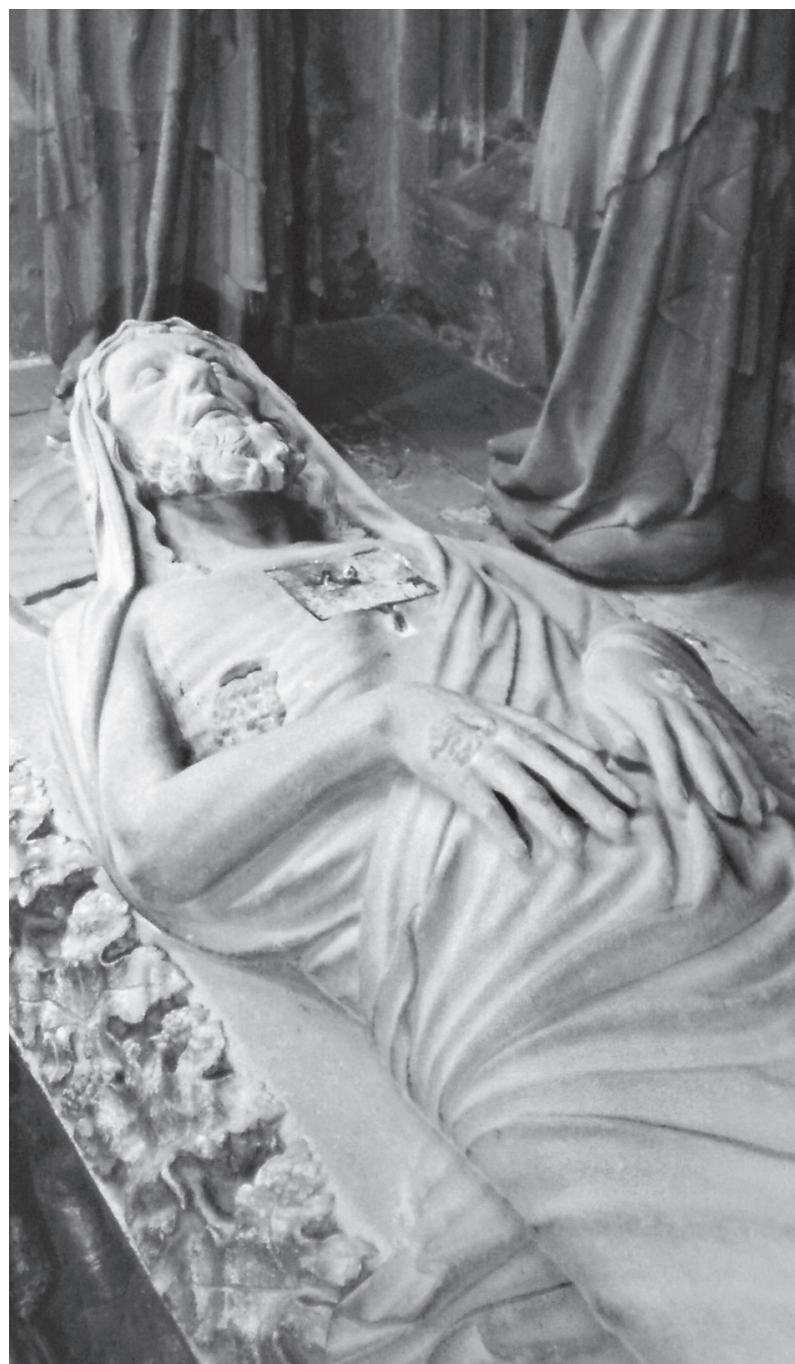

Abb. 3b. Freiburg im Breisgau, Münster, die Christusfigur im Heiligen Grab, um 1330 [Foto: Der Freiburger Münster 2011, (vgl. Anm. 6) 219.]

gehen. Das Ziel kann nicht sein, die Textstellen wie Mosaikstücke zusammenzufügen oder bei der Untersuchung der einzelnen Form- und Strukturelemente die Textquellen einseitig nur zum Beleg unserer Hypothesen heranzuziehen; sie hängen nämlich mit dem gegebenen Gegenstand meist nicht zusammen. Die beiderseits bestimmten Ziele und Ansprüche werden nicht unbedingt gleich sein, aber sie können einander in ein neues Licht stellen.

\section{PROBLEME BEI DER FUNKTIONSBESTIMMUNG}

Den Gebrauch betreffend lassen sich einerseits ständige, aus Stein gemeißelte Heilige Gräber unterscheiden, die das ganze Jahr über sichtbar waren (Abb. 3a und 4). Sie hatten also eine Funktion nicht nur wäh- rend der Karwoche, sondern auch während des ganzen Jahres, denn sie waren ständig zugänglich. Eine andere Gruppe der Heiligen Gräber wurde hingegen nur in einem bestimmten Zeitraum des Jahres, in den 


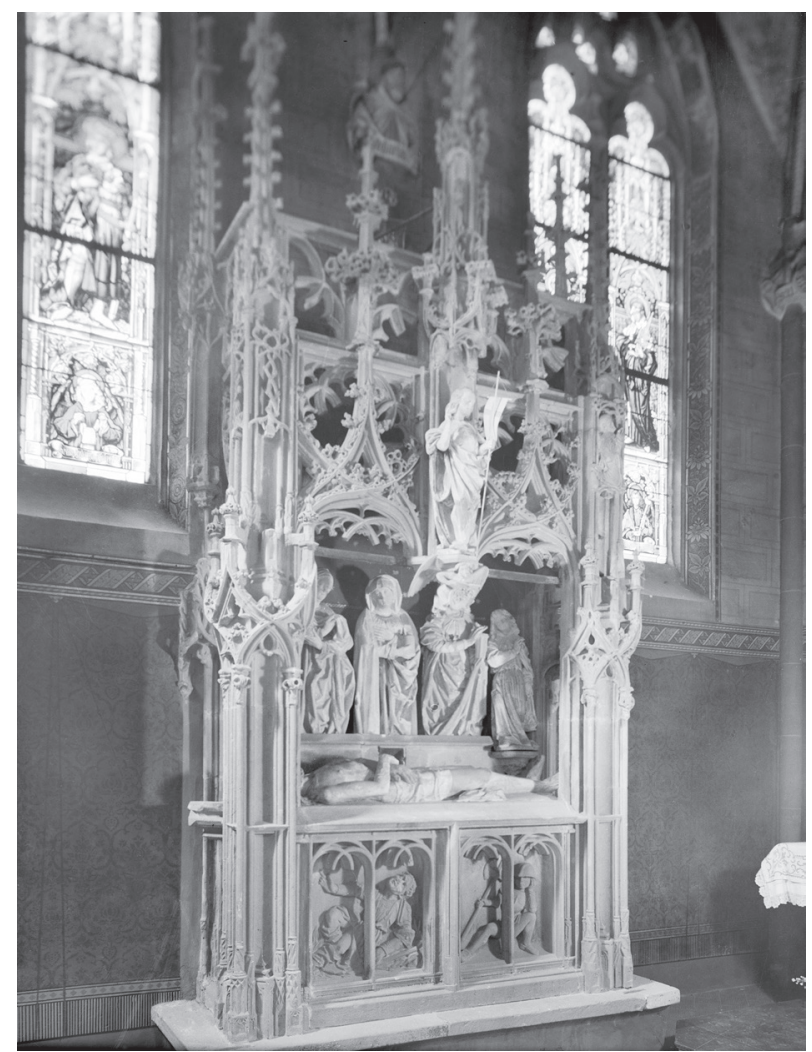

Abb. 4. Klosterkirche Gengenbach im Wissembourg, Heiliges Grab, 1505 (Foto: (C) Bildarchiv Foto Marburg)

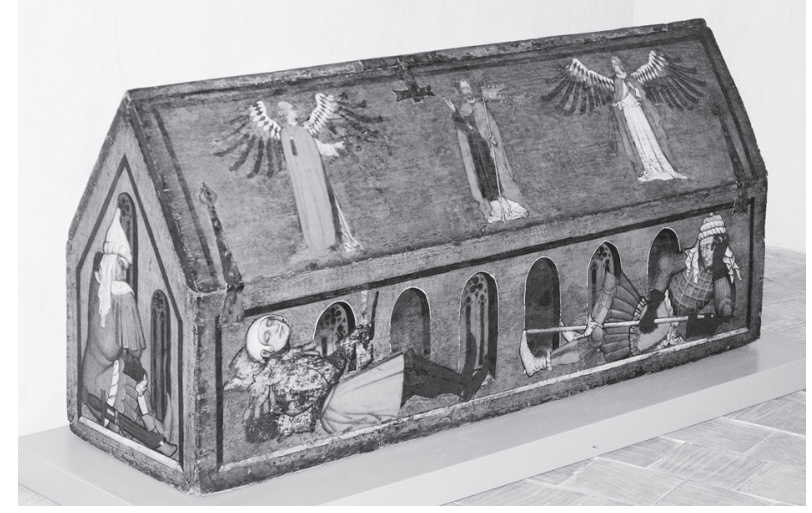

Abb. 5. Heiliggrabtruhe von Baar, um 1430, Museum Burg im Zug (Foto: https://commons.wikimedia.org/wiki/ File:Heiligengrabtruhe-Baar.JPG)

heiligen drei Tagen benutzt, dann wurden sie - nach der Feier - aus dem Kirchenraum entfernt. Sie waren aus Holz gefertigt. Ihre Qualität reichte von weniger anspruchsvollen Tischlerarbeiten bis zu vollkommen verzierten, repräsentativen Holzschnitzerarbeiten (Abb. 5 und 15). Das benutzte Material oder die Gestaltungsweise bestimmte trotzdem nicht immer die Art und Weise der Benutzung. Obwohl das Heilige Grab aus Holz von Wienhausen (Abb. 20a) nicht eingebaut war, beweist eine Notiz, dass es ganzjährig zugänglich war. ${ }^{5}$

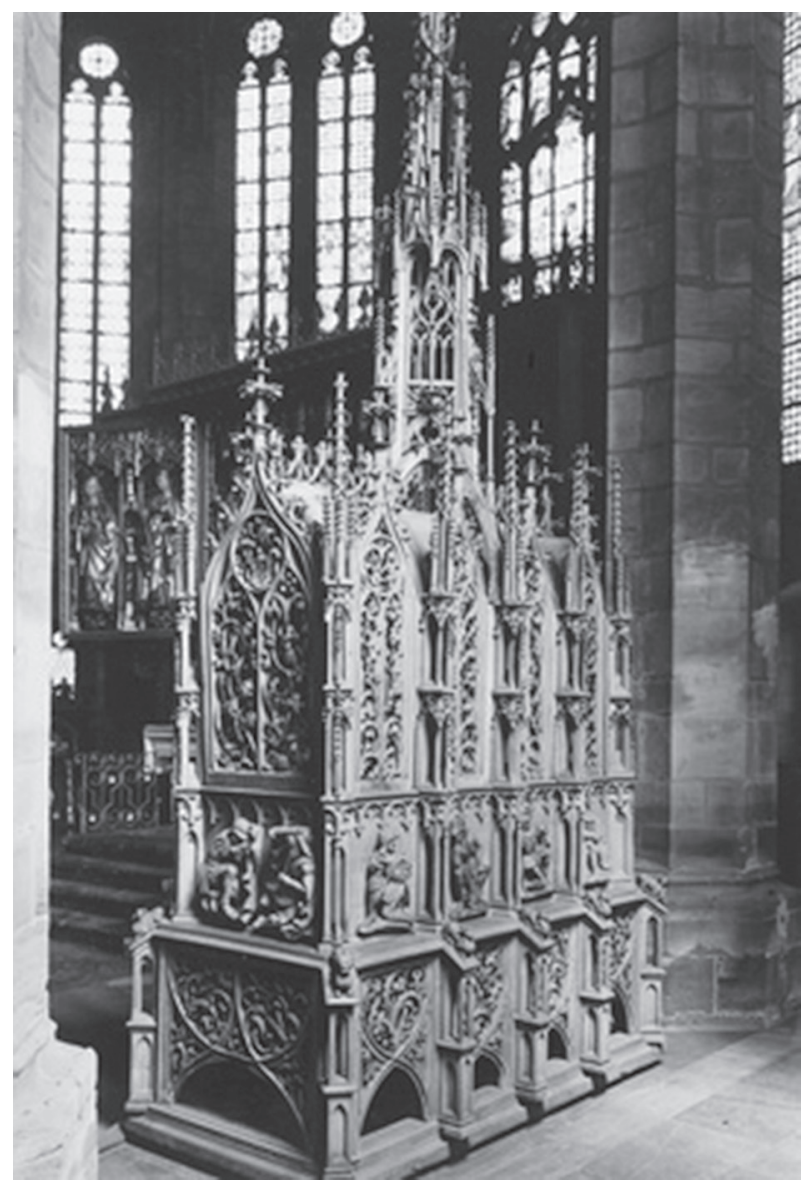

Abb. 6. Michael Heuffner: Heiliges Grab, 1507; Zwickau, Marienkirche (Foto: Deutsche Fotothek, Sächsische Landesbibliothek - Staats- und Universitätsbibliothek Dresden: http://www.deutschefotothek.de/documents/ obj/33135030)

Dies bedeutet, dass es auch außerhalb der Osterliturgie eine Funktion hatte. Man kann also von einer Doppelfunktion sprechen: Neben dem liturgischen Gebrauch diente es in der übrigen Zeit des Kirchenjahres außer der Liturgie als eine Art „offentliches Andachtsbild“.

Hinsichtlich der Deposition unterscheiden sich einerseits Heilige Gräber, die zum Einlegen der Hostie dienten und andere, die auch das Einlegen und später die Entnahme eines Kruzifixes oder der Skulptur des Leichnams Christi ermöglichten. Im Fall des Heiligen Grabes im Freiburger Münster, das um 1330 aus Stein gefertigt wurde, liegt Christus auf dem Sarg, sein Körper kann nicht abgenommen werden. Für die Hostie gestaltete man eine Vertiefung in der Brust der liegenden Christusgestalt (Abb. 3b). ${ }^{6} \mathrm{Zu}$ den Holztruhen gehörte hingegen eine Christusfigur aus Holz. Die Schriftquellen nennen den ersteren Ritus depositio hostiae, den letzteren depositio crucis. Darüber hinaus gab es auch die Kombination von beiden, unter 

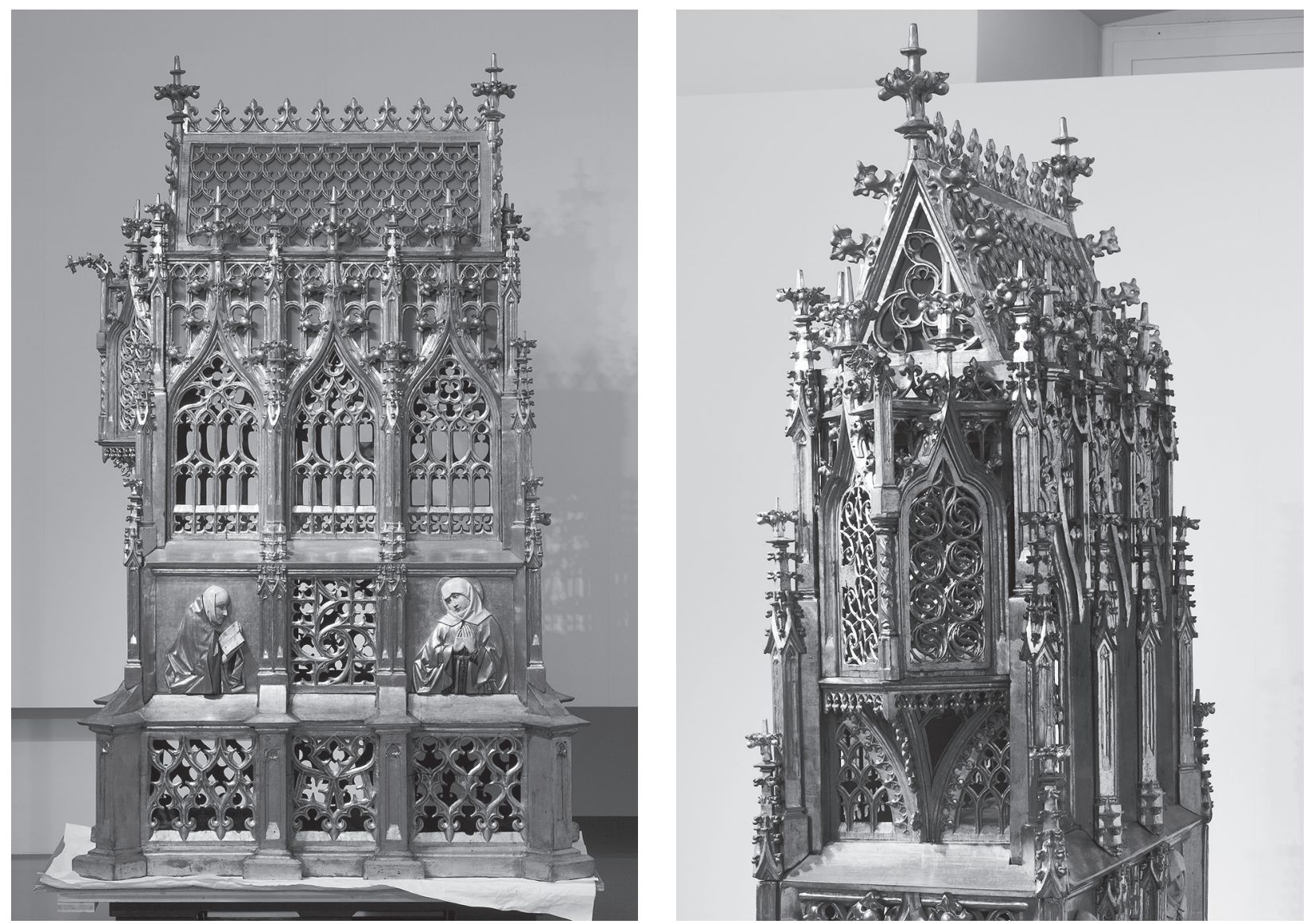

Abb. 7a-b. Salzburg, Heiliges Grab aus der Bürgerspitalkirche St. Blasius, um 1475; Salzburg Museum, Inv.-Nr. 424/30 (Foto: (C) Salzburg Museum)

dem Namen depositio crucis et hostiae, aber unter den vorhandenen Heiliggräbern kann die Gruppe, die zu diesem Ritual diente, schwerlich abgegrenzt werden. Der Depositionsgegenstand ist nicht in allen Fällen erhalten geblieben oder man kann ihn nur anhand der Abmessungen der Nische erschließen. In Zwickau ist glücklicherweise eine aus Holz geschnitzte, liegende Christusfigur erhalten, welche - nach ihrem Stil zu urteilen - mit der Werkstatt von Michael Heuffner, dem Meister des Heiligen Grabes, zu verbinden ist ${ }^{\top}$ (Abb. 6). Die Depositionsgestalt des um 1475 datierten Heiligen Grabes der Bürgerspitalkirche St. Blasius zu Salzburg (Abb. $7 a-b)$ ist beispielsweise nicht erhalten geblieben. ${ }^{8}$ In seiner Form ähnelte es sehr dem Heiligen Grab der Marienkirche von Zwickau, aber die beiden weisen wesentliche strukturelle Unterschiede auf. Im dreistöckigen Aufbau des Heiligen Grabes von Salzburg befindet sich nämlich die Tür in der Mitte der Längsseite, welche die Möglichkeit der Niederlegung einer Skulptur fraglich erscheinen lässt. Die im Dommuseum Salzburg aufbewahrte Christusfigur mit beweglichen Armen ${ }^{9}$ (Abb. 8) ist viel älter; weder ihre Datierung auf etwa 1525 noch ihre Abmessungen machen es wahrscheinlich, dass die Skulptur zu dem auf 1475 datierten, verzierten Schrein gehört hat.

Es stellt sich die Frage, ob die Depositionsgegenstände hinsichtlich der Liturgie als gleichwertig betrachtet werden können. Macht die Grablegung der am Gründonnerstag geweihten Hostie auch die Handlung liturgisch, oder wird sie liturgisch eher durch die Anknüpfung an die liturgischen Osterriten? Die Spuren eines Rituals der depositio hostiae ist nicht immer so eindeutig überliefert wie in Freiburg. Nach Annemarie Schwarzweber kann man in den Fällen, wo kein Ritus mit dem Altarsakrament nachweisbar (also kein depositorium vorhanden) ist, nicht von einem liturgischen Gebrauch, sondern nur von einer Andachtsbildfunktion sprechen. ${ }^{10}$ Die Verwendung der Skulptur - nach Schwarzwebers Beurteilung - sei nicht gleichwertig mit der Deposition des Sakraments. Im Gegensatz zu ihr betonten Johannes und Gesine Taubert beim Überblick der verschiedenen Depositionsgegenstände, dass die liturgische Funktion nicht prinzipiell mit der Anwesenheit der geweihten Hostie zusammenhängt. ${ }^{11}$ Die Grablegung des Kreuzes war nämlich nach den Schriftquellen verbreiteter und der Ritus älter als der 
der geweihten Hostie. Die Kombination beider wurde erst später im 14. Jahrhundert bekannt. Die Deposition des Kruzifixes wurde also auch an sich als liturgische Handlung betrachtet, was auch die Skulptur betraf. Hinsichtlich der Entwicklung der Depositionsgegenstände ging das Kruzifix dem Gebrauch der Christusgestalt voran. Die Funktionsbestimmung nach Tauberts stellt keine hohen Anforderungen: Während des Gottesdienstes müsse der Gegenstand an einer bestimmten liturgischen Stelle liturgisch benutzt werden, unabhängig davon, ob er mit der Eucharistie unmittelbar in Verbindung steht.

Um die Definition „Bild zum liturgischen Gebrauch“ zu vermeiden, führte Johannes Tripps einen neuen Terminus, das handelnde Bildwerk, ein: Es erfüllte seine Funktion während des Gottesdienstes - in engem Zusammenhang mit der Liturgie - an einem bestimmten Standort. In Anknüpfung an den Gebrauch eines anderen Bildtyps, der Imago Ascensionis, die während der Himmelfahrtsfeier durch ein „Himmelloch“ gehoben worden war, schlug Hans-Joachim Krause den Termin liturgisches Brauchbild vor. ${ }^{12}$ Die Betonung einer engen Verbindung zwischen der Liturgie und den Gegenständen hatte zwei Konsequenzen. Erstens lassen wir außer Acht, dass die Rituale an den heiligen drei Tagen ursprünglich ohne Bilder stattfanden, und im Fall eines Rituals, in dem man Bilder verwendet, sollen wir einen Zeichengebrauch ganz anderer Art erwarten. Der Bildgebrauch und die liturgische Verwendung der Gegenstände stehen nämlich in Widerspruch: Der Depositionsgegenstand musste nach den liturgischen Texten eingeschlossen werden, er war also nicht sichtbar. Wenn eine Skulptur als Depositionsgegenstand verwendet wurde, brauchte man in der Zeremonie selbst keine Christusgestalt als Bild darzustellen.

Die andere Konsequenz war die Trennung in der Funktion von Andachtsbild und liturgischem Gebrauch. Nach Johannes Tripps entbehre das handelnde Bildwerk der Distanz, die zur Kontemplation, dem Erleben der mystischen Vereinigung und der Vision erforderlich ist. ${ }^{13}$ Es mache die Passion unmittelbar erlebbar, rege nicht die Fantasie an und gebe keinen Raum zur Vertiefung. Gleichermaßen betonte auch Krause, wenn ein Bild während der Liturgie an Ort und Zeit ziemlich gebunden und temporär gebraucht wird, schließt es die Andachtsbildfunktion des als Kontemplationsgegenstand betrachteten Bildes aus. ${ }^{14}$ Dieselbe Auffassung bezieht sich auf das Heilige Grab als Ganzes. Nur die permanenten Heiliggräber, die außer dem Triduum Sacrum als ein öffentliches

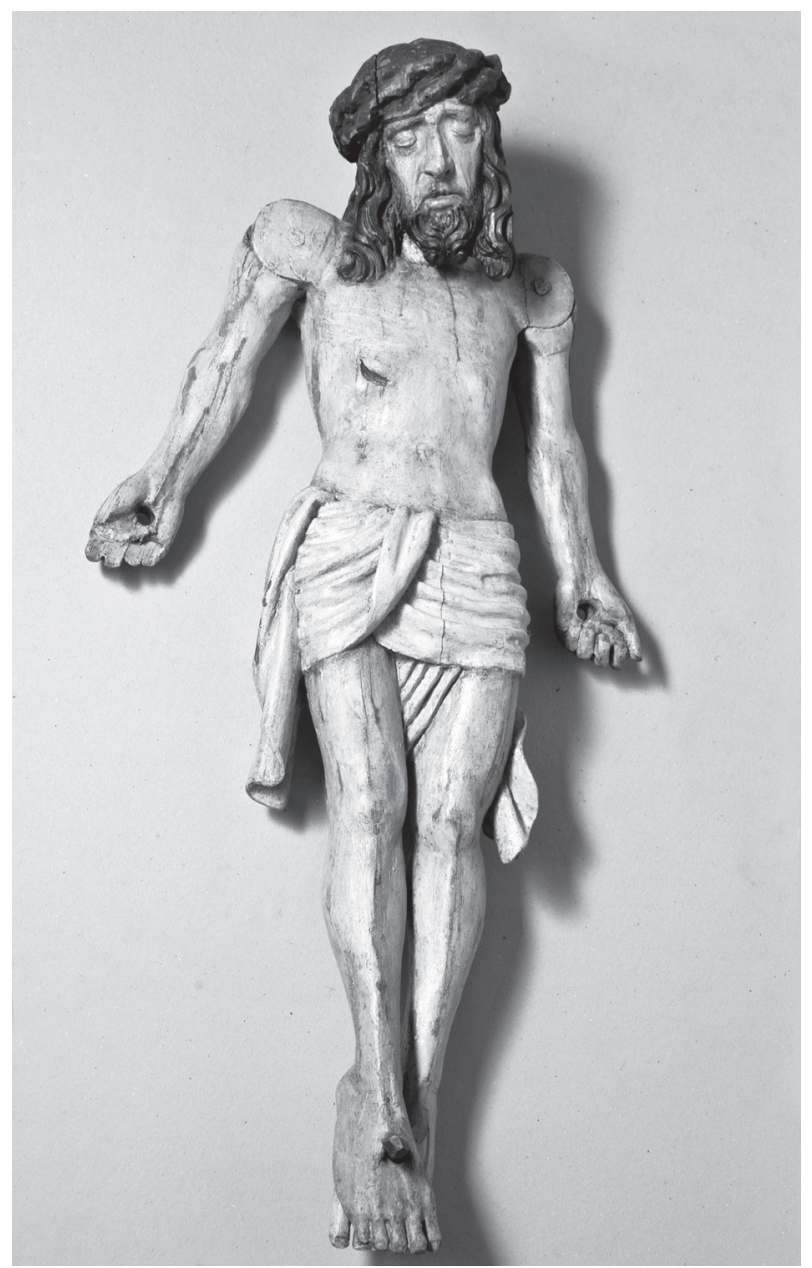

Abb. 8. Kruzifix mit schwenkbaren Armen, um 1525;

Dauerleihgabe bei dem Dommuseum Salzburg (Foto: J. Kral, (C) Dommuseum Salzburg)

Andachtsbild wirkten, hatten eine Devotionsfunktion. In diesem Fall haben sowohl die liturgische als auch die Andachtsbildfunktion ihre Zeit und ihren Ort. Da die beiden sich nicht decken, taucht das Problem des Widerspruchs in der Funktion nicht auf. Bezüglich der Heiligen Gräber wurde die Auffassung dieser Doppelfunktion allgemein geteilt. ${ }^{15}$

In diesen Auffassungen besteht eine sehr enge Deutung der Devotion und des Andachtsbildes, die jedoch der liturgischen und Gemeinschaftshandlungen entbehrt. Die Andachtsbildfunktion als eigenes Kontemplationsbild oder die Devotionsfunktion und der liturgische Gebrauch der Heiliggräber bilden zwei entgegengesetzte Pole. Im Ersteren stand das Heilige Grab im Mittelpunkt der eigenen Andacht, einer nicht geregelten religiösen Praxis, im Letzteren stand es aber im Zentrum einer institutionellen Handlung, welche für die Gemeinschaft und vor ihr vollzogen wurde. Während man zur Devotion ein Bild mit einem stän- 
digen Zugang (im Kirchenraum) brauchte, ist dies bei der liturgischen Handlung keine Bedingung. Im Zusammenhang mit dem Heiligen Grab müssen sowohl die liturgische als auch die Devotionsfunktion behandelt werden. Dieser Aufsatz verfolgt auch das Ziel, die beiden Funktionen einander näher zu bringen, da sie sich ergänzt hatten. Wir können also nicht nur über die Dualität eines feierlichen Rituals und des eigenen Gebrauchs sprechen, sondern diese Doppelfunktion bestand während der Riten des Triduum Sacrum auch gleichzeitig. Die Untersuchung der Handlungen um das Heilige Grab und die der Gegenstände wird zugleich zur Definition verschiedener Funktionsbegriffe führen.

\section{III. „SEPULCHRUM“ - DAS HEILIGE GRAB ALS LITURGISCHES MITTEL}

Die Attribute „paraliturgisch“ oder „extraliturgisch“, mit denen man die Osterriten bezeichnete, zeigen, dass die betreffenden Handlungen nicht ständiger Bestandteil der Liturgie waren. Die Ordines Romani enthalten diese Riten nicht, bezüglich der benutzten Gegenstände oder des Ablaufs der gesamten Zeremonie bildeten sich also verschiedene lokale Gebräuche heraus. Hinsichtlich des Begriffs der Liturgie gaben die Dekrete des Zweiten Vatikanischen Konzils einen Anstoß zu einer veränderten Betrachtungsweise. Als deren Auswirkung beschrieb Kolumban Gschwend bei der Untersuchung der Karfreitagsrituale in der Diözese von Brixen den Ritus des Triduum Sacrum als Nebenformen der Liturgie, der sich aus dem offiziellen Gottesdienst entwickelt hatte und eine selbstständige regionale Sitte wurde. Die depositio habe zwar die Züge der Volksgläubigkeit, könne aber als liturgisch betrachtet werden. ${ }^{16}$

Eine feste Vorschrift regelt und institutionalisiert - von den Vertretern der Liturgiewissenschaft und von der Gemeinschaft der Zelebranten bestimmt - die im engen Sinne genommene Liturgie, deren Zelebranten weder Laien noch Frauen sein können. Per definitionem knüpfen die Rituale am Heiligen Grab nur an die Osíterliturgie an, gehören aber nicht eng dazu. Im Mittelalter galt dieser Liturgiebegriff jedoch nicht. Die Riten wurden eher von einer Autorität bestimmt: Eine bischöfliche Bewilligung oder das Geschehen eines Wunders konnten zum Beispiel die Teilnahme von Laien in der Liturgie legitimieren. Nach der neueren Auffassung des Liturgiebegriffs bedeutete die Liturgie selbst im Mittelalter nicht strenge Einhaltung der Vorschriften, sondern sicherte eher einen flexiblen Rahmen, in dem verschiedene Handlungen vollzogen werden konnten. ${ }^{17}$ Der Generalnenner dieser Handlungen war ihre Ritualisierung. Catherine Bell bestimmte die Merkmale der Ritualhandlungen wie folgt: Traditionalismus, Beständigkeit (oder Invarianz), durch Gesetze festgelegter sakraler Symbolismus, Performativität. ${ }^{18}$ Diese Kennzeichen seien weder ausschließlich noch definitiv. Die von Bell aufgestellten Kriterien beschreiben den Prozess der Ritualisierung. Verschiedene Riten knüpfen in unterschiedlichem Maße an eine Tradition oder Vorschriften an, bestimmte Riten wirken eher improvisatorisch, andere stärker fixiert. Nachfolgend möchte ich die Stellung des Heiligen Grabes in den ritualisierten Handlungen erörtern. Was widerfährt dem Heiligen Grab einerseits als passivem Gegenstand während der Zeremonie und was ist seine aktive Rolle in der Gestaltung der Bedeutung während der liturgischen Handlungen?

\section{III.1. Das Heilige Grab als liturgischer Gegenstand} (die depositio des liturgischen Körpers Christi)

Eine ganze Reihe von Büchern enthalten Quellen, die sich auf die Osterriten während der Dreitagefeier beziehen. In den liturgischen Texten bezeichnen die zeremoniellen Anweisungen, die Rubriken die Ausgestaltung des Heiligen Grabes. Bis zur Verbreitung des so genannten tridentinischen Ritus galten verschiedene Ritualvarianten, welche die einzelnen Kirchen mit Bedacht bewahrten und überlieferten. Die Normtexte der Ritualvarianten erhielten sich nach ihrer Festigung im 11. und 12. Jahrhundert noch mehrere Jahrhunderte, so wurden auch die Anweisungen bezüglich der Rituale um das Heilige Grab jahrhundertelang in derselben Form niedergeschrieben. Dies bedeutet nicht unbedingt, dass die Riten unverändert, mit denselben Mitteln vollzogen worden wären. Bei den liturgischen Quellen trifft man in erster Linie Textüberlieferungen. Sie berichten nicht über den genauen Ablauf eines Rituals, sondern sie enthalten anwendbare und empfohlene Normtexte und Anweisungen, die gewissermaßen als Ausgangspunkt dienten. Wir wissen aber nicht, wie man unter verschiedenen Umständen die gewissen Rubriken an Ort und Stelle in der Praxis anwandte. Die Texte weisen auch strengere Regelungen bezüglich der Rituale 


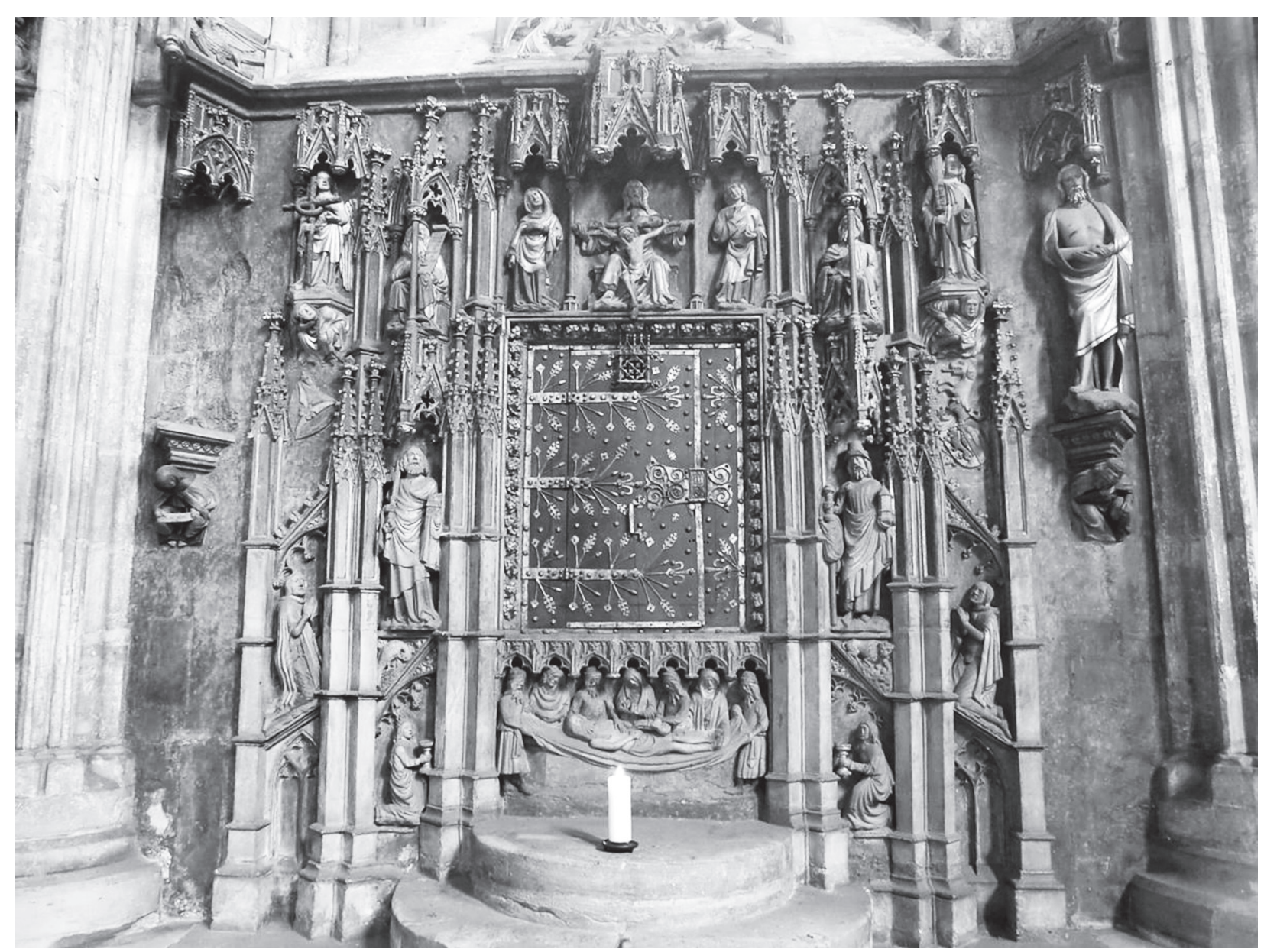

Abb. 9. Nürnberg, Sakramentsnische in der Sebalduskirche um 1375 (Foto: http://4travel.jp/travelogue/10709830)

um das Heilige Grab auf, wie man beispielsweise die symbolische Grablegung der geweihten Hostie auszuführen habe, oder welche Sicherheitsmaßnahmen dabei einzuhalten waren. Jeder einzelne Text über die depositio enthält das Deponieren des Depositionsgegenstandes, was auch als strenge Regel betrachtet werden kann. Die wortkargen und kurzen Vorschriften umfassen natürlich nicht alles, die Kirche ließ also in vieler Hinsicht, zum Beispiel bei den eingesetzten Mitteln, offensichtlich relativ freie Hand. Die liturgischen Texte geben auch Informationen über den Standort des Heiligen Grabes im liturgischen Raum. Die Untersuchung der Texte über die depositio der Eucharistie ermöglicht es, zu erschließen, in welcher Relation das sepulchrum zu anderen Einrichtungsgegenständen und Mitteln im liturgischen Raum stand.

Einige Heilige Gräber, in die man - ihrer Gestaltung nach - die Eucharistie einlegte, können auch als temporäre Tabernakel betrachtet werden. Diese Meinung beruht auf der Untersuchung von Zusammenhängen und Ähnlichkeiten in der Form und Funktion zwischen Heiligem Grab und des Tabernakels. Die
Heiliggrab-Funktion konnte sogar auf den Tabernakel übertragen werden. Nach Annemarie Schwarzweber konnte man wohl den Tabernakel aus dem 14. Jahrhundert in der Kirche St. Sebald von Nürnberg (Abb. 9) oder den der Kirche St. Jakob in Rothenburg ob der Tauber (Abb. 10), wo sich unter dem Tabernakel eine Grablegungsdarstellung findet, am Karfreitag zur depositio verwenden..$^{19}$ Die Darstellung der Grablegung selbst und die Analogie in der Funktion bildeten die Grundlage zu dieser Hypothese. Justin E. A. Kroesen betonte auch den semantischen Zusammenhang zwischen den Heiligen Gräbern und den Tabernakeln. ${ }^{20}$ In den gallikanischen Liturgien übernahm der Aufbewahrungsort des Altarsakraments oft die Bedeutung des Christusgrabes. Die Expositio Brevis antiquae liturgiae gallicanae aus dem 6. Jahrhundert beschreibt diesen Zusammenhang in der Form und der Bedeutung: „Corpus vero Domini ideo defertur in turribus, quia monumentum Domini in similitudinem turris fuit scissum in petra et intus lectum, ubi pausavit corpus dominicum, unde surrexit Rex gloriae in triumphum." 21 Der Aufbewahrungsort der konse- 
krierten Hostie und das Heilige Grab von Jerusalem werden gleichermaßen als Turm bezeichnet. Sie haben neben der Ähnlichkeit in Form und Bedeutung auch eine Analogie in der Funktion, beide dienen nämlich zum Deponieren des Körpers Christi. Die gestalteri- sche und funktionale Übereinstimmung erscheint im auf den Altar stellbaren Tabernakel von Sénanque, der einen Turm nachahmt (Abb. 11), oder in der Heiliggrabkapelle der Kathedrale von Konstanz (Abb. 2), wo beide Beispiele tatsächlich Zentralbauten nachbil-

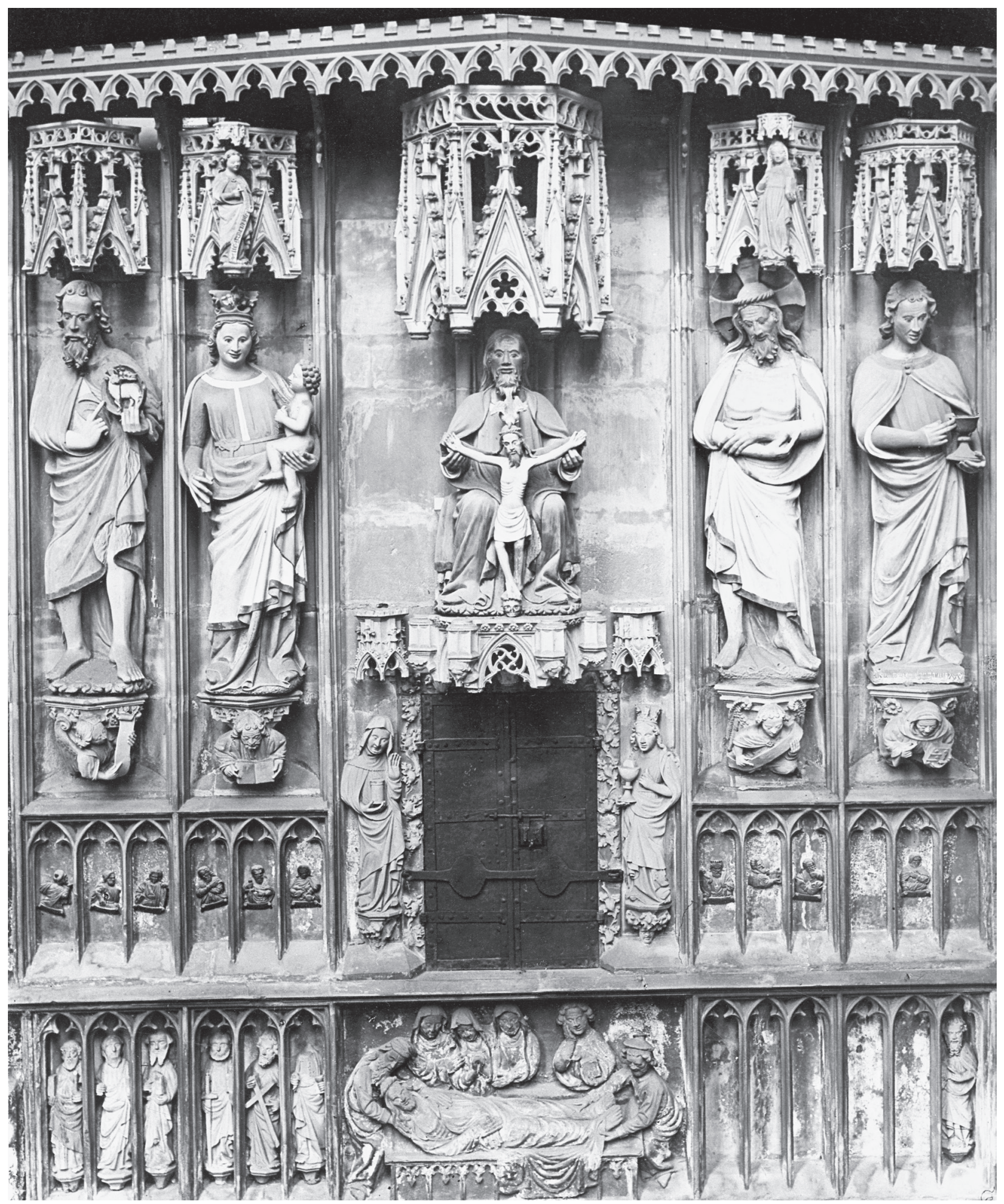

Abb. 10. Rothenburg ob der Tauber, Sakramentsnische in der Stadtpfarrkirche St. Jakob, um 1390-1400 (Foto: (C) Bildarchiv Foto Marburg) 
den. ${ }^{22}$ Diesen Zusammenhang scheint auch die Tatsache zu bestätigen, dass die als Heiliges Grab dienende Wandnische in den Kathedralen in England regelmäBig in der Nordwand des Chores angebracht wurde, ${ }^{23}$ genau an der Stelle, wo der Tabernakel des Altarsakraments auf dem Kontinent gewöhnlich gestellt wurde. Der gleiche Standort der beiden weist auf die Übereinstimmung in ihrem Gebrauch und der Bedeutung der Handlung hin. ${ }^{24}$ Heilige Gräber, die mit einem Tabernakel verbunden sind, finden sich in Südwest-

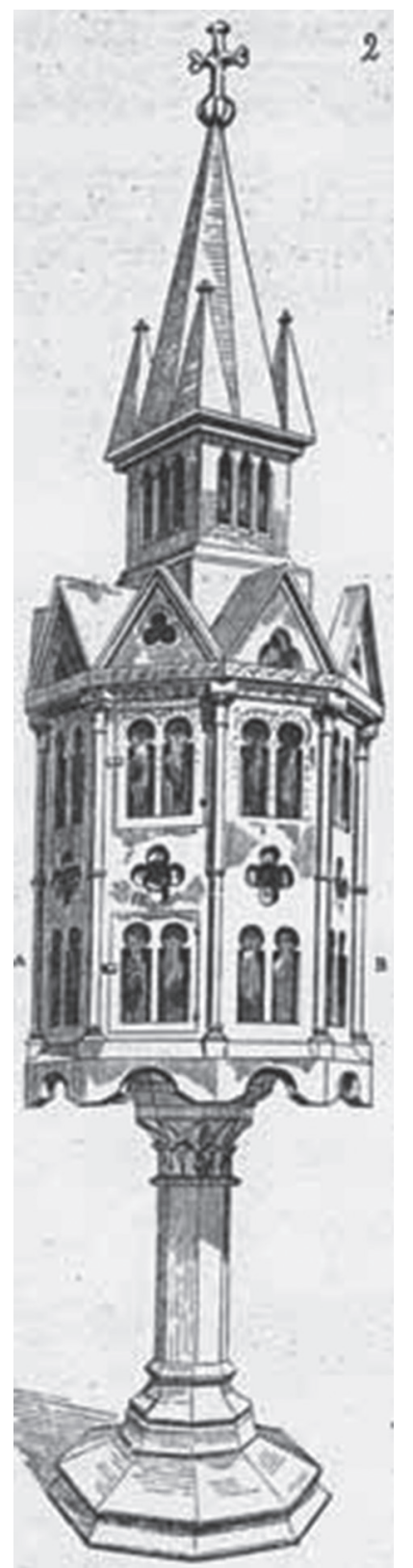

Abb. 11. Sakramentsturm aus dem Zisterzienserkloster Sénanque, frühes 13. Jahrhundert [Zeichnung von Viollet-LE-Duc: Dictionnaire, (vgl. Anm. 22) I. 247: http://college.holycross.edu/projects/kempe/worship/ eucharist/eucharist_3.html] deutschland. In der Chorwand der Kirche St. Gallus in Ötlingen ist ein Sarg mit Reliefs mit den schlafenden Soldaten eingelassen, darüber befindet sich ein Tabernakel ${ }^{25}$ (Abb. 12). Zwei Nischen verschiedener Funktionen sind hier vermutlich untereinander angebracht: Ein ganzjährig benutzter Tabernakel und darunter eine über dem Sarg eingesetzte, 1,3 m breite Nische zum Deponieren des Depositionsgegenstandes. Es ist nicht eindeutig, ob man mit der Anordnung die Verbindung in der Funktion beider Nischen betonen wollte, oder nur eine Raum sparende Lösung suchte. Wie sollte eigentlich der eventuelle formale und semantische Zusammenhang zwischen dem Heiligen Grab und dem Tabernakel bewertet werden?

Diese Frage lässt sich auch bezüglich anderer liturgischer Einrichtungsgegenstände der Kirche stellen. Zwischen dem Altar und dem Heiligen Grab ist die Bedeutungsanalogie vielleicht noch offensichtlicher, da das Wort sepulchrum nicht nur das Ostergrab bedeuten konnte, welches am Karfreitag zur depositio benutzt wurde, sondern auch den im Altar ausgestalteten Ort des Altarsakraments. Die Bedeutungsähnlichkeit mit dem Heiligen Grab erscheint zum Beispiel im Liber officialis von Amalarius von Metz, in dem er den Altar mit dem Grab Christi gleichsetzte: „Per particulam oblatae inmissae in calicem ostenditur Christi corpus quod iam resurrexit a mortuis; per comestam a secerdote vel a populo ambulans adhuc super terram; per relictam in altari iacens in sepulcris." ${ }^{26}$ Das Erheben der geweihten Hostie trägt die Bedeutung der Auferstehung, während die Eucharistie auf dem Altar Christus im Grab symbolisiert. Die Tatsache, dass sowohl der Tabernakel als auch der Altar als Heiliges Grab verstanden werden können, zeigt, dass die liturgischen Mittel in Verbindung mit der konsekrierten Hostie die Bedeutung des Heiligen Grabes übernehmen können. Diese Bedeutungsanalogien an sich beweisen aber nicht, dass ein Altar oder ein Tabernakel am Karfreitag als Heiliges Grab benutzt worden war.

Der Altar als Standort des Heiligen Grabes während der depositio erscheint in einem Teil der liturgischen Texte. Nach dem aus der Benediktinerabtei von Prüfening stammenden ordo aus dem Jahr 1489 war der Heilig-Kreuz-Altar der Ort des sepulchrum: "de corpore dominico in sarcophago in altari Sancte Crucis loco dominici sepulchri preparato recondendo" und „et fit stacio ante altare Sancte Crucis quod antea a custode loco Domenici Sepulchri lintheo magno specialiter ad hoc apto velatum existit". ${ }^{27}$ Demnach stand das Heilige Grab auf dem Altar, das heißt, dass ein Sarg auf den Altar gestellt wurde. Wir dürfen aber 
nicht außer Acht lassen, dass der Sarg die Imitation des Heiligen Grabes war, und der Altar nur den Standort des Heiligen Grabes bezeichnete, aber nicht dessen Bedeutung übernahm. Ein ordinarius um 1400 aus Narbonne beschreibt eine ähnliche Situation: „levent cum filo pannum qui est super libros argenti super altare in figura sepulchri“. ${ }^{28}$ Der Ort des sepulchrum ist auch hier der Altar und die Bezeichnung weist auf eine aus Büchern mit Silberdecken zusammengestellte Konstruktion hin. ${ }^{29}$

Auf eine Benutzung des Tabernakels zur Depositionszwecken gibt es in den liturgischen Quellen keine eindeutigen Hinweise. Der Tabernakel kann natürlich auch am Karfreitag benutzt werden, aber in den Fällen, wenn das Altarsakrament nach der Missa praesanctificatorum in die Sakristei oder in den üblichen Aufbewahrungsort, zum Beispiel in den Tabernakel, zurückgesetzt wurde, bezeichnen die liturgischen Quellen das Ritual nicht als depositio hostiae. In der Kirche St. Emmeran in Regensburg blieb das Allerheiligste nicht im sepulchrum, sondern es wurde in den Aufbewahrungsort zurückgesetzt: „Interim dominus abbas et sacerdotes locaverunt crucem et corpus domini super sepulchrum et ipsum operientes lintheo incensant et cantant responsorium [...] Tunc dominus abbas clam sub casulam accipit corpus domini precedentibus cum cereis portant ipsum in sacrarium more solito reservandum". ${ }^{30}$ Im Heiligen Grab blieb nur das Kruzifix und nur es wurde während der Elevation erhoben und dann zurückgelegt. Das Einlegen des Altarsakraments in seinen Aufbewahrungsort am Karfreitag übernahm nicht die Bedeutung der depositio und der Ort der Aufbewahrung selbst wurde nicht sepulchrum.

In den mittelalterlichen Quellen erscheint auch ein anderer Aufbewahrungsort des Altarsakraments. Der Ort nämlich, an dem man nach der Gründonnerstagmesse die konsekrierte Hostie bis zur Messe am Karfreitag aufbewahrte. Auch dieser Aufbewahrungsort übernahm im Mittelalter nicht die Bezeichnung und die Bedeutung des sepulchrum dort, wo die Sitte der depositio am Karfreitag in Gebrauch war. ${ }^{31}$ Das Verschließen des Allerheiligsten am Gründonnerstag wurde erst vom 16. Jahrhundert zum feierlichen Akt und auch der Aufbewahrungsort während des Verschließens übernahm die Bedeutung des sepulchrum. Welche Rolle der Tabernakel bei den Karfreitag- und Osterriten spielte, kann man nur aus dem Ablauf der Zeremonien erschließen. War die konsekrierte Hostie der Gegenstand der depositio, brauchte man drei verschiedene Orte zum Aufbewahren. Erstens sollte es ein sicherer Ort sein, in den das Altarsakrament nach der

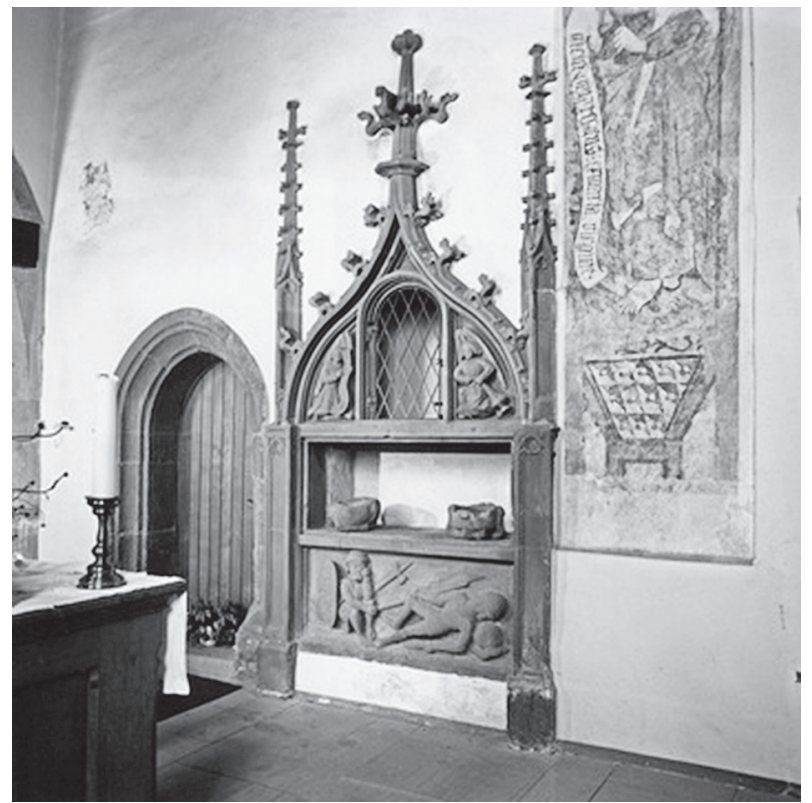

Abb. 12. Galluskirche Ötlingen (Weil am Rhein), Heiliggrabnische mit Sakramentshaus, um 1475 (Foto: Landesmedienzentrum Baden-Württemberg: https://www.leo-bw.de/media/lmz_bilddatenbank_02/ current/delivered/36001-39000/41054.jpg)

Gründonnerstagmesse eingesetzt und von wo es am Karfreitag zum Altar gebracht wurde. Danach trug man das Allerheiligste in einer Prozession ins sepulchrum, in den zweiten Aufbewahrungsort. In der Osternacht brachte man es dann zurück zum üblichen Aufbewahrungsort: Das mochte die Sakristei oder der Tabernakel sein. Er durfte jedoch nicht mit dem sepulchrum identisch sein. Zwischen den beiden Aufbewahrungsorten macht ein aus dem 15. Jahrhundert stammender Liber ordinarius aus Blaubeuren folgenden Unterschied: „Et nota diligenter, quod corpus christi non est dimittendus per illud triduum in loco sepulture, nisi repositum sit sub firma custodia: et testibus seu custodibus circa illud psallentibus adhibitis: Alias vero, ubi huius modi custodia ac psallencium vigilia non fuerit adhibita. Sacerdos finitis vesperis corpus dominicum in suum solitum [...] reportet reservatorium, ubi bene clausum conservetur.“32 Das „reservatorium“ bezeichnet den sicheren und abschließbaren Ort, der zum Aufbewahren des Allerheiligsten am geeignetsten war, das sepulchrum bedurfte jedoch besonderer Bewachung. Der Funktion des reservatorium konnte der Tabernakel entsprechen. Es ist aber nicht wahrscheinlich, dass er die Rolle des sepulchrum übernehmen konnte, da man einen Ort brauchte, von wo die konsekrierte Hostie erhoben wurde, dann einen anderen Ort, in den man das aus dem sepulchrum entfernte Altarsakrament zurücksetzte. Das symbolische Grab 
konnte also mit den zwei anderen Aufbewahrungsorten nicht identisch sein.

Auf Grund der Zusammenhänge in der Bedeutung kann man jedoch die Benutzung nicht nachweisen. In den Kirchen, die über kein ständiges Heiliges Grab verfügten, wurde ein Behelf benutzt. Auch in der St. Sebald-Kirche von Nürnberg spricht man von einer temporären Konstruktion: Ein silberner Sarg oder ein Reliquienschrein wurde auf einen Altarstein gestellt. ${ }^{33}$ Der Ort des sepulchrum dürfte wohl im südlichen Teil des Chores, in der Nähe des Marienaltars gelegen haben. ${ }^{34}$ Der Gegenstand der depositio war die konsekrierte Hostie. Also weder die Tatsache, dass kein festes Heiliges Grab in der Kirche vorhanden war, noch die Praxis der depositio hostiae führten dazu, dass man den Tabernakel als Heiliges Grab benutzt hätte. Der Altar war dazu wohl ein geeigneterer Ort, er bezeichnete aber nicht das Heilige Grab selbst, eher nur die Stelle, wo es aufgestellt oder vorbereitet worden war. Das sepulchrum markierte eine temporäre, aber selbstständige Konstruktion, die im liturgischen Raum eine spezielle Stelle hatte.

\section{III.2. Das Heilige Grab als liturgisches Zeichen} (Zeichengebrauch der Riten um das Heilige Grab)

Die Riten des Triduum Sacrum um das Heilige Grab werden nicht nur darum extraliturgisch oder paraliturgisch genannt, weil sie fakultativ waren, sondern auch weil ihr Charakter von den anderen liturgischen Handlungen abwich. Diese Abweichung kann im Unterschied des Zeichengebrauchs begriffen werden. ${ }^{35}$ Unter allen liturgischen Handlungen ist die heilige Messe am wichtigsten, die wir auch als Bezugspunkt betrachten können. Die Messe ist eine Handlung, die nicht darstellt, sondern in der sich die Transsubstantiation vollzieht, wenn sich Brot und Wein tatsächlich in Leib und Blut Jesu Christi verwandeln. Die verwendeten Zeichen - wie zum Beispiel die Klänge, das Gewand, die Gegenstände oder die Bewegungen können nicht so gedeutet werden, als veranschaulichten sie den historischen Christus und das historische Opfer, denn die Zeichen sind liturgisch übertragen. ${ }^{36}$ Es handelt sich nicht um einen mimetischen oder narrativen Zeichengebrauch. Die Analogie zwischen dem liturgischen und historischen Opfer entsteht nur durch die Hermeneutik. In der Wirklichkeit ist sie nicht wahrnehmbar, sie existiert nur in unserem Einbildungsvermögen. ${ }^{37}$ Die mittelalterlichen allegorischen Liturgieerklärungen wie das Liber officialis (818-822) von Amalarius von Metz, das Werk Mitrale (1195) von Sicardus von Cremona oder das Rationale divinorum officiorum (1286-1296) von Durandus verwandeln die während der Messe verwendeten Zeichen in die Repräsentationsform des Lebens Christi und sie verknüpfen diese Zeichen zu einem Narrativ. ${ }^{38}$ Der Zusammenhang zwischen dem Zeichen und dem Bezeichneten ist nicht evident, wurde auch im Mittelalter nicht so betrachtet, und die Analogie ist nicht einmal im Fall des als Christusgrab gedeuteten Altars nachvollziehbar. Ein Zeichen konnte mehrere Deutungen haben.

Der Dialog zwischen dem Engel und den Marien, die visitatio sepulchri, auch officium sepulchri genannt, bedurfte hingegen keiner allegorischen Deutung, da seine Funktion gerade in der mimetischen Repräsentation bestand. Sie wies auf das historische Ereignis am Ostermorgen hin. Christoph Petersen nennt die in der visitatio benutzten Zeichen „theatralisch kodiert":39 Dies bedeutet, dass die Repräsentation durch die Umkodierung der sonst liturgischen Zeichen entsteht. Die im Regularis Concordia beschriebene visitatio sepulchri weist auf gewisse Vorbereitungen hin, die bezeichnen, dass es hier nicht um einen üblichen liturgischen Zeichengebrauch handelt. Der den Engel repräsentierende Bruder kleidete sich in Alba und hielt einen Palmenzweig in der Hand. Die anderen drei Brüder, welche die Marien darstellten, trugen Cappa und brachten Weihrauchgefäße mit. Das Grab wurde am Altar gestaltet (assimilatio sepulchri, in una parte altaris, qua uacuum fuerit) und mit einem Schleier umgeben (uelamen quoddam in gyro tensum). Die Mittel unterscheiden sich in der Tat nicht von den gebräuchlichen Gegenständen der Liturgie: Die liturgischen Gewänder und Weihrauchgefäße, die in der visitatio als Salbengefäß erscheinen, haben an sich keine eindeutig nachvollziehbare Referenz. Der szenische Zusammenhang ergibt sich nur aus dem Ensemble der Mittel, welches eindeutig macht, dass es hier nicht um eine liturgische Erinnerung an die Grabesszene, sondern um die Inszenierung, die Nachahnung des biblischen Besuchs am Grab geht. ${ }^{40}$ Die als „Kostüm" verwandte liturgische Kleidung dient nicht dazu, die liturgische Funktion der Teilnehmenden zu verdecken, aber die Art ihrer Benutzung weicht vom üblichen liturgischen Gebrauch ab. ${ }^{41}$ Ebenfalls ist auch das sepulchrum nicht nur als ein liturgisches Objekt in der visitatio anwesend. Hier sind nicht die verwendeten Zeichen spezifisch, sondern die Weise ihrer Benutzung, man muss nämlich die Zeichen auf die Elemente des in den Evangelien beschriebenen Grabbesuchs beziehen. 
In der visitatio entstehen neue Zeichen, deren narrative Kohärenz nicht erdacht oder spekulativ, sondern real und beabsichtigt ist. Auch das sepulchrum ist ein neues Zeichen. Johannes Beleth identifiziert das sepulchrum folgendermaßen: "quendam locum, ubi ymaginarium sepulchrum adaptatur". ${ }^{42}$ Er nennt es einen Ort, wo das scheinbare Heilige Grab oder seine Nachahmung aufgestellt wird. Die Bezeichnungen - wie das schon zitierte "in figura sepulchri“ aus Narbonne oder das Zitat "sepulchrum dominicum representat ${ }^{\text {"43 }}$ aus dem um 1260 entstandenen Liber ordinarius aus Zürich - deuten nicht nur auf den Akt des Nachahmens hin, sondern auch darauf, dass das sepulchrum im Ritus das historische Christusgrab repräsentiert. Was das sepulchrum von den anderen, rein liturgischen Geräten unterscheidet, ist seine beabsichtigte Bedeutung im Ritual. Im Fall der Altäre oder der Sakramentenschränke, die als Grab Christi gedeutet wurden, können wir über eine nachträgliche Bedeutungsübertragung sprechen und über eine Deutung, die von der Absicht des Rituals unabhängig ist.

Wir können also im Fall der visitatio sepulchri, bei der Messe und der Messallegorese mit dreifacher Darstellungsform rechnen. In der visitatio kommt die darstellende, in der Messe die liturgisch-rituale und in der Messeauslegung die rememorative Darstellung zur Geltung. Das sepulchrum als Zeichen kann mit der allegorisch-rememorativen Vergegenwärtigung nicht vereinbart werden, aber lässt sich mit der liturgisch-ritualen Anwesenheit in Einklang bringen. Das sepulchrum nahm nicht nur an der visitatio, sondern auch an den Riten der depositio und elevatio teil, die jedoch keine Abbildungen des biblischen Geschehens sind. Das Ziel beider Letzteren ist nämlich nicht die Nachahmung der biblischen Geschichte, aber sie sind gleichzeitig auch nicht rein liturgische Vergegenwärtigungen. Im semantischen Zentrum liegt der liturgische Körper Christi, der nicht nur anwesend, sondern auch sichtbar ist. ${ }^{44}$ Falls der liturgische Körper Christi der Gegenstand der depositio oder der elevatio ist, ist die Referentialität des Zeichens eindeutig, besonders wenn der Gegenstand eine vom Kreuz abnehmbare Christusgestalt war.

Die Handlung mit dem liturgischen Christuskörper vollzog sich in einem temporären Raum, am Heiligen Grab, welches sich vom liturgischen Raum - der auch als allegorisch zu deuten war - sowohl physisch als auch semantisch unterschied. Diese Temporarität lässt sich im Charakter und auch in der Zeitlichkeit nachvollziehen. Das Heilige Grab enthielt nämlich den Gegenstand der depositio nur vorübergehend und es selbst war oft nur temporär im Kirchenraum ersichtlich. Das sepulchrum bedarf seiner eigenen Mittel. Die Niederlegung der geweihten Hostie oder des Kruzifixes im Grab bedeutete, dass diese Mittel aus dem liturgischen Raum entnommen worden waren. ${ }^{45}$ Bei der elevatio gelangten beide in den ihnen gewährten liturgischen Raum zurück, ins Zentrum der institutionellen Anwesenheit von Corpus Christi. Das semantische Zentrum der visitatio sepulchri, das leere Grab vermochte also, sich aus einem liturgischen Zeichen in ein theatralisch kodiertes Zeichen zu umwandeln. Daneben hatte es aber auch einen sakralen Charakter durch den liturgischen Kontext, es nahm nämlich auch an liturgisch kodierten Handlungen teil. ${ }^{46}$ Man kann auch im Regularis Concordia lesen, dass die Marien das leere Grab beweihräuchern, das eine rein liturgisch kodierte Geste der Verehrung war. Das Heilige Grab als Zeichen war also Mittel einer liturgischen Handlung einerseits, aber auch Mittel einer Handlung nachahmenden Charakters.

\section{III.3. Die rituelle Funktion des Heiligen Grabes als Darstellung}

Auf Grund der liturgischen Quellen können wir das Heilige Grab nur als ein Zeichen in liturgischem Kontext deuten. Nach den Texten konnte nämlich das Ritual auch ohne Abbildungen vollzogen werden. Das sepulchrum hatte wohl seinen nachahmenden und narrativen Charakter nicht dem Bildgebrauch zu verdanken. Die Repräsentation erfolgte also nicht durch Darstellungen, eher wurden visuelle Zeichen einbezogen, die sich in gewissen Gesten oder durch ihre Benutzungsweise von anderen liturgischen Zeichen unterschieden. Es geht gleichzeitig um Handlungen, die nicht mit einem Publikum rechneten, also sie dienten nicht dazu, betrachtet zu werden. Die szenische visitatio sepulchri richtete sich nach den liturgischen Texten nicht nach den als Betrachter anwesenden Laien: Das Tuch wurde meist in Richtung der Chormitglieder hochgehoben, der ganze Dialog war oft für die Laien überhaupt nicht wahrnehmbar. Die Personen in der Handlung vertraten die Gemeinde der Anwesenden, die Gültigkeit und die Wirkung der Handlung bedingte nicht die Sichtbarkeit.

Eine eventuelle Benutzung von figuralen Heiligen Gräbern geht aus den liturgischen Texten einerseits darum nicht hervor, da Depositionsbilder und Heiliggrab-Darstellungen erst nach der Festigung der Normtexte erschienen. Andererseits gab es einen Teil 
der Gemeinschaftsrituale, den die liturgischen Texte nicht regelten. Die Erscheinung der figuralen Heiliggräber ist auf die Änderung des Publikums und auf das Auftreten neuer Ansprüche zurückzuführen. Sie hängt ferner mit der Umformung des Kirchenraums, mit der steigenden Zahl der Seitenaltäre und der Kapellen zusammen. Die liturgischen Quellen deuten in einigen Fällen unmittelbar auf die möglichen Rezipienten dadurch hin, dass sie Angaben bezüglich des Standorts des sepulchrum mitteilen. Wenn sich das Heilige Grab beim Altar befand, nahmen Laien an den Ritualen nicht teil, wenn es sich um Kathedralen oder Abteikirchen handelte. Auch das Regularis Concordia schrieb den Ritus einer engen Mönchsgemeinschaft vor. In den Kirchen jedoch, wo das Heilige Grab auf oder bei dem Heiliggrab-Altar im Kirchenschiff aufgestellt, beziehungsweise sein Standort „im Zentrum“ angegeben wurde, ${ }^{47}$ können wir mit einem Laienpublikum rechnen.

Ende des Mittelalters können wir nicht mehr nur über die liturgischen Übungen der Geistlichen sprechen, sondern auch verschiedene Laienorganisationen schlossen sich an die Riten an. Die Beschreibung der Feierriten aus Biberach an der Riß, die von einem unbekannten Betrachter 1531 niedergeschrieben wurde, berichtet darüber, dass die Bürger und die Zünfte auf dem Heiligen Grab Kerzen aufgestellt und den psalmodierenden armen Schülern Geldspenden gesammelt hatten. ${ }^{48}$ Während der elevatio entfernten die Geistlichen das Allerheiligste aus dem Heiligen Grab und legten es in den Tabernakel zurück. Die Schüler trugen zuerst die Christusgestalt dreimal in der Kirche herum, dann trugen Laienorganisationen sie durch die Stadt. Ein weiteres Beispiel geht aus einer Urkunde hervor, in der Friedrich II. (der Weise) für die Allerheiligenkirche in Wittenberg einen Ritus der feierlichen Kreuzabnahme und der Zeremonie um das Heilige Grab stiftete. ${ }^{49}$ Man sammelte laut dessen für die ausgewählten 14 Männer, die Hausarme, arme Studenten oder bedürftige Schüler sein sollten, Geldspende und Kleidung. Diese Personen übernahmen auch bei der Kreuzabnahme eine Rolle. Nach der Abnahme vom Kreuz legte man die Christusfigur auf eine Totenbahre und die vier Kapläne brachten sie in der Begleitung von den 14 Männern zum HeiligkreuzAltar. Während der Trauer brannten 36 Wachskerzen um das Grab und wurden ununterbrochen Psalmen gesungen. Während dieser Zeit besuchten die 14 Männer und die Priester noch viermal das Heilige Grab.

Die Bürger von Hall regten selbst die Stiftung eines Heiligen Grabes an, das Georg, der Bischof von Brixen in einer Urkunde im Jahr 1438 genehmigte. Aus der Urkunde geht hervor, dass die depositio und elevatio crucis hier schon früher Brauch waren. ${ }^{50}$ Neben dem Heiligen Grab wurde der Ritus auch mit der depositio der Eucharistie ergänzt: „Ut huius eukaristie [sic] sacramentum reverenter et decenter per manus sacerdotum in dicto ciborio seu sepulchro ponatur". Der Bischof von Brixen genehmigte die Stiftung unter gewissen Bedingungen: Er betonte, dass das Sakrament durch die Hände einer geistlichen Person mit tiefster Verehrung ins Grab gelegt werden dürfe, ferner forderte er strenges Wachehalten am Grab des Herrn: „Adhibita tamen a ministris eiusdem ecclesie fida custodia, ne ad ipsum Sacramentum temerarie manus possit extendi ad aliqua nepharia exercenda". ${ }^{51}$ Das Heilige Grab wurde nur noch geplant, und wir wissen nicht, was genau im Bittgesuch stand, aber es ist vorstellbar, dass die Bürger die Grablegung des Kruzifixes oder die der Christusgestalt selbst vollziehen wollten. In jedem Fall der Beispiele sehen wir, dass die Laien nicht nur die Betrachter, sondern aktive Teilnehmer an den Riten der depositio und elevatio waren. In diesen Riten spielte die Christusgestalt als Depositionsgegenstand und Grabbild eine zentrale Rolle. Die Laienorganisationen dürften wohl an Handlungen teilgenommen haben, die in der Regel in den liturgischen Normtexten nicht festgelegt waren und in engerem Sinne nicht zur Liturgie gehörten.

Aus den zitierten Texten ergibt sich, dass zweierlei rituelle Handlungen im Triduum Sacrum am Heiligen Grab vollzogen werden konnten: eine mit dem liturgischen Körper Christi und die andere als Riten der Laienorganisationen oder der Kultusgemeinschaften, wo auch der Bildgebrauch eine wichtige Rolle einnahm. Ich verstehe unter dem Begriff „zweierlei rituelle Handlungen", dass es verschiedene Rezeptionsebenen der Feierriten am Heiligen Grab geben konnte. Das Heilige Grab als liturgisches Zeichen war gleichzeitig das Mittel des liturgisch-ritualen Zeichengebrauchs und das der mimetischen Repräsentation, die sich mit dem Bildgebrauch und der aktiven Teilnahme der Laien auch ersichtlich abtrennte. Mit der Benutzung eines figuralen Heiligen Grabes ergab sich der mimetische Charakter nicht mehr nur durch die nachahmenden Handlungen - das heißt, dass das liturgische Mittel umkodiert worden war -, sondern das Heilige Grab war auch an und für sich mimetisch. Die mimetische Repräsentation und der liturgische Zeichengebrauch kamen nicht nur in der visitatio zur Geltung. In der Gestalt Christi, die man bei der depositio benutzte, wurde eher der mimetische, in der 
Grablegung der geweihten Hostie trotzdem der liturgische Zeichengebrauch betont und wahrnehmbar. Diese Trennung bedeutet jedoch keine Abgrenzung benutzt wurde nämlich ein gemeinsames Mittel (das Heilige Grab) -, sondern die beiden ergänzten einander.

In engerem Sinne war aber der liturgische Christuskörper der Gegenstand der depositio. Der liturgische Körper Christi, das heißt die geweihte Hostie oder das Kruzifix nach den liturgischen Quellen sind Vergegenwärtigungen, die in den Ort, aus dem man sie entnommen hatte, zurückgesetzt werden mussten. Sie mussten also in den ihnen zukommenden liturgischen Raum zurückgelangen. Wir müssen die Depositionsgestalt theoretisch darum gesondert behandeln, denn die liegende Leichnamsfigur Christi konnte das Kruzifix und das Altarsakrament nicht substituieren - nur mit der Ausnahme, wenn sie eine vom Kruzifix abnehmbare Gestalt war, die in ihre ständige und würdige Stelle zurückgesetzt werden konnte. In breiterem Sinne können wir jedoch über liturgische oder rituale Funktion sprechen. Die bei der depositio hingelegte Christusfigur und das als Bild erscheinende Heilige Grab repräsentieren etwas, aber nicht an und für sich, sondern durch etwas. Einerseits wirkte das Bild durch die rituale Handlung - die eine Wirklichkeit bildete und die Anwesenheit von etwas hervorbrachte - als Teil der ritualen Wirklichkeit. Dem Bild wurde einigermaßen die Gegenwärtigkeit (Ubiquität) des liturgischen Körpers Christi zuteil. Nicht nur das Ritual, sondern auch die Anwesenheit der Eucharistie verlieh der Darstellung diese Allgegenwart, Letztere bezeichnete aber gleichzeitig, dass die Gegenwärtigkeit des Sakraments nicht dem Bild eigen ist. Die Eucharistie betont den Zeichencharakter des Bildes. Das mit figuralen Darstellungen versehene sepulchrum und der Gebrauch der Christusgestalt als Depositionsgegenstand machten die Bedeutung der Handlung mit der geweihten Hostie noch eindeutiger. Es geht aber nicht nur darum, dass die Repräsentation schon mit Einbeziehung von Bildern erfolgte, sondern auch eine Bedeutung durch die Handlung dem Heiligen Grab selbst verliehen wurde, es war nämlich an sich weniger begreifbar.

Die Stelle der Heiligen Gräber liturgischer Funktion ist im Narrativ der Passion aus einem ikonografischen Gesichtspunkt schwieriger zu bestimmen, als im Fall der Darstellungen der Pietà oder der Beweinung Christi und der Grablegung. Dies hat den Grund, dass der narrative Zusammenhang zwischen den Figuren am Heiligen Grab nicht eindeutig ist, oder es gibt überhaupt keine Relation zwischen den Gestalten. Das Heilige Grab von Chemnitz stellt die Figuren der Beweinungsszene, Joseph von Arimathia, Nikodemus und die heiligen Frauen dar, aber die Gestalten haben kein Verhältnis zur Leichnamsfigur Christi. Auf dem Aufbau des Heiligen Grabes von Garamszentbenedek bilden die Apostel eine selbstständige Gruppe und auch hier gibt es keinen Zusammenhang mit der toten Figur im Grab. Häufige Gestalten der Heiligen Gräber waren die heiligen Frauen beim Leichnam Christi, eventuell begleitet von Engeln, ferner die Reliefs der Wächter an den Sargseiten. Die Relation zwischen den Figuren ist aber auch auf diese Weise nicht eindeutig.

Am Heiligen Grab von Freiburg im Breisgau nehmen die Frauen von der in Tuch eingehüllten liegenden Gestalt Kenntnis, aber es ist nicht begreiflich, wie ihre gleichzeitige Anwesenheit gedeutet werden kann. Die Drei Marien finden nämlich am Ostermorgen ein leeres Grab vor, aber diese Deutung trifft hier nicht zu, wie auch nicht die der Grablegung oder der Beweinung. Die Gestalten sind trotzdem in einem Raum arrangiert. Denkt man an die Rituale um das Heilige Grab, kann das Ensemble als eine Darstellung betrachtet werden, die sich an den Inhalt von mehreren Riten anlehnen kann. Die Abbildung kann also auf die Grablegung und den Morgen der Auferstehung sowie auch auf die Zeit im Grab hinweisen, da sie Motive aus jeder Szene aufweist. ${ }^{52}$ Der Ritus gibt dem Bild den Kontext, in dem auch eine narrative Herangehensweise möglich ist. Die Christusgestalt und die Marien erscheinen in jeder Szene, alleine die Reliefs der schlafenden Wächter sind diejenigen, die sich inhaltlich nur auf den Zeitabschnitt der Grabeswache beschränken. Wir sollen das figurale Programm nicht selbstständig betrachten, sondern zusammen mit dem Gegenstand der depositio, der geweihten Hostie und den Riten um das Grab, die zur Gestaltung der Bedeutung in hohem Maße beitragen. Die Aufmerksamkeit wird dem gegenwärtigen Körper des im Grab liegenden Christus, der Eucharistie geschenkt und der Sarg wird gewissermaßen ein Opferaltar und weist damit auch auf das Moment des Kreuzesopfers hin. Nach der Entnahme des Altarsakraments wurde das Heilige Grab trotz dem ein leeres Grab, dass die eingebaute Leichnamsfigur Christi noch immer dort lag. Die Umdeutung in ein leeres Grab erfolgte in diesem Fall, da der eucharistische Körper Christi entfernt und in den ihm gewährten Ort zurückgesetzt wurde.

In Freiburg wird die Liegefigur des toten Christi aus dem Gesichtspunkt der ganzen Komposition 


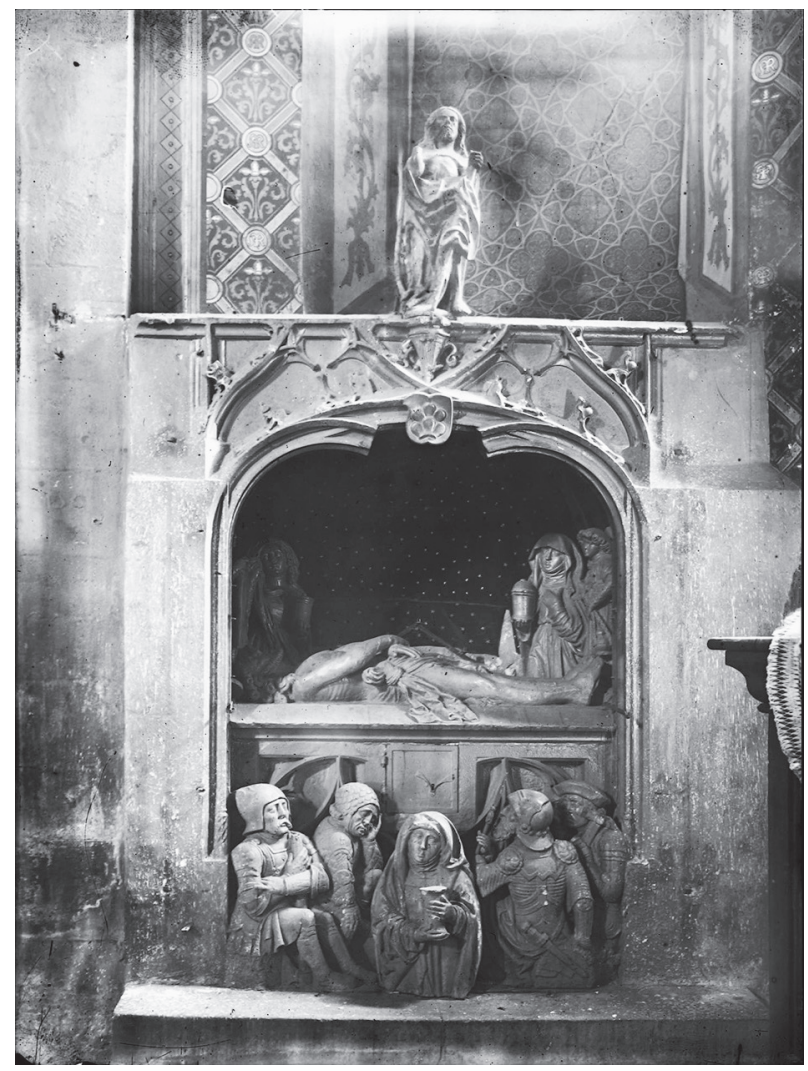

Abb. 13. Breisach, Sankt Stephansmünster, Rosenkranzkapelle, Heiliges Grab, 1520 (Foto: Landesarchiv Baden-Württemberg, Abt. Generallandesarchiv Karlsruhe: https://www.leo-bw.de/media/labw_findmittel_02/ current/delivered/bilder/labw-4-1082053-1.jpg) weniger betont und die Drei Marien gelangen in den Fokus der Aufmerksamkeit. Sie sind diejenigen, die zwischen dem Betrachter und dem Heiligen Grab vermitteln. Ihre Geste macht die Betrachter auf das Grab Christi aufmerksam und auf dessen Lage vor oder nach der Auferstehung, ob das Allerheiligste hier gegenwärtig ist oder nicht mehr. Die Abwesenheit des Altarsakraments ist von derselben Bedeutung als seine Anwesenheit. Beim Heiligen Grab der Benediktinerabtei von Gengenbach (Abb. 4) und dem der Kathedrale von Breisach (Abb. 13) zeigt sich zwar der enge Zusammenhang zwischen dem Altarsakrament und der Gestalt des toten Christi, im Verhältnis zwischen Darstellung und geweihter Hostie scheint jedoch die Darstellung stärker betont zu sein. Dies hat den Grund, dass die Darstellungen nicht das Dasein der Eucharistie interpretieren, sondern umgekehrt. Das Allerheiligste - durch seine An- oder Abwesenheit lieferte einen Anhaltspunkt zur richtigen Herangehensweise zum figuralen Programm. Die Eucharistie wurde in der Tat Teil der figuralen Komposition. Aber sie aktivierte durch die An- oder Abwesenheit nicht nur die Deutungsebenen der Komposition, sondern sie bestimmte auch den Status der Bilder und die Weise des Betrachtens. Nach der Entnahme der geweihten Hostie verloren die Darstellungen nicht ihre Referenz, denn die Referenz wurde das leere Grab selbst.

\section{DAS HEILIGE GRAB ALS ANDACHTSBILD}

Das Heilige Grab als Bildform wurde von Wilhelm Pinder und Georg Dehio als Andachtsbild definiert, das zwar als Monumentalplastik zur ständigen Ausstattung der Kirche gehörte, aber kein Teil der liturgischen Einrichtung war, sondern der Devotion, der Kontemplation im öffentlichen Raum diente. ${ }^{53}$ Ein Beispiel sei das um 1330 entstandene Heilige Grab im Münster von Freiburg. Dieser Andachtsbildbegriff beruht auf einer emotionalen Zugänglichkeit der Bilder, welche die Gefühle Mitleid, Schmerz und Bewegtheit erwecken kann. Erwin Panofsky schlug einen ikonografisch-stilgeschichtlichen Andachtsbildbegriff vor: Der Darstellungstyp grenzt sich einerseits vom szenischen „Historienbild“ und andererseits vom kultischen „Repräsentationsbild“ ab, indem das Andachtsbild mit dem Betrachter Kontakt aufzunehmen vermochte und zur Eigennutzung gestaltet worden war. ${ }^{54}$ Diese Auffassung bedingt, dass das Historienbild, das Repräsentationsbild und das Andachtsbild als Bildformen verschiedene Funktionen erfüllten. Der Termin „Andachtsbild“ als Bildform, die eine Funktion der kontemplativen Versenkung ermöglicht, kann nicht vollkommen auf ein Bild angewendet werden, das Teil eines Gemeinschaftsrituals bildet. Möglicherweise ist die Andachtsbildfunktion auch im Heiligen Grab präsent, da wir auch Kenntnis von seiner extraliturgischen Funktion als Andachtsbild haben. 1489 wurden zum Beispiel von den Klarissen in Roskilde Ablassbriefe ausgestellt, mit denen den Nonnen ein 40-Tage-Ablass durch Gebete vor dem Grabchristus gewährt wurde ${ }^{55}$ Ein weiteres Beispiel ist der Fall der Klosterfrau Mechthilt, die vor dem Heiligen Grab im Kloster St. Katharinental in der Schweiz ein Wunder erlebte, als sie die Hände und Beine Christi in die Hand nahm und sie zu bluten begannen, als gehörten die Körperteile zu einem Mann aus Fleisch und Blut. ${ }^{56}$

Der Andachtsbildbegriff erweiterte sich nach der Mitte des 20. Jahrhunderts. Die Begriffe „funktiona- 
les Andachtsbild“ von Rudolf Berliner und „devotional image" von Sixten Ringbom haben die Grenzen zwischen den unterschiedlichen Bildfunktionen aufgelöst. ${ }^{57}$ Sie bestritten zwar die Existenz einer verbindlichen Darstellungsform für Andachtsbilder, über den Charakter der frommen Übungen selbst machten sie keine Angaben. Das Bild hat möglicherweise mehrere Funktionen und daher kann die Andachtsfunktion keinem Bild, das in einem öffentlichen Raum steht und eine liturgische Funktion hat, aberkannt werden. Das Verhältnis zwischen öffentlicher und individueller Nutzung der Bilder erörterte Hans Belting folgendermaßen: Wir müssen nicht nur mit den verschiedenen Weisen des Bildgebrauchs, also mit der Interaktion zwischen dem öffentlichen, korporativen und privaten Bildkult rechnen, sondern auch mit einem fließenden Übergang zwischen den verschiedenen Funktionsbereichen der Bildformen. ${ }^{58}$ Belting fasste die Andacht als einen kollektiven Stil affektiver Religiosität auf, die sich auch auf die Betrachtungsweise der Bilder auswirkte, und dadurch Bildkonventionen schuf, die auch die öffentlichen Kultbilder beeinflussten. ${ }^{59}$ Das Andachtsbild kann also nach Belting weder auf eine Bildform noch auf einen konkreten Bildgebrauch beschränkt werden. Das Andachtsbild wirke als ein Funktionsbegriff, sein Sinn hänge aber davon ab, von welchem Funktionsbegriff wir sprechen. Belting schlägt drei Funktionsbegriffe vor, deshalb können wir auch über die Andachtsbildfunktion in drei Bedeutungen sprechen. Die Erste ist die sozialpsychologische Funktion, die den Umgang mit den Bildern oder den Bedarf an solchen kennzeichnet. Diese aus der Sicht der Rezeptionshaltung des Publikums beschreibbare Funktion beschränkt sich nicht auf eine umgrenzte Situation, trägt größtenteils subjektive Züge und ist in erster Linie aus dem Bild selbst zu verstehen. ${ }^{60}$ Auf dessen Grund beschränkt sich das Andachtsbild nicht auf die Bilder der privaten Andacht, wir sprechen nämlich über die Betrachtungsweise der Bilder; der spezielle Bedarf an Devotion könnte also auch auf öffentliche Kultbilder bezogen werden. Der zweite Funktionsbegriff bezeichnet den Bildgebrauch, den konkreten Fall nämlich, in dem das Bild seine Funktion erfüllte. ${ }^{61}$ Dies kann in erster Linie aus dem zugeordneten Kontext abgeleitet werden. Konkrete Fälle des Bildgebrauchs werden mit Termini wie Altarbild, Gnadenbild, Privatbild klassifiziert, aber diese Begriffe beziehen sich nur auf die primäre Funktion oder eher auf den Kontext. Nach Beltings Definition konnte das Andachtsbild mit Rücksicht auf den Bildgebrauch auch sekundäre Funktion eines Altarbildes sein. Die dritte Funktionsdimension sei die Artikulierung des Bildinhaltes in der gegebenen Bildform, ${ }^{62}$ sie zeigt also, mit welchen Bildmitteln eine theologische Konzeption visualisiert wird. Für jeden Funktionsbegriff kann das Andachtsbild verwendet werden: Es handelt sich um einen Oberbegriff, der kennzeichnet, welche Erwartungen man in einem bestimmten Zeitalter an die Bilder stellte. ${ }^{63}$ Schließlich führt auch Beltings dreifacher Funktionsbegriff dazu, dass sich Bildformen nicht nach Funktion unterscheiden lassen, aber das ist grundsätzlich auch nicht nötig. ${ }^{64}$ Das Andachtsbild ist auch nach Richard Marks kein autonomer Bildtypus, sondern es entsteht im Moment der Begegnung mit dem Bild - wenn sich der Betrachter mit Devotionsabsicht dem Bild nähert. Marks versteht also unter dem Begriff die Weise der Bildbetrachtung. ${ }^{65}$ Der Bildsinn kommt nämlich da zustande und erfüllt nun sein Potenzial als Mittel zur Andacht.

Nachfolgend untersuche ich die Möglichkeiten des Gebrauchs von Bildern mit Andachtsfunktion und die möglichen Bildbetrachtungsweisen bezüglich des Heiligen Grabes im Triduum Sacrum.

\section{IV.1. Möglichkeiten des devotionalen Bildgebrauchs}

Die Funktion der Heiligen Gräber ist - wie schon erwähnt - in zwei zeitliche Gruppen einzuteilen: Ein Teil von ihnen war in der Liturgie, während der Gemeinschaftsrituale im Gebrauch, aber andere Typen waren das ganze Jahr über für die private Andacht zugänglich. Bei den Frömmigkeitsübungen geht es aber nicht ausschließlich um die einsame Kontemplation. Vor allem muss man über die Beziehung zur Liturgie sprechen. Wie auch der Begriff der Liturgie im erweiterten Sinne verstanden werden kann, lässt sich auch die Devotion auf den Bereich der Gemeinschaftsübungen erstrecken. Die Andacht kann aus bestimmten Aspekten als Gegenteil der Liturgie betrachtet werden, aber ihr enger Zusammenhang mit der Liturgie und die Tatsache, dass die beiden in Raum und Zeit nebeneinander praktiziert waren, machen es unnötig, den Gegensatz zu betonen. Andachtsbücher für Laien konnten zum Beispiel Praktiken und Gebete beinhalten, die im Kirchenraum, sogar ausdrücklich im Anschluss an die Messe ausgeübt und gesprochen werden mussten. Daneben zeugen auch Holzschnitte davon, dass es einen Bedarf an Bildern gab, die während der Messe mitzubringen waren. ${ }^{66}$ Die Teilnahme in der Gemeinde stand dem Erleben der privaten Andacht eigentlich nicht im Wege. Bei der Erörterung 
der liturgischen Funktion des Heiligen Grabes betonte ich seine Rolle in der ritualisierten Handlung. Mit der Andachtsbildfunktion möchte ich hingegen seine davon abweichenden Eigenheiten beleuchten. Auch die Frömmigkeitsübungen können sowohl ritusartige wie auch ihnen entgegengesetzte Züge aufweisen. Sie knüpfen beispielsweise nicht an Tradition und Formalismus an und sind nicht fest. Sie können nicht als selbstständige Riten betrachtet werden, sondern sie sind Übungen, die sich an mehrere Situationen adaptieren lassen: Sie können sich an Riten, aber auch an allägliche Übungen anschließen. ${ }^{67}$ Unter Devotion verstehen wir Übungen wie Gebet, Lesen und Singen von Texten und Gesängen, Ausdruck des Danks, Meditation, Kontemplation. Die Andacht ist jedoch nicht identisch mit der Ausübung gewisser Handlungen, sondern sie ist auch eine mentale Leistung, welche die handelnde Person in Anspruch nimmt. Die Devotion ist der Prozess der Bedeutungsproduktion selbst während einer Handlung, in der auch die Wahl der Person eine Rolle spielt. ${ }^{68}$ Die Frömmigkeitsübungen sind nicht verbindlich, auch die Andachtsbücher bieten nur Möglichkeiten, die der geistigen Entwicklung der Person dienen.

Die feierlichen Zeremonien boten Gelegenheit auch zu tieferer Kontemplation und frommen Übungen, besonders in der Zeit zwischen Grablegung und Auferstehung. Am Heiligen Grab wurde Stundengebet gehalten, an dem auch Laien teilnehmen durften, vor allem an der Matutin des Ostersonntags. Die Teilnahme der Laien am Stundengebet wandelte es nicht zur Devotionsübung, es blieb Teil der Liturgie. Aber wie schon betont, schließen die Gemeinschaftsriten die Möglichkeit eines individuellen Einfühlens nicht aus. Dieses Potenzial im Stundengebet dürfte man auch im Mittelalter erkannt haben. Oft übernahmen Laien das Wachehalten am Grab des Herrn. Wir können das Wachehalten auch als eine Handlung betrachten, die parallel zum Stundengebet stattfindet und mit dem sich verschiedene Frömmigkeitsübungen wie das Gebet oder die Meditation verbinden lassen. Dazu gab das schon zitierte Dokument des Bischofs von Brixen ein Beispiel. Er genehmigte die Stiftung des Heiligen Grabes unter anderem mit der Bedingung, dass das Heilige Grab - wegen des darin enthaltenen Allerheiligsten - streng bewacht werden müsse: „Adhibita tamen a ministris eiusdem ecclesie fida custodia, ne ad ipsum Sacramentum temerarie manus possit extendi ad aliqua nepharia exercenda“. 69 Die Bürger mussten ferner beim Wachehalten am Grab über die Leiden Christi meditieren, solange das Altarsakrament im
Heiligen Grab lag, und für ihre Ausdauer wurde ihnen Ablass gewährt. ${ }^{70}$ Die vorgeschriebene Praxis des Wachehaltens musste mit einer nützlichen, seelisch erbaulichen Tätigkeit verbunden sein und das Erfüllen der Aufgabe mit einer Belohnung, in diesem Fall mit dem Ablass, gesichert oder wenigstens gefördert werden. Die Meditation als Devotionsübung wurde empfohlen, aber der Vollzug konnte - im Gegensatz zu den viel strenger geregelten rituellen Handlungen nicht überprüft werden. Für die frommen Übungen konnte man nur die Rahmen bestimmen, wie es auch aus der zitierten Urkunde hervorgeht.

Auf Grund der Quellentexte, deren Großteil liturgisch ist, ist es schwer zu erkennen, was tatsächlich am Heiligen Grab geschah. Meistens ist nur die Möglichkeit der Devotionsübungen nachweisbar. Die Texte liefern nur einen Anhaltspunkt zur Feststellung, was das Heilige Grab dem Betrachter bot. Es war Mittel und auch Gegenstand zur Meditation. Daher ist eine wichtige Frage, was es enthielt: Ob die geweihte Hostie zusammen mit einem Christusbild oder nur die Eucharistie alleine im Grab lagen. Die gemeinsame Gegenwärtigkeit der beiden gab dem Betrachter die Möglichkeit, entweder das eine oder das andere in den Vordergrund $\mathrm{zu}$ stellen, oder versetzten ihn in den Stand, den Anblick in voller Komplexität wahrzunehmen. Dies lag aber nicht nur im Belieben der Person, sondern ergab sich auch aus der Gestaltung des Heiligen Grabes, d. h. aus dem, was man sehen konnte. Von den feierlichen Gebräuchen aus Biberach an der Riß wissen wir, dass man vom Karfreitag bis Ostersonntag im Heiligen Grab neben der toten Christusgestalt das Allerheiligste in einer pixis hängte: „... da ist gestanden ein hüpsch, gemahlets, verguldts Grab. Da ist ein andechtiger Herrgott gelegen, verdeckht mit ainem Tünnen Thuech, das man Unnseren Herrgott dadurch hat mögen sehen, den das grab ist vergöttert gesein...". Am Grab wurden bis zur Auferstehung Psalmen gesungen. Obwohl die Gestalt Christi - „ein andechtiger Herrgott" - im Heiligen Grab zu sehen war, betont nachher ein Absatz ausdrücklich, dass das Gebet dauert, solange sich das Allerheiligste im Grab befindet: „Man hat auch das recht Sacramendt in das Grab gehenckht, dasselbig uhnzuebetten, bis Unnser Herrgott erstanden ist. So hat man es den wider in das Sacramenthauss thon" " ${ }^{71}$ Beide Gegenstände der depositio waren sichtbar, aber es stellte sich die ernste Frage, was tatsächlich der Gegenstand der Kontemplation und der Devotion war.

Kolumban Gschwend beschrieb den Text der Urkunde von Hall als eines der ersten Dokumente des 
Vierzigstundengebets vor der Eucharistie. Der Bischof betonte das Wachehalten am Grab des Herrn wegen des im Grab aufbewahrten Altarsakraments. ${ }^{72}$ Die Ehrung der vierzig Stunden der Grabesruhe war eine selbstständige Kultform der Eucharistie, die in der ersten Hälfte des 16. Jahrhunderts entstand und später mit den barocken Nachbauten des Heiligen Grabes verbunden wurde. Gschwend nahm die Prämisse zum Ausgangspunkt, dass es zwischen den mittelalterlichen und den Barockritualen am Heiligen Grab einen Übergang gab, den der betonte Gebrauch des Allerheiligsten kennzeichnet. Zuerst müssen wir jedoch auf theoretischer Ebene einen Unterschied zwischen den zweierlei Heiliggrab-Typen, dem mittelalterlichen Depositionsgrab und dem barocken Expositionsgrab, machen. ${ }^{73}$ Das Heilige Grab der depositio diente zur symbolischen Grablegung des Kruzifixes und/oder des Altarsakraments, später der Leichnamsfigur Christi. Es war Mittel der rituellen Vergegenwärtigung der Grablegung und der Auferstehung. ${ }^{74}$ Der Gegenstand der depositio wurde in jedem Fall im Grab verschlossen und bis zum Ostermorgen bewacht. Die wichtigste Funktion des barocken Heiligen Grabes war hingegen die Demonstration des in der Eucharistie gegenwärtigen Christi und lieferte eine Art Hintergrund oder Kulisse zum vierzigstündigen Gebet vom Karfreitag bis Ostermorgen $^{75}$ (Abb. 14). Beim Expositionsgrab stand das in die Monstranz gesetzte Altarsakrament im Mittelpunkt. Sie wurde nicht verschlossen und die Zeremonie wurde eher eine spezifische Verehrungsform der Eucharistie. $\mathrm{Zu}$ Ostern brachte man das Allerheiligste feierlich auf den Hochaltar zurück. Dies erfolgte bei der mittelalterlichen elevatio der geweihten Hostie generell geheim. Unter der Monstranz erschien der Grabchristus nur noch als eine Darstellung und verlor seine rituelle Funktion. Ein grundsätzlicher Unterschied zum Depositionsgrab ist es, dass das sepulchrum und die Christusgestalt nicht die Mittel, sondern nur die Kulissen der Zeremonie waren. ${ }^{76}$ Das Expositionsgrab war eine Entwicklung der Neuzeit, aber daneben konnte man wohl auch den Ritus der depositio mittelalterlicher Herkunft praktizieren. ${ }^{77}$

Der auf dem Heiligen Grab gezeigten expositio ging das vierzigstündige Gebet voraus. Zum ersten Mal begegnen wir dieser Praxis im Jahre 1527: Gian Antonio Belotti forderte in seiner Fastenpredigt in der Mailänder San Sepolcro-Kirche die Gläubigen auf, im Vierzigstundengebet auszuharren, mit dem sie die Hilfe des Herrn in der Kriegsnot erbaten. ${ }^{78}$ Die Übung musste in vier Feiern im Jahr wiederholt werden. Aber hier geht es noch nicht um die Aussetzung und Zur-

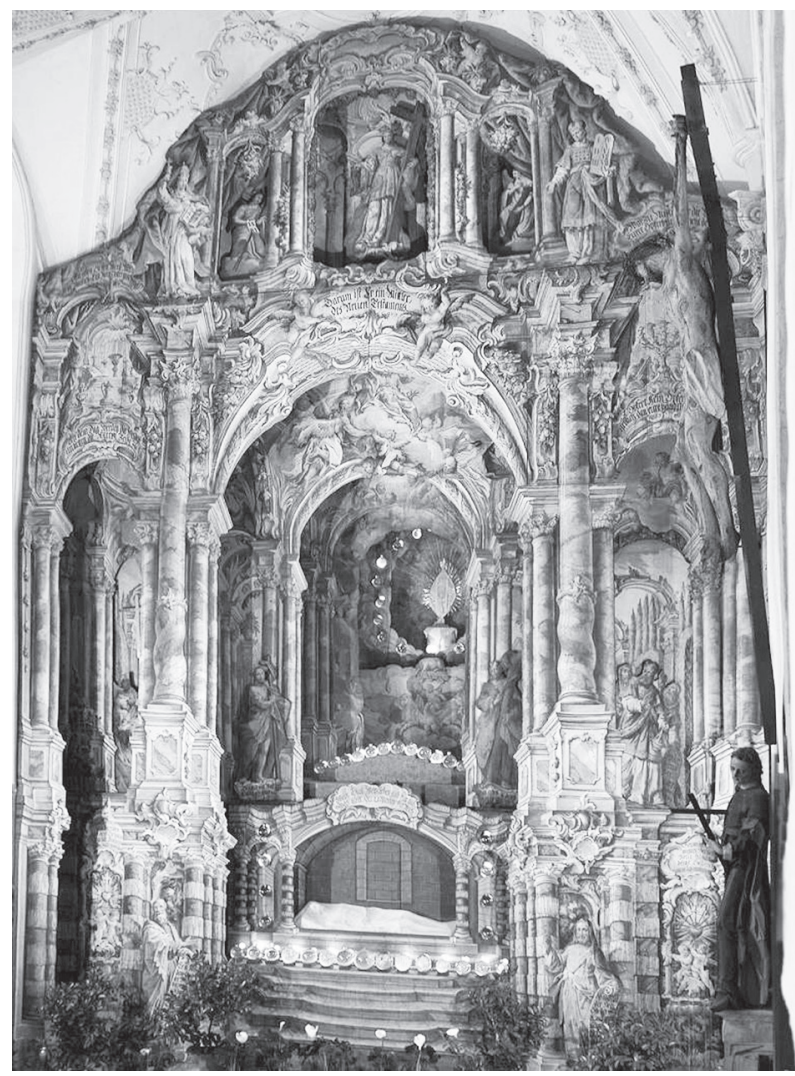

Abb. 14. Christoph Anton Mayr: Heiliges Grab, 1764; Schwaz, Franziskanerkloster (Foto: http://www. franziskaner-schwaz.at/Ostergrab.jpg)

schaustellung der Hostie. Zum ersten Mal hielt man 1536 im Mailänder Dom die Ehrung der vierzig Stunden vor dem ausgesetzten Altarsakrament. ${ }^{79}$ Die Jesuiten übernahmen den Brauch im Jahr 1553 und sie spielten eine bedeutende Rolle bei seiner Verbreitung. Diese spezielle Kultform des Heiligen Grabs und der Eucharistie verknüpften sich zuerst Mitte des 16. Jahrhunderts. Die erste ausdrückliche Angabe über ein Expositionsgrab ist aus der Jesuitenkirche von Prag aus dem Jahr 1559 bekannt. ${ }^{80}$ Man kann aber nicht nur nach der Entstehung und der Herkunft zwischen dem mittelalterlichen Wachehalten und dem Vierzigstundengebet unterscheiden. Das Wachehalten am Grab des Herrn erfolgte nämlich im Mittelalter parallel zum Stundengebet, es bot Rahmen und Möglichkeit zu den Frömmigkeitsübungen. Der Gegenstand der Devotion war das ganze Heilige Grab, er wurde zumindest nicht konkreter bestimmt. Das vierzigstündige Gebet am Expositionsgrab wurde hingegen zu einer organisierten Kultform der Eucharistie und war damit stärker ritualisiert als die mittelalterliche Praxis. Man kann aber nicht eindeutig von einem Übergang oder einer Kontinuität zwischen den beiden sprechen, da die Voraussetzungen der barocken Verehrungsübung 
außer der Praxis des mittelalterlichen Wachehaltens auffindbar sind.

Nicht nur die Ausübung des Vierzigstundengebets, sondern auch die formalen Voraussetzungen des Expositionsgrabs entwickelten sich unabhängig von den mittelalterlichen Heiliggräbern. Der wichtigste inhaltliche und gestalterische Vorläufer des barocken Expositionsgrabs war das zur Trauerfeier benutzte Trauergerüst. Oft fertigten dieselben Künstler den kulissenartigen, zeitweiligen Aufbau über dem Katafalk, wie die barocken Heiliggräber, nicht selten unter Verwendung derselben Elemente. ${ }^{81}$ Da kein frühes Expositionsgrab aus der Mitte des 16. Jahrhunderts erhalten ist, kann man nur schwer feststellen, welche gestalterischen Zusammenhänge zwischen den beiden Heiliggrab-Typen bestanden. Die formalen und funktionalen Voraussetzungen können nämlich auch ohne das mittelalterliche Heiliggrab geklärt werden. Auf diese Weise lässt sich die Vorstellung, dass es Ende des 15. und Anfang des 16. Jahrhunderts einen Übergangstyp zwischen dem Depositions- und dem Expositionsgrab gegeben hätte, nicht beweisen. ${ }^{82}$ Es ist eher vorstellbar, dass man in der Anfangszeit einige der mittelalterlichen Heiliggräber - obwohl sie meistens nicht dazu geeignet waren - zur neuen Praxis der expositio verwendete.

Sowohl in der Genehmigung des Bischofs von Brixen aus dem Jahr 1438 als auch in der Beschreibung der Zeremonie am Heiligen Grab von Biberach erscheinen Elemente, die auf die würdige Aufbewahrung der Eucharistie hindeuten. Auf Grund der Deskription können die genauen Geschehnisse während der vierzig Stunden trotzdem nicht eindeutig rekonstruiert werden: Ob sich der Text auf das Vierzigstundengebet oder nur das im Mittelalter gebräuchliche Wachehalten und das Stundengebet bezieht. Die würdige Aufbewahrung der Eucharistie bedarf vor allem der Anwesenheit der ins Stundengebet und ins Wachehalten einbezogenen Laien beziehungsweise der Anwesenheit des Allerheiligsten im Heiligen Grab. Diese Bedingungen existierten auch in der mittelalterlichen Praxis. ${ }^{83}$ Der Brauch der depositio hostiae begann erst vom 13. Jahrhundert sich zu verbreiten. Das Wachehalten am sepulchrum ist jedoch eine spätere Entwicklung. Nach dem Liber Ordinarius von Moosburg um 1400 nahmen auch Laien am Gebet und am Wachehalten teil, ${ }^{84}$ aber ins Grab wurde nur das Kruzifix gelegt. Beide Elemente bildeten sich voneinander unabhängig heraus. Die Anwesenheit der Laien hängt also nicht unbedingt mit der Anwesenheit der Hostie in der Depositionspraxis zusammen, welche aber die
Bedingung des Vierzigstundengebets vor dem Expositionsgrab wäre. Obwohl die beiden Elemente - d. h. die Teilnahme der Laien und die Gegenwart der Eucharistie - gleichzeitig präsent waren, bedeutet es keineswegs spezifische Gegebenheiten, nach denen man eine angehende Kultform rekonstruieren könnte.

Die Ehrung der Eucharistie am barocken Heiliggrab äußerte sich formal darin, dass das Altarsakrament in eine zentrale Lage und in der Form des Tabernakels ausgesetzt wurde. In den Quellentexten bezüglich der mittelalterlichen Karwochenzeremonien findet man Hinweise auf beide Ehrungsformen. In Bezug auf den 1580 in Nagyszombat entstandenen Ordinarium von Miklós Telegdi nahm Karl Young an, dass man dort die Monstranz mit der geweihten Hostie in einen Altartabernakel eingesetzt hatte. ${ }^{85}$ Die Vorstellung, dass der zum Heiliggrab gehörende Tabernakel selbst die Herausgestaltung der Expositionsgräber vorankündigt ${ }^{86}$ wird jedoch von der liturgischen Praxis nicht gestützt. Im Ordinarium Telegdi ist der Gegenstand der depositio alleine das Allerheiligste: „Demum pontifex vel sacerdos officians, exuta casula, portans in manibus alteram hostiam consecratam quae pro sepultura heri fuit reservata, in patena supra calicem collocatam, palla et linteolo tectam, descendit cum ministris versus Sepulchrum, praecadentibus ceroferaris et turribulo, quod semel circumit. Deinde imponet in illud eandem Hostiam una cum calice, claudit, obseignat et per circuitum incensat, choro cantante responsoria...". Der Text betont, dass das Altarsakrament versiegelt und abgeschlossen wird. Diese zwei Momente sind Bräuche mittelalterlicher Herkunft und weisen eher auf ein Depositionsgrab hin. Wir finden aber keinen Bezug zu Frömmigkeitsübungen nach einer eventuellen Deposition. Ein öffenbares und abschließbares Objekt auf der Altarmensa kann tatsächlich ein Altartabernakel sein, aber die Zeremonie selbst wird nicht nur durch die benutzten Mittel bestimmt. Der Tabernakel ist ein Mittel zur Aufbewahrung des Altarsakraments. Der Ausgangspunkt der Ehrung der Eucharistie dürfte wohl die Praxis der Aufbewahrung selbst gewesen sein, denn anfangs inspirierte dies die Verehrung des Allerheiligsten. Die speziellen Formen der Ehrung bildeten sich erst später heraus. ${ }^{87}$ Der Tabernakel an und für sich weist also nicht auf eine neue, sich formierende Kultform hin.

Das zwischen 1552 und 1554 entstandene Brixener Dommesner-Buch beschreibt auch ein frei stehendes Heiliges Grab mit der zugehörigen Christusgestalt, deren Vorbereitung die Aufgabe des Kirchendieners sei: „Des morgens jn aller frue, so sper die Kirchen 
auff. due das oster grab herfür, Sez das an sein gewonliche ortn. Von erst nim die figur herauß, unnd trags in Sagrer leg die auff das pret, darauff man die figur zum grab tragt...". ${ }^{88}$ Die in die Monstranz gesteckte geweihte Hostie wurde in den zum Heiliggrab gehörigen Tabernakel eingesetzt und abgeschlossen: „der Biester steigt Huber die flattern hinauf mit der monstranzn, und sezt die in tabernackl hinein, als er den tabernackl zue hat gemacht, und wiederum herab steigt..." 89 Der Tabernakel war so hoch angebracht, dass man dazu auf eine Leiter steigen musste. Die Monstranz wurde während der elevatio ohne besondere Zeremonie entnommen. Aus der Beschreibung geht nicht hervor, dass das Allerheiligste während des Wachehaltens eine besondere Rolle gespielt hätte. Wir wissen nur, dass Psalmen am Christusgrab gesungen wurden. Das Wachehalten war aus Sicherheitsgründen nötig: „... das du selb ander, oder dritter seist, damit du guette wacht hast, von wegen der monstranzen auff dem Grab. Auch von wegen der Kerzen bey dem grab...".90 Das Anbringen des Altarsakraments auf dem Heiligen Grab beweist aber nur, dass das Einbeziehen der Eucharistie in die Praxis der Deposition die Ausübung des Wachehaltens beeinflusste.

Auch einer der Libri Ordinario aus Polling bei Innsbruck vermutlich aus der Mitte des 16. Jahrhunderts beweist, dass sich die ausgezeichnete Stelle der geweihten Hostie nicht mit ihrer expositio verbinden lässt. Im Heiligen Grab war die Christusgestalt zu sehen und die Eucharistie wurde am obersten Teil des Grabs in einer pixis angebracht: „et ipse prelatus sacramentum cum pixide in superiori parte sepulchri locet, sacerdotibus interim imaginem crucifixi tenentibus. Locato [sic?] vero sacramento eandem imaginem dominus prelatus accipiat et in sepulchrum ponat cooperiatque syndone."91 Trotz der scheinbar exponierten Lage der Eucharistie genoss nicht sie, sondern die Christusgestalt größere Popularität: „Et recedentibus fratribus de sepulchro, devote ab omnibus prius imago Christi deosculetur". Die Mönche küssten das Bild Christi.

Das Einbeziehen der geweihten Hostie in die Praxis der depositio bewirkte Ende des Mittelalters keinen grundsätzlichen Wandel in der Zeremonie. Die in das Heilige Grab gelegte Eucharistie konnte zwar Gegenstand der Devotion werden, aber wir können auf Grund der Quellen kaum über eine selbstständige Kultform des Allerheiligsten - wie im Fall der barocken Heiliggräber - sprechen. Das Wachehalten am Grab des Herrn war keine selbstständige Kultform, sondern eine Tätigkeit, die man mit Stundengebet oder mit Frömmigkeitsübungen ausfüllen konnte. Die Devotions- übungen am Expositionsgrab knüpften sich dagegen an eine organisierte Kultform an. Diese Letzteren haben keine eindeutigen Spuren aus dem Mittelalter, es ist aber zweifellos, dass die Eucharistie immer größere Verehrung genoss und ein immer größerer Anspruch bestand, sie zur Schau zu stellen, auch während der Hochfeste. Das Heilige Grab war - da die Eucharistie wegen seiner rituellen Funktion abzuschließen war zur Erfüllung dieses Anspruchs nicht besonders geeignet. Auch die formalen und strukturellen Eigenschaften der mittelalterlichen Heiligen Gräber zeugen davon.

Nicht nur die ausgezeichnete Lage der Eucharistie ist fraglich, sondern wir können uns auch nicht über die Gegebenheit und die Weise der Anbringung des Altarsakraments sicher sein. Der zum Heiligen Grab von Garamszentbenedek (Abb. 15) gehörige Grabchristus blieb zwar erhalten (Abb. 16), wir haben jedoch weder Angaben noch eindeutige Spuren einer eventuellen Anwesenheit der geweihten Hostie. Um den Aufbewahrungsort der Eucharistie festzustellen, entstanden zweierlei Hypothesen. Nach einer wurde das Altarsakrament im Turm über dem Eingang des Schreins aufbewahrt - diese Lösung deutet auf die Praxis der expositio hin. ${ }^{92}$ Die andere Hypothese besagt, dass man die Eucharistie im polygonalen Gefäß auf der Konsole am Eingang aufbewahrte, was auch mit der Funktion der expositio verbunden wurde. ${ }^{93}$ Beide Vermutungen setzen voraus, dass das Heilige Grab den deutlich markierten Aufbewahrungsort der geweihten Hostie enthalten musste. Die Kunstgeschichtsschreibung proklamierte also auf diese Weise das Heilige Grab von Garamszentbenedek zu einem speziellen Gegenstand des Kultes der Eucharistie. Es bestand jedoch die Möglichkeit der Anbringung der konsekrierten Hostie in einem gesonderten Gefäß nicht nur im Fall des Schreins von Garamszentbenedek, sondern auch beim Heiligen Grab aus der Kirche St. Blasius von Salzburg (Abb. 7a-b) und bei der Anlage von Möchling (Abb. 17), die in die Ambraser Sammlung gelangt war, bevor sie im Zweiten Weltkrieg zerstört wurde. ${ }^{94} \mathrm{Zu}$ diesem Grabtyp knüpft auch heute noch die Vorstellung an, dass es sich um eine spezielle Art der mit einem Tabernakel versehenen Heiliggräber handelt, die dem Typ des Expositionsgrabs aus dem Ende des 16. Jahrhunderts vorausgingen. ${ }^{95}$

Es gibt aber auch innerhalb einer Gruppe bedeutende Unterschiede unter den Typen, sogar ihre Benutzung ist nicht immer eindeutig. Das Heilige Grab der Jakobikirche von Chemnitz (Abb. 18) besteht aus einem Schrein mit den Reliefs der schlafenden Soldaten und darauf erhebt sich ein mit Skulpturen ver- 


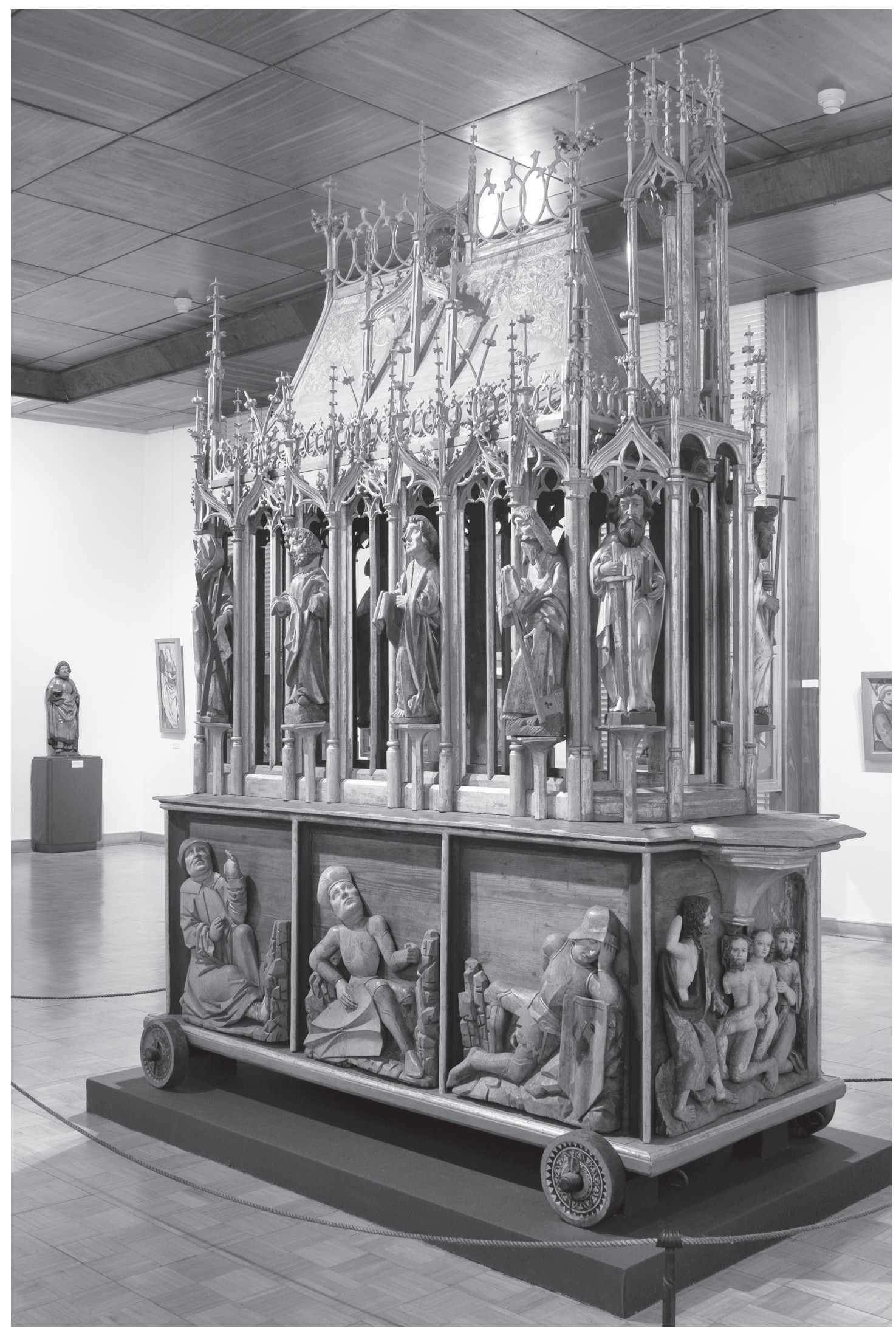

Abb. 15. Heiliges Grab aus der Benediktinerabtei Garamszentbenedek/Hronský Ben̆adik, um 1480/1490; Keresztény Múzeum, Esztergom, Deposit des Domes zu Esztergom (Foto: Attila Mudrák) 


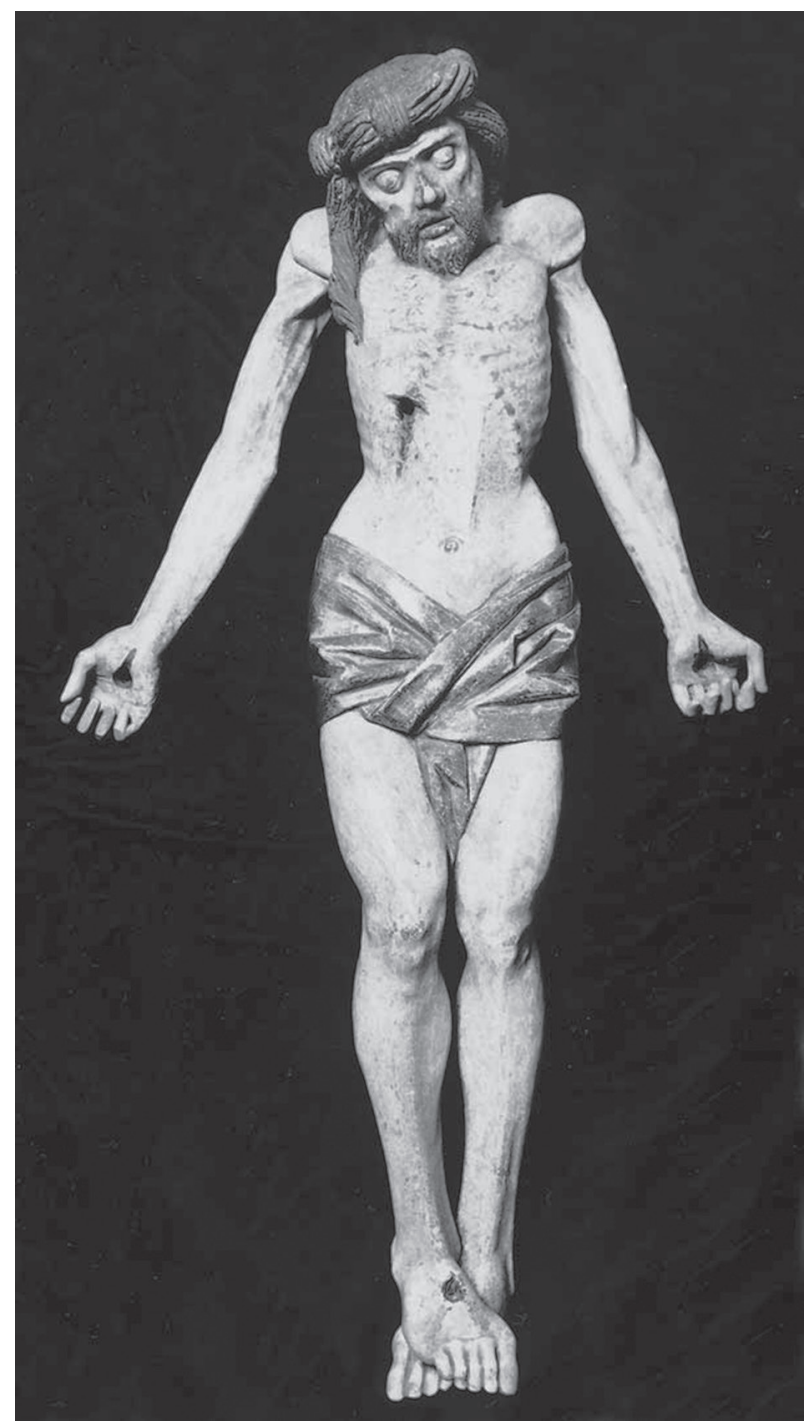

Abb. 16. Corpus mit beweglichen Armen der Benediktinerabtei Garamszentbenedek/Hronský Ben̆adik, um 1480/1490 [Foto: Paradisum Plantavit 2001, (vgl. Anm. 93) 182 ; Abb. 52]

zierter einräumiger Aufbau, der mit einem verzierten Dach gekrönt wurde, aber es gibt keine Spuren eines abschließbaren Tabernakels. Dasselbe gilt für das Heilige Grab der Marienkirche von Zwickau (Abb. 6). ${ }^{96}$ Die aus Möchling stammende Anlage ohne figurale Darstellungen wurde aus Holz geschnitzt und ahmt die Form einer gotischen Kapelle nach. Nach einigen Vorstellungen enthielt der Schrein damals den Grabchristus und man könnte wohl im schmaleren Chorteil am Karfreitag die geweihte Hostie aufbewahrt haben. ${ }^{97}$ Die prachtvolle Struktur wurde im Zweiten Weltkrieg verwüstet, wir kennen sie nur von Fotoaufnahmen und verfügen nicht einmal über eine genaue Beschreibung. Die Anlage stand nach Berichten aus dem 19. Jahrhundert auf einem ungefähr zwei Meter hohen

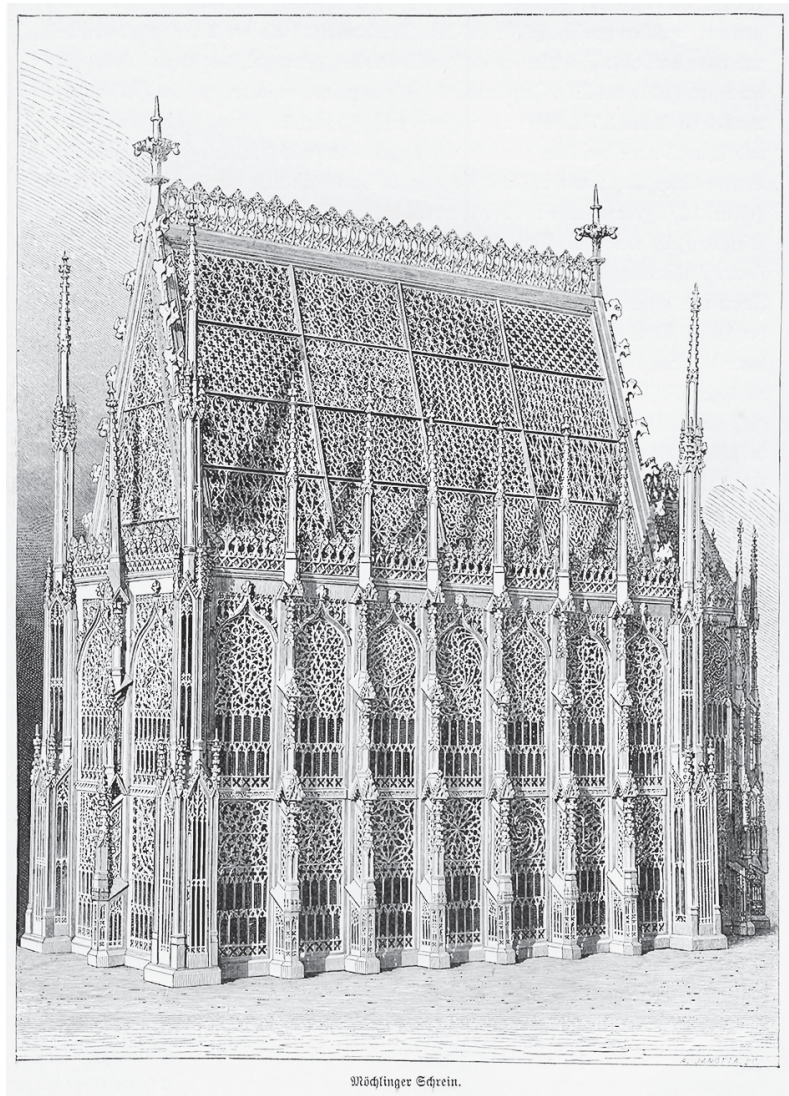

Abb. 17. Zeichnung des Möchlinger Schreines [Janotta 1891, (vgl. Anm. 94) 227: https://de.wikipedia. org/wiki/Pfarrkirche_M\%C3\%B6chling\#/media/ File:Moechlinger_Schrein.jpg]

Unterbau, in dem die Reste eines Leichnams lagen. 98 Nach der Tradition sollte das Grabmal die Relikte des Markgrafen Paul Alboin ( $† 975)$, Vater des Bischofs Alboin von Brixen, hüten. ${ }^{99}$ Aus den Untersuchungen der Reste im Jahr 1996 ging hervor, dass die Sporen und die Pastorale aus dem 15. Jahrhundert stammen, sie entstanden also fünf Jahrhunderte nach dem Tod des Bischofs. Die reich verzierte Holzstruktur wurde 1872 restauriert. 1873 gelangte sie in die Sammlung vom Schloss Ambras. 1874 wurde der vollständige Unterbau abgetragen. Es lässt sich nur vermuten, dass es sich hier um ein Grabmal handelte. ${ }^{100}$ Wir haben keine Angaben, ob es am Karfreitag in die Liturgie einbezogen wurde. Da man es auf einer Grabkammer errichtet hatte, dürfte es wohl auch zur Anbringung von Reliquien gedient haben.

Auf dem gefärbten und holzgeschnitzten Prunkschrein der Bürgerspitalkirche St. Blasius zu Salzburg befindet sich tatsächlich ein abschließbarer Tabernakel auf einer der kurzen Seiten. Dass aber der Tabernakel zur Depositionsfunktion am Karfreitag verwendet worden wäre, beweisen keine Geschichtsquellen. Das 


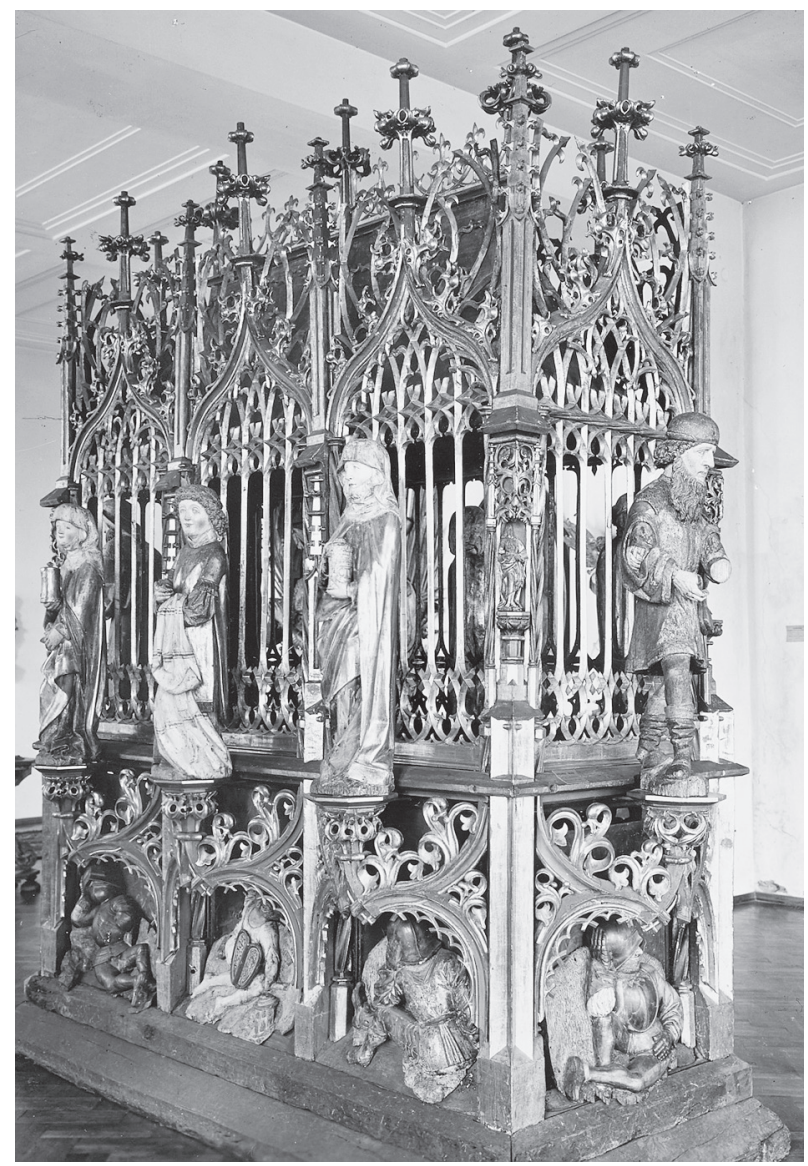

Abb. 18. „Meister Jörg“: Heiliges Grab aus der Jakobikirche Chemnitz, um 1480/1490; Schlossbergmuseum Chemnitz, Leihgabe der Kirchengemeinde St. Jakobi (Foto: Deutsche Fotothek, Sächsische Landesbibliothek - Staats- und Universitätsbibliothek Dresden)

Inventar aus dem Jahr 1802 nennt ein Objekt „Kerker Christi“, das man am Gründonnerstag verwendete. Die für den Karfreitag bestimmte Eucharistie wurde nach der Messe dort eingesteckt. ${ }^{101}$ Dieser Brauch passt sich an die liturgische Praxis der Barockzeit an, in der die konsekrierte Hostie am Gründonnerstag in einem Ziborium auf einen der Seitenaltäre gestellt wurde. Man entnahm das Sakrament am Karfreitag dem Ziborium und setzte es über das Heilige Grab. Das Ziborium blieb aber auf dem Seitenaltar. In der Kirche St. Blasius könnte jedoch der Aufbewahrungsort der Eucharistie nicht ein Seitenaltar, sondern der Tabernakel des Prunkschreins sein. Die Erwähnung eines tatsächlichen Heiligengrabs stammt aus dem Jahr 1654: Man beschäftigte jährlich zwei Tischler, um für die Karwoche die Konstruktion aufzubauen und nachher abzutragen. ${ }^{102}$ Dies könnte wohl ein barockes, tragbares und kulissenartiges Heiligengrab gewesen sein, welches auch das oben erwähnte Inventar beschreibt. ${ }^{103}$ Wir wissen von keiner Angabe über ein eventuelles Heiliggrab aus dem Mittelalter. Die Heiliggrabfunktion des Objektes ist auch hier unbeweisbar. Die vier Marienreliefs auf dem zweiten Geschoss sind mit dem Tragschrein nicht zeitgleich und zeigen die Spuren einer nachträglichen Anbringung auf. ${ }^{104}$ Darstellungen der Anlage, aus denen man auf eine Heiliggrabfunktion des Schreins schließen könnte, sind nicht bekannt. Eine symbolische Grablegung der geweihten Hostie während der depositio lässt sich auch nicht nachweisen. Vor 1575 haben wir überhaupt keine Kenntnis von einer eventuellen depositio der Eucharistie in Salzburg. Zur Zeit der Fertigung des Prunkschreins bestand - nach den liturgischen Texten - kein Bedarf für geeignetes Heiliggrab zur Aufbewahrung der geweihten Hostie am Karfreitag. Sollte man Ende des Mittelalters den Schrein zur Bewahrung des Altarsakraments am Karfreitag verwendet haben, wurde die Eucharistie darin eher verborgen und nicht aufgezeigt. Auch die Maße des Tabernakels sind recht gering und zu wenig betont, um das Sakrament in den Mittelpunkt zu stellen.

Auch die Beispiele, wo die Heiliggrabfunktion der Anlagen viel wahrscheinlicher war, also in Zwickau und Chemnitz, geben keinen Anhaltspunkt zur Art der Aufbewahrung der geweihten Hostie. Die mehrmals behandelten formalen Gegebenheiten, wie der deutlich markierte Anbringungsort des Tabernakels und der Eucharistie, sind eigentlich für diesen Typ nicht charakteristisch. Der polygonale Behälter auf der Konsole an der Vorderseite des Heiligen Grabs von Garamszentbenedek entspricht nicht der Anforderung, abschließbar zu sein, genauso wenig der Turm über dem Eingang des Schreins, da er von allen Seiten offen ist. In der mittelalterlichen Praxis der depositio war es unvorstellbar, dass die Eucharistie im Heiligen Grab nicht abgeschlossen worden wäre. Es war nicht nur aus Sicherheitsgründen wichtig, sondern es war auch ein bestimmendes Moment in der Liturgie der depositio. Nach der Größe des Turms scheint er geeigneter zu sein, eine Skulptur zu bewahren. In diesem Fall könnte sich eine Gestalt des auferstandenen Christi an das ikonografische Programm der Anlage anpassen. Mehrere Alternativen bieten sich zur Bestimmung der Funktion der polygonalen Konsole: Dort dürfte wohl ein Behälter für die Heilig-Blut-Reliquie oder einen Kerzenhalter gestanden haben.

\section{IV.2. Das Heilige Grab als Andachtsmittel}

Da der Depositionsgegenstand verschlossen wurde, gibt es einen scheinbaren Widerspruch zwischen der 


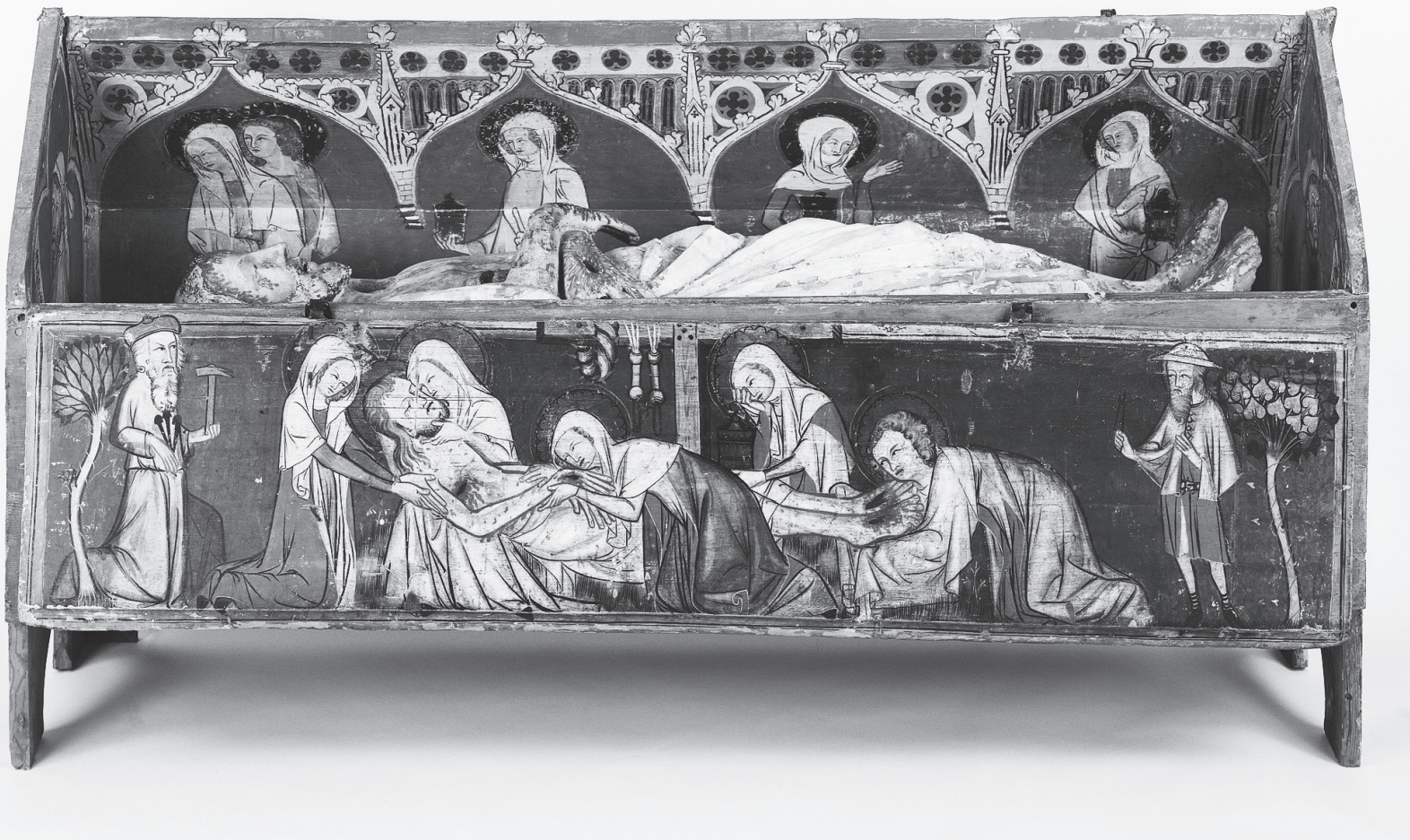

Abb. 19. Das Ostergrab der Zisterzienserinnenabtei Magerau/Maigrauge, um 1345-1360;

(Foto: (c) Musée d'art et d'histoire Fribourg)

rituellen Funktion und dem Devotionsbedarf. Wie es sich oben bei der Untersuchung der Funktionsmöglichkeiten schon herausstellte, gehörte das Zeigen der Eucharistie nicht zu den Aufgaben der mittelalterlichen Heiliggräber. Nicht nur, dass keine Spuren der Verehrung der Eucharistie erhalten blieben, sie wurde sogar auch vor den Blicken verschlossen und ziemlich hoch angebracht. Von der Anwesenheit der geweihten Hostie im Heiligen Grab konnte man nur wissen, aber sie ließ sich nicht wahrnehmen. Oft war nur die Stelle der Aufbewahrung des Sakraments zu bestimmen. Man hatte Anspruch natürlich auch im Spätmittelalter, das Altarsakrament zu sehen, es ist aber fraglich, ob das Heilige Grab diesen Anspruch erfüllte. Um die Frömmigkeitsübungen zu vollziehen, war der Anblick der Eucharistie nicht unbedingt erforderlich. Vom Karfreitag bis zum Morgen des Ostersonntags gewährte das abgeschlossene depositorium den optischen Reiz, dann am Ostertag das geöffnete und leere depositorium. Dies veranschaulicht auch das Heilige Grab des Stephanmünsters von Breisach: Die Eucharistie wurde unter der Christusgestalt durch eine kleine Tür abgeschlossen und während des Wachehaltens war davon nichts zu sehen. Wegen der Anforderung, dass das Sakrament abgeschlossen wer- den muss, war prinzipiell auch die Sichtbarkeit des Christusbildes eingeschränkt. Auch die schon zitierten Quellen, die die depositio einer Christusgestalt beschreiben, erwähnen den Verschluss. Im Gegensatz dazu war der Grabchristus in Biberach nach der Beschreibung während des Wachehaltens ersichtlich. Die Schaubarkeit musste aber hier eher partiell sein. Bei den vorhandenen Heiliggräbern war das Christusbild sicherlich nur im Fall zu sehen, wo es ursprünglich in die Nische eingebaut worden war, also an der depositio nicht teilnahm. Bei den Heiliggräbern, wo wir eine depositio nur vermuten, war das Zeigen des Christusbildes nicht garantiert. Die Form und Weise der Ausgestaltung des Grabs bestimmt meistens, was es und in welchem Maße dem Betrachter erblicken ließ.

Es ist zum Beispiel nicht eindeutig, wann das Christusbild in der Holztruhe schaubar war: Während der Heiligen Drei Tage oder für den Rest des Jahres. Das um 1329 entstandene Ostergrab aus dem Zisterzienserkloster von Magerau zeigt den Grabchristus in einem offenen Schrein mit gemalten Passionsszenen (Abb. 19). Wir haben keine Kenntnis von Schriftquellen über den mittelalterlichen Gebrauch. Erst aus dem Anfang des 20. Jahrhunderts stammt eine Beschreibung, nach der das Heilige Grab nur vom Aschermitt- 
woch bis zum Ostermontag offen aufgestellt wurde. ${ }^{105}$ Vom Karfreitagabend bis Ostersonntag vollzogen die Nonnen die Verehrung der Wundmale Christi. Für den Rest des Jahres wurde das Heiliggrab in einer abseitigen Ecke der Kirche zugemacht gelagert. Während der Feier war also der Schrein überhaupt nicht geschlossen. Es besteht aber die Frage, ob der neuzeitliche Brauch, im Triduum Sacrum den Grabchristus im Ostergrab zu zeigen, nicht auf die Barocksitten zurückzuführen ist. Die Heiliggrabtruhe war abschließbar und sie wurde - auf Grund der Ausmalung - augenscheinlich für offenen wie für zugemachten Zustand bestimmt. Dies spielte gewiss während der Osterriten eine wichtige Rolle. Der mittelalterlichen Praxis entsprechend musste das Heilige Grab in den Stunden der Grabesruhe in geschlossenem, bei der Auferstehung in geöffnetem Zustand sein.

Nach der Meinung von Peter Jezler habe das Ostergrab von Magerau bei den Osterriten der depositio und der elevatio eine aktive Rolle gespielt, die Christusgestalt sei demnach bewegbar gewesen. ${ }^{106}$ Die Grablegung der Skulptur wirft deshalb Fragen auf. Der Depositionsgegenstand war regelmäßig das Kruzifix, welches vorher während der adoratio crucis verehrt worden war. Für diesen Zweck war aber das Bild des toten Christi nicht geeignet. Man konnte es auch nicht nach der elevatio auf den Altar zurücksetzen, da es die Idee der Auferstehung nicht vertrat und auch nicht als Siegessymbol betrachtet werden konnte. In diesem Fall wurde die Christusgestalt nach der elevatio eher in der Sakristei versteckt. Man bedurfte eines anderen Depositionsgegenstands, da die Skulptur nicht jede Funktion zu erfüllen vermochte. Wie ich oben darauf schon hingewiesen habe, war der Gegenstand der depositio in engerem Sinne der liturgische Körper Christi, der von der Skulptur getrennt behandelt werden konnte. Man konnte also die Zeremonie der depositio auch vollziehen, wenn das Christusbild daran überhaupt nicht teilnahm. Zur Grablegung war auch ein Kruzifix kleineren Formats geeignet, man konnte es auf den Grabchristus legen und an der Matutin des Ostersonntags beide entfernen. Eine andere Möglichkeit zur depositio bestand darin, dass das Sakrament in den Ausschnitt der betont ausgestalteten Seitenwunde Jesu eingesetzt wurde. ${ }^{107}$ Damit wurde die Christusgestalt zum Behälter der Eucharistie. Ein 1260 entstandener Liber Ordinarius aus Zürich, dessen Verwendungsort zum Standort des Heiliggrabs am nächsten lag, bestimmt die Grablegung eines kleineren Kruzifixes. ${ }^{108}$ Es äußert sich aber ausdrücklich auch die Eucharistie betreffend: „Nam contra omnam rationem est, quod in quibusdam Ecclesiis Eucharistia in huiusmodi archa Sepulchrum representante poni consuevit et claudi. Ibi enim Eucharistia, que est verum et vivum Corpus Christi, ipsum Christi Corpus mortum representat, quod est indecens penitus et absurudum." Demnach sei die Grablegung des Sakraments nicht angemessen, da es als wirklicher und lebender Körper Christi den toten Christus nicht repräsentieren könne. Auf Grund des Textes ist also ein Depositionsritus wohl vorstellbar, der auf die Grablegung der geweihten Hostie verzichtet. Ein in den Brustkasten Jesu gestecktes Sakrament konnte sicherlich nur im Fall vorkommen, wenn die Christusgestalt in das Heilige Grab fest eingebaut worden war. In der Brust der liegenden Figur aus Freiburg wurde ein viereckiger Ausschnitt ausgestaltet, der nicht mit der Seitenwunde identisch ist. Daraus lässt sich schließen, dass die Seitenwunde der Christusgestalt aus Magerau nicht sicherlich zur depositio am Karfreitag ausgestaltet wurde, sondern sie weist auf eine mögliche Verwendung der Skulptur außer den Osterfeiertagen hin. Die Verehrung der Wundermale Christi war nämlich im Kreis der Zisterziensernonnen ziemlich verbreitet. Es ist möglich, dass eine Reliquie darin gesetzt wurde. Die Heiliggrabtruhe zeigt in geöffnetem Zustand die Szene der Grablegung. Dies kann auch auf die Verehrung der Wundmale Christi hindeuten und damit ein Andachtsthema der Nonnen bieten.

Bezüglich des um 1440 von Katarina von Hoya gestifteten Heiligen Grabs im Kloster Wienhausen ${ }^{109}$ (Abb. 20a) steht uns eine konkrete Angabe zur Verfügung, dass es erst während der Osterfeiertage verwendet wurde. Peter Jezler veröffentlichte insgesamt sechs Quellen, die sich auf zwischen 1314 und 1570 entstandenen Ewig-Licht-Stiftungen beziehen. Diese Quellen weisen darauf hin, dass die ewigen Lichter das Ziel hatten, die Gläubigen nicht nur an den Karfreitag, sondern an jeden Freitag des Jahres - das heißt an den Todestag Christi - zu erinnern. Dies bedeutet, dass das Heiliggrab das ganze Jahr über ersichtlich war. ${ }^{110}$ Jezler war der Erste, der die Depositionsfunktion der Christusgestalt bestritt. Er nahm an, dass das Christusbild nicht an der symbolischen Grablegung teilnahm und auf Ostersonntag nicht entfernt wurde. Dies belegen auch die Tatsachen, dass die um 1290 entstandene Figur wegen seiner Größe und seines Gewichts zur Bewegung nicht geeignet war und auch die Ausmalung nur für eine Ansicht gefertigt wurde. ${ }^{111}$ Die liturgische Funktion der Skulptur wurde auf diese Weise befragt und nur die ganzjährige offentliche Andachtsbildfunktion der Christusge- 
stalt konnte erwiesen werden. Die Ausgestaltung der Heiliggrabtruhe deutet trotzdem darauf hin, dass eben wenn der Grabchristus nicht entfernt wurde, erfüllte auch das Grab während des Triduum Sacrum irgendwelche Rolle. Die Grabtruhe ist sowohl innerhalb wie auch außerhalb ausgemalt und sie kann der Struktur nach in drei Zuständen aufgestellt werden, wie das Ostergrab von Magerau. ${ }^{112}$ In offenem Zustand konnte das Grab zur geistigen Vertiefung und der Verehrung der darin gesetzten Reliquie dienen. In der Zeit vom Karfreitag bis zur Auferstehung müsste es wohl in geschlossenem Zustand gewesen sein (Abb. 20c). Bei der Auferstehung konnte es aber mit dem Aufmachen der unteren Tür das leere Grab repräsentieren, während die Christusgestalt in der Grabtruhe im oberen Teil abgeschlossen blieb (Abb. 20b). Der untere Teil dürfte wohl dazu geeignet gewesen sein, darin ein kleineres Kruzifix niederzulegen, dann während der elevatio es zu entnehmen. ${ }^{113}$ Dieser Typ der ausgemalten Holzgrabtruhen zeigte das Christusbild für den Rest des Jahres. An den Heiligen Drei Tagen war das Heiliggrab entweder geschlossen oder leer zu sehen.

Auf Grund der erwähnten zwei Beispiele kann festgestellt werden, dass die Christusgestalt gewissermaßen den liturgischen Körper Christi ergänzte und damit wurde ihr eine rituale Funktion zuteil. Diese rituale Funktion erwies sich nicht durch das Zeigen des Christusbildes, sondern eben durch seinen Verschluss und seine Entnahme. Das Christusbild konnte jedoch auch außer der Liturgie verwendet werden. Das liturgische Heilige Grab ist also nicht vollkommen identisch mit dem als Bild erscheinenden Heiliggrab, ihre Funktionen decken sich nicht unbedingt.

Die Beispiele der frei stehenden Heiliggrab-Typen, wie die Heiligen Gräber von Chemnitz, Garamszentbenedek oder Zwickau, ließen teilweise auch nach dem Abschließen einen Einblick auf die Liegefigur des toten Christi. Das Heiliggrab ermöglichte aber in keinem Fall die vollkommene Ansicht der Figur - sie war nämlich eben von dem Schrein teilweise verdeckt. Beim Heiliggrab von Garamszentbenedek bezieht die Architektur über dem Schrein die Apostelfiguren in das architektonische System ein, die Gestalten bilden nämlich eine Art Trennwand. Die Abwechslung der Figurennischen und der durchbrochenen Fenster beeinflusst die Wahrnehmung des Grabs: Die Fenster gewähren einen Einblick in das Innere der Anlage, aber die Gestalten behindern ihn eher und lenken die Aufmerksamkeit des Betrachters auf sich zurück. Der Prozess der visuellen Wahrnehmung ähnelt sich sehr einiger Typen der Reliquienschreine. Ein ähn- liches Beispiel ist der auf Ende des 13. Jahrhunderts datierte Schrein der Passionsreliquie, der in der Basilika San Francesco von Assisi aufbewahrt wird. ${ }^{114}$ Die Reliquie verbirgt sich im mittleren Teil, davor findet sich ein ornamentales Gitter. Das Gitter ist mit Vierpassen in Kreissegmenten verziert. Im Giebelfeld darüber erscheint der halbfigürliche Jesus als Richter. Das Ornament des Gitters ist durchbrochen und lässt teilweise die verborgene Reliquie erblicken. Der Anblick ist nur relativ: Es berücksichtigt den Anspruch auf das Erblicken der Reliquie, erschwert jedoch die Sichtbarkeit dadurch, dass das Gitter die Ansicht zerschneidet und führt den Blick des Betrachters auf sich selbst, auf die Ebene des Ornaments zurück. Der Blick ist also gezwungen, zwischen der Ebene des Ornaments und dem Raum des Schreins zu wandern, wo man aber nur die verschwommenen Konturen der in Seide verhüllten Reliquie sehen kann, und die Neugier wird dadurch nicht befriedigt. Das Gitter stellt eine Rückfrage an den Betrachter: Was ist das, was wir sehen können und sehen möchten? Die Reliquie gehört zur Sphäre des Irdischen. Die Reliquien Christi sind die Beweise seiner irdischen Inkarnation, die aber sein Gottwesen nicht erblicken lassen. Das Gitter thematisiert unsere eingeschränkte Fähigkeit des Sehens, und obwohl es nicht figural ist, bietet eine Möglichkeit zur Kontemplation darüber, was nicht zu erblicken, nur vorzustellen ist - was allerdings auch auf die figurale Darstellung zurückwirkt.

Der Funktion nach können der architektonische Aufbau und die zugehörige Apostelreihe des Heiliggrabs von Garamszentbenedek ähnlich dem oben erwähnten Gitter betrachtet werden. Die Apostelreihe ist hier nämlich nicht nur ein Bauelement, sondern hat die Funktion wie das Gitter am Reliquienschrein. Sie bildet eine Schwelle oder eine Grenze, die den suchenden Blick aufhält und auf sich selbst zurückführt. Sie lenkt die Aufmerksamkeit auf das geistige Zentrum im Mittelpunkt der Anlage, aber macht den Betrachter auch darauf aufmerksam, die Wirklichkeit des Wesentlichen nicht nur mit den Augen zu suchen. Bei den Heiliggräbern, die einen dem von Garamszentbenedek ähnlichen Aufbau haben, übernimmt normalerweise ein für die Reliquienschreine charakteristisches Maßwerkgitter diese Funktion. Im Fall des Heiliggrabs der Jakobikirche von Chemnitz finden sich die Skulpturen zum Beispiel vor der ununterbrochenen Reihe der Maßwerkfenster. Sie gliedern sich nicht in die Architektur ein wie die Apostelfiguren in Garamszentbenedek. In Chemnitz trennt sich die architektonische Struktur von den Gestalten, sie bilden keine 
Einheit. Eher die Maßwerkstruktur bestimmt hier den Anblick. Der Aufbau des Heiliggrabs aus der Marienkirche von Zwickau hat eine rein ornamentale Struktur. Bei den aus Holz gefertigten, frei stehenden Heiliggrab-Typen spielen die Elemente, die den Anblick beeinflussen - den Reliquienschreinen ähnlich - eine wichtige Rolle. Durch die Einschränkung des Aktes des Sehens lenkt die Anlage unsere Aufmerksamkeit auf die Begrenztheit der Wahrnehmung. Im Heiligen Grab diente die Zurschaustellung des Depositionsgegenstandes nicht zur Andachtsfunktion während der Zeremonien des Triduum Sacrum.

Nicht nur sichtbare Dinge können Gegenstände der Devotion sein. Die Meditation entsteht nach der mittelalterlichen Deutung durch Erinnern und Heraufbeschwören. Der Gegenstand der Meditation ist eigentlich das heraufbeschworene Ereignis selbst, die Darstellung ist nur Mittel der Meditation. Die geweihte Hostie oder das Christusbild, die verdeckt waren und von denen man nur ihr Aufbewahrungsort wahrnehmen konnte, konnten auch Gegenstände der Meditation sein. Von der Grablegung bis zur Auferstehung diente eher nur der eingeschränkte Anblick zur Andacht. $\mathrm{Zu}$ Ostern war es das leere Grab oder eher der Anblick des Grabs, aus dem der Depositions- gegenstand entnommen worden war. Dies drückt das Mysterium des Todes und der Auferstehung aus. Die Erkenntnis des eingeschränkten Sehens, die Denkarbeit am Unsichtbaren beanspruchte eine ausdrücklich intellektuelle Leistung. Robert Suckale betonte bezüglich der Zeichenhaftigkeit des Andachtsbildes, dass die Devotion neben dem Gefühlsaspekt auch eine intellektuelle Leistung war: Der Gedanke und das den Gedanken auslösende Gefühl können in der Praxis nicht getrennt werden. ${ }^{115}$ Das Heilige Grab betreffend bedürfen nicht nur das Artikulieren und das Begreifen der abstrakten Fragen des Glaubens und des Heils intellektueller Leistung, sondern auch die Wahrnehmung des wesentlichen Unterschieds zwischen dem Bezeichnenden und dem Bezeichneten sowie die Entfaltung der Aussage des zum Zeichen konzentrierten Bildes. In der Urkunde von Hall bestimmte der Bischof von Brixen die Grablegung des Kruzifixes und der Eucharistie - beide waren Ausgangspunkte zur Meditation. Auf die Rezeptionshaltung des Publikums finden wir darüber hinaus den folgenden Hinweis: „Nos igitur eorundem Consolum opidanorum et Incolarum pium desiderium atque iustam peticionem attenderemus, quodque ut etiam ibidem signatum cum signo conveniat ac ipsius dominice passionis misterium in cordi-

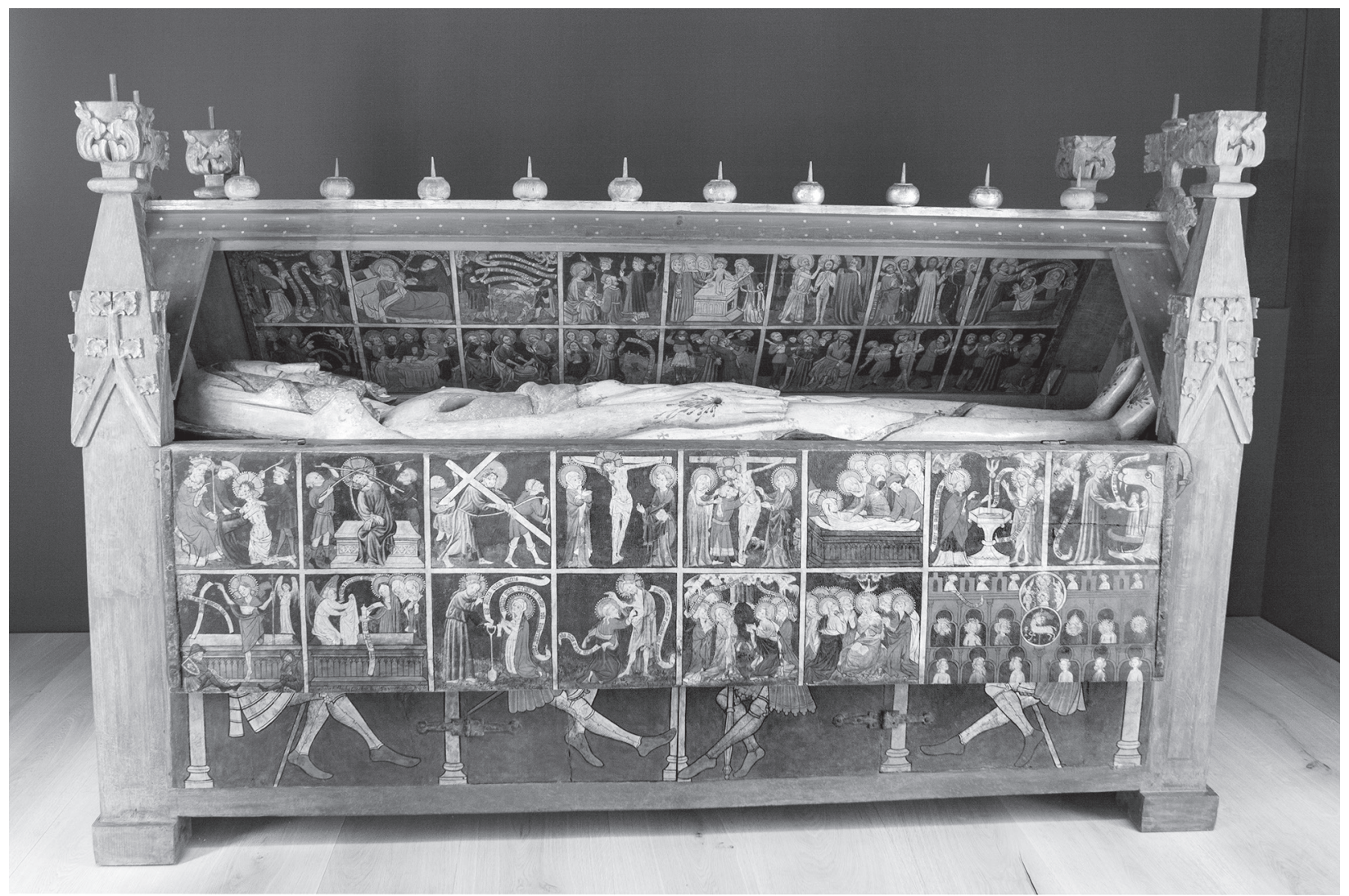

Abb. 20a. Das Heilige Grab im Kloster Wienhausen, 1448 (Foto: (C Lüneburger Klosterarchive Kloster Wienhausen) 


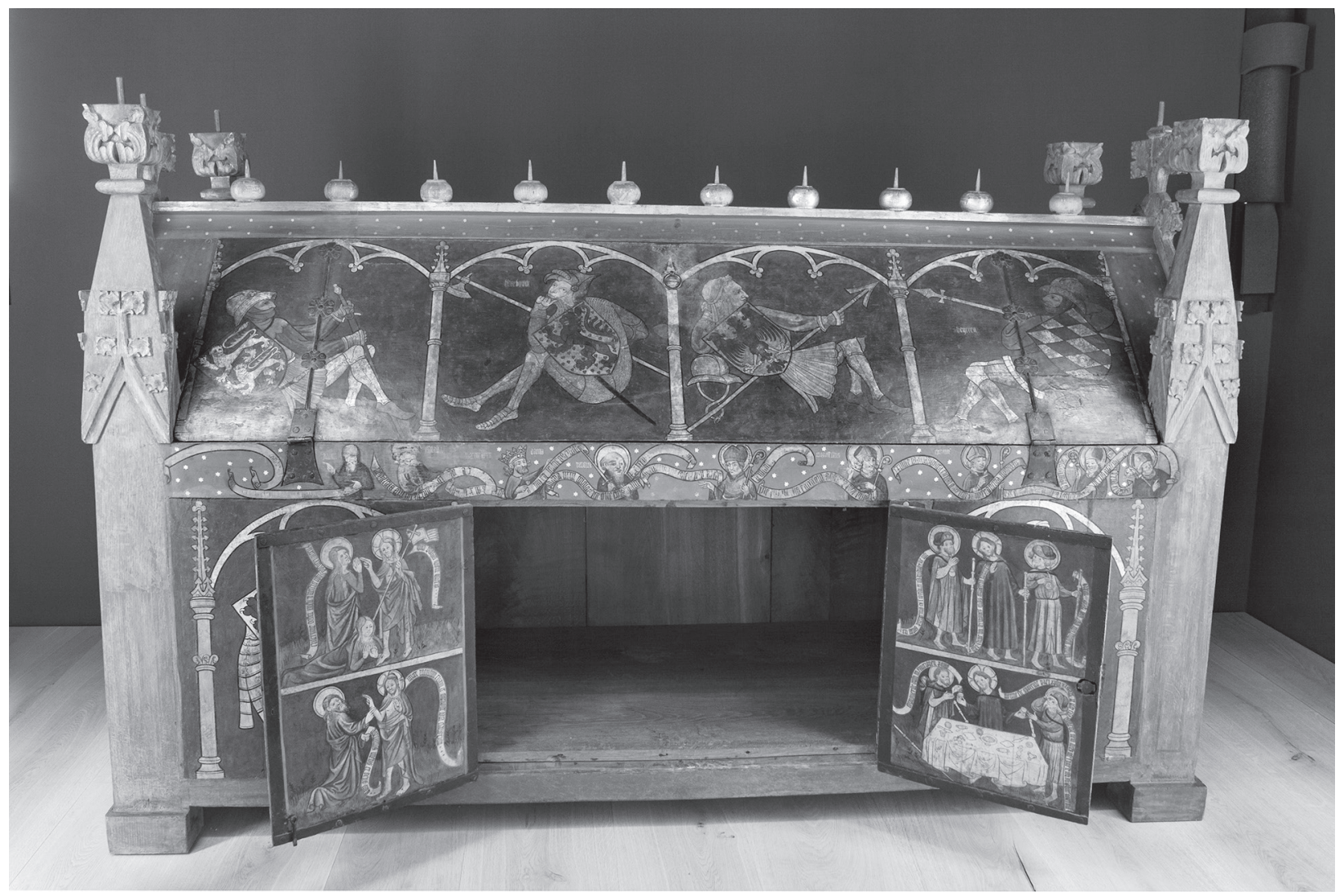

Abb. 20b. Das Heilige Grab im Kloster Wienhausen, 1448 (Foto: (c Lüneburger Klosterarchive Kloster Wienhausen)

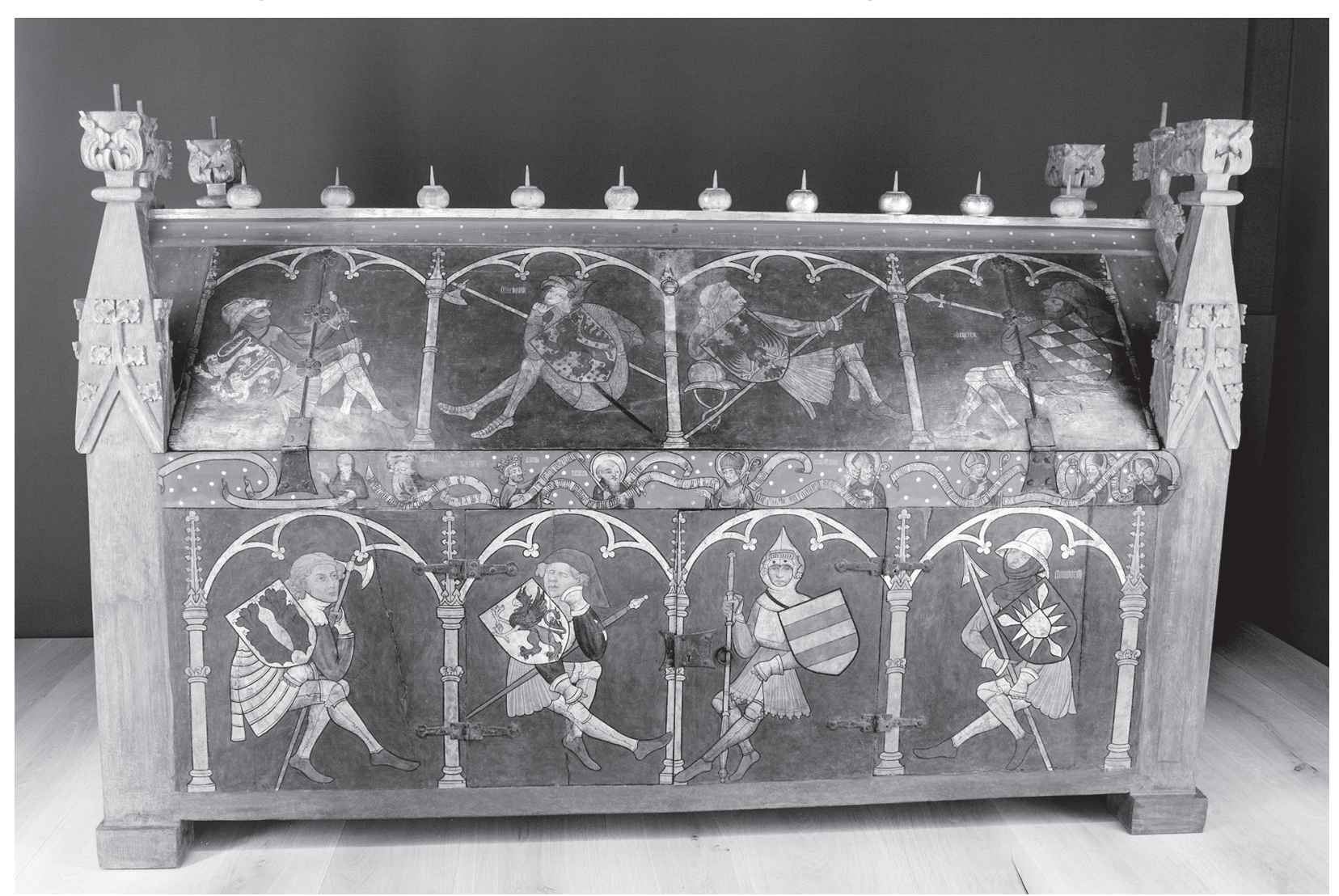

Abb. 20c. Das Heilige Grab im Kloster Wienhausen, 1448 (Foto: (c) Lüneburger Klosterarchive Kloster Wienhausen) 
bus fidelium ardentius infigatur...".116 Es wird betont, dass das Bezeichnende und das Bezeichnete in der Eucharistie übereinstimmen und zur Erregung einer Gefühlsreaktion beim Mysterium der Passion musste man es zuerst offenbar verstehen. Nach der Urkunde wird auch ein anderes Zeichen im künftigen Heiligen Grab sein, und dies ist das Kruzifix. Wenn es das Christusbild trug, muss man nicht nur mit der Übereinstimmung des Bezeichnenden und des Bezeichneten in der Eucharistie rechnen, sondern auch mit der des Zeichens und des Bildes. Das gemeinsame Dasein scheint zum ersten Blick ziemlich komplex zu sein. Aber in der mittelalterlichen Denkweise gab es keinen scharfen Unterschied zwischen Zeichen und Bild. Der mittelalterliche Zeichenbegriff verschmolz oft mit dem Bild oder dem Text. Bonaventura bestimmte die folgende Definition: „Signa divinitus data [...] (vel picturae; simulacra et spectacula) [...] sunt exemplaria vel potius exemplata, proposita mentibus adhuc rudibus et sensibilibus, ut per sensibilis, quae vident, transferantur ad intelligibilia, quae non vident, tamquam per signa ad signata“. ${ }^{117}$ Wegen der Übereinstimmung in der Funktion gliedert er die Bilder, die Simulakren und die Spektakel - solche Performance-Typen wie das Passionsspiel - in den Kreis der Zeichen ein. Sie haben das Ziel, durch das Wahrnehmbare den Betrachter zu dem Unsichtbaren zu führen. Er betont nicht die Übereinstimmung zwischen dem Bild und dem Zeichen, sondern ihre Ähnlichkeit, und dass sie potentiell gleichwertig sind. Vom 14. Jahrhundert wurde entweder das vom Kreuz abnehmbare Bild oder die Liegefigur des toten Christi an Stelle des Kreuzes immer häufiger verwendet. Formal werden die beiden als Bild betrachtet, aber in den Zeremonien waren sie als Zeichen aufzufassen, der Funktion nach waren sie dem Zeichen ähnlich.

Die gemeinsame Gegenwärtigkeit der Eucharistie und des als Zeichen begreifbaren Bildes ist auch in einem anderen Medium, im Passionsspiel, zu finden. Die rezeptionsästhetische Untersuchung der Figur als Zentralbegriff der mittelalterlichen Simultanbühne als kulturelles Medium kann auch bezüglich der Gegenstände des Heiliggrabs und der depositio aufschlussreich sein. ${ }^{118}$ Im Mittelpunkt der Passionsspiele und der Fronleichnamsprozessionen stand der eucharistische Körper Christi. Die Figur Christi wurde durch die geweihte Hostie vergegenwärtigt. ${ }^{119}$ Die Figur hatte im Rahmen der mittelalterlichen Bühne verschiedene Bedeutungen: Sie konnte sich auf das ganze Spiel, auf eine einzige Szene, auf eine Kulisse beziehen oder konnte auch lebendiges Bild bedeuten. ${ }^{120}$ Glenn
Ehrstine betonte die Zeichenhaftigkeit der einzelnen Gestalten und Szenen, wo er die Figur vor allem als dramaturgischen Begriff verstand. ${ }^{121}$ Im Passionsbild hatten die Aufführung und die Darsteller als zeichenhafte Körper nur eine Rolle der Vermittlung und der Andeutung. Der Darsteller identifizierte sich überhaupt nicht mit seiner Rolle, die Rolle und der Darsteller bleibt bis zum Schluss getrennt. Der Bischof von Meißen genehmigte 1502 den Bürgern der Stadt Kamenz, von da an die Prozession am Tag der Auffindung des Heiligen Kreuzes mit Figuren abzuwickeln: „Sed cum omnis (!) vulgus ad talia meditanda aptius faciliusque induci nequit, quam per corporales quasdam figuras et signa, quibus tanquam libris quibusdam passionem dominicum legere habeant...".122 Die in Kostüme eingekleideten Figuren vergegenwärtigten die Passion. Der Bischof stellte die Figuren den zeichenhaften Körpern gleich, welche die Laien wie ein Buch lesen konnten. Er bestimmte ferner auch die richtige Betrachtungsweise und die Ziele der Figuren: Die Funktion der Figur sei, die Besinnung des einfachen Volks zur Meditation über die Passion Christi anzuregen, ferner die Passion mit den Zeremonien und Gebräuchen ins Gedächtnis zu prägen. ${ }^{123}$

Während des Passionsspiels richtete der Proklamator die Aufmerksamkeit des Publikums von einer Szene auf die andere. Das auf um 1480 datierte Passionsspiel aus Donaueschingen war das Erste, bei dem der Proklamator das Spiel und die Szenen Figur nannte: „dar vmb so losen liebe kind / ir werdent ir sehen in menschlicher natur / gar menig schön andächtig figur / die vns armen sünder zeguott / geschechen sind vom höchsten guot / dar vmb da ser vns selig macht [...] / wie das begriffet vnser globen / das werdent ir alles schowen / in figuren und ernstlicher geschicht". ${ }^{124}$ Der Proklamator machte das Publikum auch auf die richtige Rezeption aufmerksam, um die Figur des Passionsspiels so zu betrachten, als wäre sie aus göttlicher Gnade für die Sünder entstanden und würde auf den Erlösungsakt Christi hindeuten. Obwohl die Figur in Menschenkörper erscheint, bietet sie an und für sich keinen sicheren Anhaltspunkt zur richtigen Rezeption. Dies wird auch durch die Interpretationsrolle des Proklamators beziehungsweise durch die Präsenz der Eucharistie gefördert. In den Passionsspielen wurden nicht nur die Szenen oder die Rollen Figur genannt, sondern auch Objekte, Zeuge, Kulissen, die ebenfalls auf eine Handlung oder Person hinwiesen. In Dresden bekam ein gewisser Hans Straßberg für die Ausbesserung der Figuren eines Schauspiels 1 Schilling und 20 Groschen. ${ }^{125}$ 
Die Bezeichnung Figur kam nicht nur in den Passionsspielen vor. Im Dialog der visitatio sepulchri erscheinen die drei Marien und die den Engel darstellenden geistlichen Personen auch oft als Figuren, wie zum Beispiel in Melk: „... deinde duo vel tres cum totidem thuribulis figuram mulierum tenentes procedant ad sepulchrum...".126 Die Figur bezeichnet auch hier nicht nur einfach eine Gestalt oder eine Form. Die Darsteller kleideten sich in keine Kostüme, sie verwendeten nur ein symbolisches Kennzeichen. Sie ahmten die historischen Persönlichkeiten nicht nach. Die Figur betont die Gegenwärtigkeit der Handlung und des Dialogs, der am leeren Grab stattfindet. Er ist nicht weniger gegenwärtig und verweist auf ein Versprechen. Die Figur, die aus den Texten der Liturgie der Heiligen Drei Tage hervorgeht, bezieht sich häufiger auf lebende Personen, und das Wort Imago bezeichnet in der Regel Gegenstände oder Bilder. Wie man das Wort Figur in den Passionsspielen auch für Objekte anwendete, kam es auch vor, dass die Figuren in den Osterriten Bilder bezeichneten.

Das schon erwähnte Dommesner-Buch aus Brixen nennt das am Karfreitag ins Heilige Grab niedergelegte Christusbild eine Figur: „due das oster grab herfür, sez das an sein gewonliche ortn. Von erst nim die figur herauß unnd trags in Sagrer leg die auf das pret, darauff man di figur zu grab tragt". ${ }^{127}$ Statt der Bezeichnung Imago, die bei der Beschreibung der depositio gebräuchlich war, erscheint hier das Wort Figur, was einen ähnlichen Aspekt der Rezeption voraussetzen kann, wie die im Passionsspiel erscheinende Figur. Ihre Ähnlichkeit mit der von Menschen gespielten Figur besteht in erster Linie nicht darin, dass sie unter den anderen Teilnehmern der Zeremonie bewegt und auf diese Weise Akteur der Handlungen wurde. Der Terminus handelndes Bildwerk von Tripps drückt aus, dass die "Handlung“ oder eher die Bewegung selbst zum Wesen dieser Skulpturen gehörte. Auch der früher erwähnte Liber Ordinarius aus Narbonne bezeichnet das Heilige Grab als Figur: „levent cum filo pannum qui est super libros argenti super altare in figura sepulchri“. ${ }^{128}$ Ein eventueller Vergleich des Christusbildes der Deposition und des Heiliggrabs mit der Figur der Passionsspiele wird auch dadurch begründet, dass sie nicht jederzeit verwendet werden durften. Sie ließen sich nicht wie ein Andachtsbild hervorbringen und waren nicht ständig im Inneren einer Kirche zu sehen. Dies gilt nicht nur für die aus Holz gefertigten beweglichen Heiliggräber und ihre Depositionsbilder, sondern auch für die monumentalen Skulpturen wie die Heiligen Gräber aus Freiburg oder Gengenbach, die das ganze Jahr über ersichtlich waren. Die gemeinsame Präsenz und Verschmelzung des liturgischen Körpers Christi und des Christusbildes kommt nämlich nur einmal im Jahr vor. Auch ein Teil der Depositionsbilder war dem Publikum außer der Karwoche-Liturgie nicht zugänglich. Im Fall der vom Kreuz abnehmbaren Christusgestalten ist es möglich, dass sie ganzjährig am Kreuz zur Schau gestellt waren. Die Kreuzabnahme und die Grablegung erfolgten jedoch nur einmal im Jahr und in dieser Zeit war das Christusbild in einer anderen Beschaffenheit präsent als sonst.

Bild und Figur haben scheinbar ähnliche Funktionen, trotzdem sind sie nicht identisch. Das Bild, die Imago war viel mehr verbreitet, aber die Tatsache, dass man in dem Brixener Dommesner-Buch anstatt des Bildes eher die Figur verwendete, bezeichnet, dass eine Doppelfunktion dem Bild während des Festes beigemessen wurde. Die Bedeutungsebenen des Wortes Figur können ihre Doppelfunktion im Verhältnis zum Wort Imago beleuchten. Bei den Kirchenvätern tauchte das Wort Figur meistens in realprophetischem Sinn auf: Man deutete die Gestalten des Alten Testaments als Figuren des Neuen Testaments. Die Figur ging also zeitlich der Erfüllung voran. Sie wurde aber im Passionsspiel nicht nur zu den Gestalten des Alten, sondern auch den des Neuen Testaments verwendet. Im Letzteren deuten auch die Figuren aus dem Neuen Testament auf etwas Künftiges hin, denn die evangelische Inkarnation ist auch nicht die endgültige Erfüllung. Die Figur muss nicht nur als historisch oder vorläufig aufgefasst werden, denn es beinhaltet auch das künftige Urbild. ${ }^{129}$ Die Figuren sind zwar historisch, körperlich und wirklich, sie sind keine leeren Dinge. Im Passionsspiel ist die Figur auf diese Weise nicht nur die Nachahmung oder das Bild einer vergangenen geschichtlichen Tatsache, sondern sie erhebt sich in der jeweiligen Gegenwart auf den Rang der geschichtlichen Wirklichkeit, als wäre sie die Figur von etwas Künftigem: die Figur eines Versprechens, einer Erfüllung oder die des Kommens des Gottesreiches. Die in der Beschreibung von Brixen erscheinende Depositions- oder Heiliggrab-Figur ist also nicht nur die Darstellung einer historischen Person oder die Nachahmung eines historischen Ortes, sondern die Figur ist auch an und für sich ein gegenwärtiges Ereignis, Teil eines Ritus, ein zur Schöpfung gehörendes Ding, das auch auf ein künftiges Ereignis hinweist, auf die Endzeit, das Versprechen der Auferstehung des Körpers.

Die Imago deutet auf die Erscheinungsform des Gegenstands hin, die Figur jedoch auch auf eine Ver- 
wendungsweise. Das Heilige Grab und die zur Deposition verwendete Figur sind natürlich auch Bilder, die schaubar und die Abbildung oder die Nachahmung eines Abwesenden sind. In den Riten der depositio und der elevatio wie in der Periode dazwischen lassen sich die Figuren auch als Bild betrachten. Da aber das Bild nicht statisch genug war oder gegebenenfalls auch abgeschlossen wurde, konnte es als Bild eher nur außer der Liturgie betrachtet werden. Die Figur hat eine wahrnehmbarere Präsenz oder Wirklichkeit als die Imago, da die Figur aktiv an der Zeremonie teilnimmt. Dem Heiligen Grab und der zugehörigen Christusgestalt wurden aber die Eigenschaften der
Figur nur durch die aktive Teilnahme erst während der Zeremonie zuteil. Die Andachtsfunktion kann jedoch nicht nur auf den statischen Zustand des Bildes bezogen werden. Wenn das Passionsspiel als eine Serie von Figuren zur Andacht geeignet war, galt dasselbe auch für die Osterriten um das Heilige Grab. Auch die Riten können nämlich als Serie von Figuren aufgefasst werden. Andachtsmittel war nicht nur das Heilige Grab, das als Figur oder Bild erschien, sondern auch die daran anschließende liturgische oder halbliturgische Handlung. Bild und Ritus unterstützten einander in der Bedeutungsproduktion und bildeten zusammen den Gegenstand der Devotion.

\section{FAZIT: DIFFERENZIERUNG DER FUNKTIONSBEGRIFFE}

Das Heilige Grab bedeutet einerseits einen ikonografischen Typ und einen Bildtypus, andererseits repräsentiert es auch eine Bildgebrauchsweise im Rahmen der Liturgie. Diese umfassen die Funktionsmöglichkeiten der Heiliggräber. Hans Belting unterschied dreifache Begriffe bezüglich der Funktion mittelalterlicher Bilder. ${ }^{130}$ Der eine bezieht sich auf die Bestimmung des Kontextes, es geht also um den konkreten Verwendungsort und die Verwendungsweise des Bildes. Der andere Begriff umfasst die Funktion als die Rezeptionshaltung des Publikums, die mangels weiterer Angaben selbst aus dem Bild abgeleitet werden kann. Die Rezeptionshaltung kann nicht unabhängig vom Bildgebrauch sein, und umgreift die ans Bild gestellten Erwartungen beziehungsweise die Auswirkung der Bildmittel auf den Betrachter. Der dritte Funktionsbegriff umschließt das Verhältnis von Inhalt und Form, also die Art und Weise, wie der Bildinhalt mit visuellen Mitteln artikuliert wird. Nach Belting ist diese Funktion von den äußeren Zielen des Bildes, also vom Bildgebrauch, unabhängig. Im Fall des Heiligen Grabs wird der Bildinhalt durch den liturgischen Kontext weder vom Gebrauch noch von der Rezeptionshaltung der Betrachter unabhängig. Die Grenzen der dreifachen Funktionsbegriffe verfließen so, dass sie nur im Prinzip abzutrennen sind.

Während der Untersuchung der Heiliggrabfunktionen entfalteten sich in diesem Aufsatz zwei größere Gruppen: die liturgische oder rituelle beziehungsweise die Andachtsfunktion. Diese Einordnung kann nach dem Bildgebrauch und den Bildfunktionen weiter gegliedert werden, aber diese Klassifizierungen sind schon in den oben beschriebenen drei Funktionen einbegriffen. Die eine Funktion ist die des Gebrauchs, der dem Bild sozusagen passiv widerfährt, der ihm passiert. Dies umgreift die Bestimmung des Kontextes: Unter welchen Umständen und Handlungen wir das Bild wahrnehmen und was für Erwartungen wir an das Bild stellen. In Kenntnis des Kontextes müssen wir das Bild aus dem Aspekt untersuchen, wie es dem schon bekannten oder vermuteten Bildgebrauch mit seinen eigenen Bildmitteln diente. Dies ist der zweite Funktionsbegriff, der sich auf die private Funktion des Bildes bezieht: Wie es funktioniert, wie es mit dem Betrachter kommuniziert und wie es zur Bedeutungsproduktion beiträgt. Dazu gehört der semantische Zusammenhang zwischen Form und Inhalt des Bildes.

Das Heilige Grab als liturgisches Mittel war Teil einer fest geregelten rituellen Handlung. Der liturgische Gebrauch bedurfte keines Bildes. Das liturgische Heilige Grab, das sepulchrum erwarb nämlich durch die Handlung seine Bedeutung und seine rituelle Präsenz. Der Bildgebrauch in rituellem Kontext kann mit der immer größeren Teilnahme der Laienorganisationen erklärt werden. Wir können die eigene Rolle des Bildes in der Zeremonie danach bestimmen, dass es in den Riten den historischen Christus und das historische Grab Jesu abbildete und deren Gegenwärtigkeit betonte. Also nicht nur die liturgische Handlung bestimmte das Objekt, sondern auch das Heilige Grab als Bild nahm aktiv an der Bedeutungsproduktion und an der Repräsentation teil.

Auch unter den Andachtsfunktionen des Heiligen Grabs lässt sich seine Verwendung zu Devotionszwecken unterscheiden. Dies deutet darauf hin, bei welchen Gelegenheiten das Bild betrachtet wurde, was für fromme Handlungen um das Bild vollzogen wurden und welche Erwartungen man an das Bild stellte. Hier 
geht es nicht nur um eine eigene Betrachtungsweise des Bildes, sondern wir können auch während der Zeremonie über eine Andachtsfunktion sprechen, in der nicht nur das Bild, sondern auch der vollzogene Ritus einbegriffen wurden. Der zweite Funktionsbegriff, d. h. die eigene Andachtsfunktion des Bildes, bezieht sich auf die eigenen Bildmittel: Wie man das Heilige Grab wahrnehmen konnte, was das Heilige Grab dem Betrachter zeigte, wie die Bildform die Betrachtungsweise bestimmte. Das Heilige Grab zeigte sich wegen des Depositionsgegenstandes ganz anders während und außer der Zeremonie. Dies kann einerseits zu einer physisch geänderten Bildform, aber auch zu einer anderen Art der Existenz des Bildes führen. Während der Zeremonie wurde das Bild des Heiligen
Grabs in die liturgische Gegenwart versetzt, nach den Osterriten umwandelte es sich jedoch in das Bild von etwas Abwesendem.

Der Gebrauch und die Bildfunktionen sind im Fall des Heiligen Grabs nicht unbedingt in Einklang. Die beiden sind nicht auseinander abzuleiten. Die liturgisch-rituelle Verwendung, auf die wir größtenteils aus den liturgischen Texten schließen können, erklärt nicht immer die speziellen formalen und strukturellen Eigenschaften der Heiliggräber. Aus den Eigenheiten der Gegenstände können wir ferner nicht unbedingt eine mögliche Verwendungsweise erschließen. Durch die Differenzierung der verschiedenen Funktionsbegriffe lassen sich das liturgische Heilige Grab und das Heiliggrab als Bildform viel mehr unterscheiden.

\section{ANMERKUNGEN}

${ }^{1}$ KRAUTHEIMER, Richard: Introduction to an Iconography of Medieval Architecture, Journal of Warburg and Courtauld Institutes 5. 1942. 3.

2 SCHWARZWEBER, Annemarie: Das heilige Grab in der deutschen Bildnerei des Mittelalters, Freiburg im Breisgau: Albert, 1940. 10-60; Kroesen, Justin E. A.: The Sepulchrum Domini through the Ages. Its Form and Function, Leuven-Paris-Sterling, Virginia: Peeters, 2000. 45-108.

${ }^{3}$ Über Depositionsgegenstände und die Christusgestalten mit beweglichen Armen siehe: TAubert, Gesine - TAUBERT, Johannes: Mittelalterliche Kruzifixe mit schwenkbaren Armen. Ein Beitrag zur Verwendung von Bildwerken in der Liturgie, Zeitschrift des Deutschen Vereins für Kunstwissenschaft 23. 1969. 79-121.

${ }^{4}$ BRoOKs, Neil C.: The Sepulchre of Christ in Art and Liturgy, with Special Reference to the Liturgic Drama, University of Illinois, 1921. 59-70.

${ }^{5}$ Grinder-Hansen, Poul: Public Devotional Pictures in Late Medieval Denmark, in Images of Cult and Devotion. Function and Reception of Christian Image in Medieval and Post-Medieval Europe, eds. KasPersen, Soren - HaAsrupt, Ulla, Museum Tusculanum Press, University of Copenhagen, 2004. 236. Peter Jezler war der Erste, der die Christusfigur aus Wienhausen als Depositionsgegenstand identifizierte. Siehe: Jezler, Peter: Ostergrab und Depositionsbild, Lizenziatsarbeit am Kunstgeschichtlichen Seminar der Universität Zürich, 1982. 41-44.

${ }^{6}$ Der Freiburger Münster, hrsg. von BeCKSMAnn, Rüdiger - ECHTEnACHER, Götz (Freiburger Münsterverein), Regensburg: Schnell \& Schneider, 2011. 219.

${ }^{7}$ Alltag und Frömmigkeit am Vorabend der Reformation in Mitteldeutschland, Katalog zur Ausstellung „Umsonst ist der Tod“, hrsg. von KüHnE, Hartmut - BünZ, Enno - Müller, Thomas T., Petersberg: Imhof, 2013. Kat.: 6.4.7.

8 Schwarzweber 1940, (vgl. Anm. 2) 42.; Kroesen: The Sepulchrum Domini 2000, (vgl. Anm. 2) 106; Husty, Peter: „Der Kerker Christi“ in der Bürgerspitalkirche St. Blasius, in Ars Sacra. Kunstschätze des Mittelalters aus dem Salzburg Museum (Jahresschrift des Salzburg Museum. Vol. 53.), hrsg. von Husty, Peter - Laub, Peter, Salzburg: Salzburg Museum, 2010. 183.

${ }^{9}$ Taubert 1969, (vgl. Anm. 3) 88. Kat. 27.

10 SChWARZWEber 1940, (vgl. Anm. 2) 44.

11 Taubert 1969, (vgl. Anm. 3) 112.

12 KraUse, Hans-Joachim: „Imago ascensionis“ und „Himmelloch“. Zum „Bild“-Gebrauch in der spätmittelalterlichen Liturgie, in Skulptur des Mittelalters. Funktion und Gestalt, hrsg. von MöBIUS, Friedrich - SCHUBERT, Ernst, Weimar: Hermann Böhlaus Nachfolger, 1987. 281-353.

${ }^{13}$ TRIPPS, Johannes: Das handelnde Bildwerk in der Gotik. Forschungen zu den Bedeutungsschichten und der Funktion des Kirchengebäudes und seiner Ausstattung in der Hoch- und Spätgotik, Berlin: Gebr. Mann, 1998. 12.

14 Krause 1987, (vgl. Anm. 12) 334.

15 Tripps 1998, (vgl. Anm. 13) 130; Kroesen: The Sepulchrum Domini 2000, (vgl. Anm. 2) 176.

${ }^{16}$ Gschwend, Kolumban: Die depositio und elevatio crucis im Raum der alten Diözese Brixen, Sarnen: Buchdruckerei Louis Ehrli \& Cie, 1965. 1.

${ }^{17}$ Flanigan, C. Clifford - Ashley, Kathleen - Sheingorn, Pamela: Liturgy as Social Performance: Expanding the Definitions, in The Liturgy of the Medieval Church, ed. HefFerNAn, Thomas J. - MatTer, E. Ann, Kalamazoo, Michigan, 2001. 695-714.

${ }^{18}$ Bell, Catherine: Ritual. Perspectives and Dimensions, New York: Oxford University Press, 1997. 137.

19 SCHWARZWEBer 1940, (vgl. Anm. 2) 45.

${ }^{20}$ Kroesen, Justin E. A.: Heiliges Grab und Tabernakel. Ihr Zusammenhang im mittelalterlichen Kirchenraum, Das Münster 53. 2000. 291-292; KROESEN: The Sepulchrum Domini 2000, (vgl. Anm. 2) 71.

${ }^{21}$ Kroesen: The Sepulchrum Domini 2000, (vgl. Anm. 2) 71.

22 Viollet-Le-Duc, Eugène-Emmanuel: Dictionnaire raisonné du mobilier français de l'Epoque Carolingienne à la Renaissance, Paris, 18682. I. 247; Lexikon der Christlichen Ikonographie, hrsg. von KiRsCHBAUM, Engelbert, Bd. II, Freiburg i. Br.: Herder, 1970. 183-185; KROESEN: The Sepulchrum Domini 2000, (vgl. Anm. 2) 72. 
${ }^{23}$ SHEIngORn, Pamela: The Easter Sepulchre in England, Western Michigan University, Kalamazoo, 1987. 34.

${ }^{24}$ Kroesen: The Sepulchrum Domini 2000, (vgl. Anm. 2) 69.

25 Kroesen: Heiliges Grab 2000, (vgl. Anm. 20) 292.

${ }^{26}$ Kroesen: The Sepulchrum Domini 2000, (vgl. Anm. 2) 71.

${ }^{27}$ München Staatsbibliothek. ms. clm 23018. 66b: Lateinische Osterfeiern und Osterspiele, hrsg. von LIPPHARDT, Walther, Teil 2, Berlin-New York: Walter de Gruyter, 1976. 311; TAubert 1969, (vgl. Anm. 3) 92.

${ }^{28}$ Brooks 1921, (vgl. Anm. 4) 61.

${ }^{29}$ Chambers, Edmund Kerchever: The Medieval Stage, Oxford University Press, 1903. Vol. II. 21.

30 Ordinarium, Regensburg, St. Emmeran. München, Staatsbibl. ms. clm. 14073. Nr. 15. 40a-40b: LOO, (vgl. Anm. 27) Teil 2. 1976, 325

31 Brooks 1921, (vgl. Anm. 4) 50.

32 Ordinarium 15th century, Stuttgart, Landesbibliothek Hb I. 77. 18a: LOO, (vgl. Anm. 27) Teil 2. 1976, 201.

33 „Item ein silberein sarch, den man nuczt am karfreitag

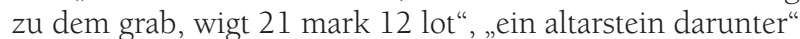
in WeILAnd, Gerhard: Die Sebalduskirche in Nürnberg. Bild und Gesellschaft im Zeitalter der Gotik und Renaissance, Petersberg: Michael Imhof Verlag, 2007. 167.

${ }^{34}$ Ibid.

35 Christoph Petersen differenzierte aus dem Gesichtspunkt des Zeichengebrauchs die verschiedenen religiösen Performance-Typen. Siehe: Petersen, Christoph: Ritual und Theater. Meßallegorese, Osterfeier und Osterspiel im Mittelalter, Tübingen: Max Niemeyer Verlag, 2004.

36 Petersen 2004, (vgl. Anm. 35) 17.

${ }^{37}$ Petersen 2004, (vgl. Anm. 35) 25-26.

38 Petersen 2004, (vgl. Anm. 35) 30.

39 Petersen 2004, (vgl. Anm. 35) 85.

40 Petersen 2004, (vgl. Anm. 35) 98.

${ }^{41}$ Petersen 2004, (vgl. Anm. 35) 94.

42 Ibid.

${ }^{43}$ Liber ordinarius 1260, Zürich, Zentralbibliothek. ms. C 8b. 51b: BroOKs 1921, (vgl. Anm. 4) 109.

${ }^{4}$ Petersen 2004, (vgl. Anm. 35) 121.

45 Petersen 2004, (vgl. Anm. 35) 122.

46 Petersen 2004, (vgl. Anm. 35) 118.

47 Brooks 1921, (vgl. Anm. 4) 55.

48 Schilling, A.: Die religiösen und kirchlichen Zustände der ehemaligen Reichstadt Biberach unmittelbar vor Einführung der Reformation, Freiburger Diöcesan-Archiv, Organ des kirchlich-historischen Vereins für Geschichte, Alterthumskunde und christliche Kunst der Erzdiöcese [sic] Freiburg mit Berücksichtigung der angrenzenden Diöcesen 19. 1887. 127.

49 Thüringisches Hauptstaatsarchiv Weimar, EGA Reg. O 158, 24r-30v: „Stifftung der abnemung des bildnus vnsers lieben hern vnd Seligmachers von Creutz vnd wie die besuchung des grabs von den viertzehen manßpersonsen etc. zcu witenberg in aller heyligen kirchen bescheen sooll“. Veröffentlicht: TAUBERT 1969, (vgl. Anm. 3) 98-101; Alltag und Frömmigkeit 2013, (vgl. Anm. 6) 6.4.8.

50 „Huius namque dominice passionis zelo, uti credimus, divinitus inspirati, dilecti in christo consules opidani et Incole opidi Hallensis nostre diocesis quoddam ciborium sub forma sepulchri subtiliter elaboratum, ac hodie per munus nostre benedictionis benedictum et consecratum fieri ordinarunt, In quo christianum signum sancte crucis iuxta ritum sancte matris Ecclesie reponi eadem die instituerunt, sup- pliciantes humiliter, ut ad ampliorem christi fidelium excitandam devotionem ipsis concedamus et indulgemus dignaremus, ut illis diebus, quibus huius signum sancte crucis in eodem ciborio seu sepulchro continetur, etiam Sacrotissimum Eucharistie sacramentum in illud valeant collocare." Veröffentlicht: GsCHWEND 1965, (vgl. Anm. 16) 56

${ }^{51}$ Veröffentlicht: GsCHWEND 1965, (vgl. Anm. 16) 56-57.

52 BOERnER, Bruno: Bildwirkungen. Die kommunikative Funktion mittelalterlicher Skulpturen, Berlin: Dietrich Reimer Verlag, 2008. 198

${ }^{53}$ DeHIO, Georg: Geschichte der deutschen Kunst, BerlinLeipzig II. (1921) 1930. 117-118; PInder, Wilhelm: Die deutsche Plastik von ausgehendem Mittelalter bis zum Ende der Renaissance I, Wildpark-Potsdam (1924) 1929. 92-107.

${ }^{54}$ PANOFsky, Erwin: „Imago Pietatis“. Ein Beitrag zur Typengeschichte des „Schmerzensmanns“ und der „Maria Mediatrix“, in Festschrift Max J. Friedländer, eds. FrIEDLÄNDER, Max Jakob - KRISTELler, Paul - Bock, Elfried et al., Leipzig: E. A. Seemann, 1929. 261-308.

55 Grinder-Hansen 2004, (vgl. Anm. 5) 239.

56 Gertsman, Elina: Image and Performance: An Art Historian at the Crossroads, Research on Medieval and Renaissance Drama 51. 2012. 51.

${ }^{57}$ Berliner, Rudolf: Arma Christi, Münchner Jahrbuch der bildenden Kunst 3. Folge, Bd. 6. 1955. 35-152; RinGBOM, Sixten: Icon to narrative: The rise of the dramatic close-up fifteenth-century devotional painting, in Acta Academiae Aboensis, Humaniora Vol. 31. 1965.

58 Belting, Hans: Das Bild und sein Publikum im Mittelalter. Form und Funktion früher Bildtafel der Passion, Berlin: Gebr. Mann, 1981. 103.

${ }^{59}$ Belting 1981, (vgl. Anm. 58) 98.

${ }^{60}$ Ibid.

${ }^{61}$ Belting 1981, (vgl. Anm. 58) 99.

62 Belting 1981, (vgl. Anm. 58) 100.

${ }^{63}$ Belting 1981, (vgl. Anm. 58) 103.

${ }^{64}$ Hamburger, Jeffrey: The Visual and the Visionary. Art and Female Spirituality in Late Medieval Germany, New York, 1998. 131.

${ }^{65}$ MARKS, Richard: Image and Devotion in Late Medieval England, Phoenix Mill, 2005. 13

${ }^{66}$ SkInNeBACH, Laura Katrine: Practises of Perception - Devotion and the Senses in Late Medieval Northern Europe (Dissertation), University of Bergen, Norway, 2013, 146.

67 SKINNEBACH 2013, 154.

68 SKINNEBACH 2013, 155.

${ }^{69}$ Veröffentlicht: GSCHWEND 1965, (vgl. Anm. 16) 56-57.

70 „Nos enim eisdem diebus, quibus ipsum Sacramentum in dicto Ciborio remanet collocatum... christifidelibus vere penitentibus confessis et contritis, qui devotis orationibus divinam misericordiam duxerint Implorandam passionis dominice misterium devote meditando, ac orationem dominicam septies cum tot angelicis salutationibus ac uno simbolo apostolorum devote dicendo de mane a cin sero die qualibet pro qualibet vice, Quadraginta dies indulgentiarum de iniunctis eis penitentiis in domino nostro relaxamus. In cuius testionem ac perpetuam rei memoriam." Veröffentlicht: GSCHWEND 1965, (vgl. Anm. 16) 56.

71 SCHILLing 1887, (vgl. Anm. 48) 127.

72 GsChWEND 1965, (vgl. Anm. 16) 59.

${ }^{73}$ Jezler, Peter: Bildwerke im Dienste der dramatischen Ausgestaltung der Osterliturgie - Befürworter und Gegner, 
in Von der Macht der Bilder, hrsg. von UlLmann, Ernst, Leipzig: Seemann, 1983, 236-237.

${ }_{74}$ JeZler 1983, (vgl. Anm. 73) 236.

75 JeZLer 1983, (vgl. Anm. 73) 237.

76 Ibid.

77 Obwohl die 1580 veröffentlichte verbindliche Missale Romanum von Pius V. erzielte, die westliche Liturgie zu vereinheitlichen, blieben die 200 Jahre älteren Ritusvarianten auch weiterhin erhalten. Auch die Karfreitag- und Osterriten mittelalterlicher Herkunft konnten sich auf diese Weise auferhalten.

78 Jungmann, Josef Andreas: Die Andacht der vierzig Stunden und das Heilige Grab, Liturgisches Jahrbuch 2. 1952. 184; JeZler 1983, (vgl. Anm. 73) 241.

${ }^{79}$ Nussbaum, Otto: Die Aufbewahrung der Eucharistie, Bonn: Hanstein, 1979. 166

80 Sein Grab wird herrlich sein. Heilige Gräber als Zeugen barocker Frömmigkeit, Ausstellungskatalog, hrsg. von KamM, Thomas, Salzburger Barockmuseum, Stadt- und Spielzeugmuseum Traunstein, Vachendorf, Werr, 2003. 29.

${ }^{81}$ Ibid. 27.

82 Kroesen: The Sepulchrum Domini 2000, (vgl. Anm. 2) 164.

83 Jungmann 1952, (vgl. Anm. 78) 185.

${ }^{84}$ Jungmann 1952, (vgl. Anm. 78) 191.

85 Young, Karl: The Drama of the Medieval Church, University of Michigan, 1933. I. 125.

86 Kroesen: The Sepulchrum Domini 2000, (vgl. Anm. 2) $164-165$.

${ }^{87}$ Nussbaum 1979, (vgl. Anm. 79) 102.

88 Directorium seu Rubrica pro utilitate chori ac Editui Ecclesie Brixinensis (1550), Domkapitelarchiv Brixen Fol. 85r. Zitiert: GsCHWEND 1965, (vgl. Anm. 16) 91.

${ }^{89}$ Ibid. Fol. 90v. Zitiert: GsCHWEND 1965, (vgl. Anm. 16) 94.

90 Ibid. Fol. 91r. Zitiert: GsCHwend 1965, (vgl. Anm. 16) 96.

${ }^{91}$ Bayerische Staatsbibliothek, München, ms. clm 11735. 60a: LOO, (vgl. Anm. 27) Teil 4. 660.

92 Dankó, József Károly: A húsvéti isteni szolgálat a régi magyar egyházban [Gottesdienst zu Ostern in der alten ungarischen Kirche], Esztergom: Horák E. Ny., 1872. 47; DANKÓ, József: A nagypénteki isteni szolgálat [Gottesdienst am Karfreitag], Új Magyar Sion 2. 1871. 179; SCHWARZWEBER 1940, (vgl. Anm. 2) 43-44; Kroesen: The Sepulchrum Domini 2000, (vgl. Anm. 2) 164.

93 GereVICH, László: A garamszentbenedeki úrkoporsó, in Emlékkönyv: Gerevich Tibor születésének hatvanadik fordulójára, Budapest: Franklin Társulat, 1942. 46; Nach Gerevich: PRokopr, Mária: A garamszentbenedeki Úrkoporsó az Esztergomi Keresztény Múzeumban, Budapest: Helikon Kiadó - Corvina, 1982, 28; BODORNÉ SzENT-GÁlY, Erzsébet: Szent Benedek Úrháza. Adatok a garamszentbenedeki úrkoporsó liturgikus használatához, Mưvészettörténeti Értesítô 36. 1987. 155; Keresztény Múzeum Esztergom, hrsg. von CsÉFAlvay, Pál, Budapest: Corvina, 1993. 178; TAKÁCS, Imre: Garamszentbenedek temploma és liturgikus felszerelése, in Paradisum Plantavit: Bencés monostorok a középkori Magyarországon, Ausstellungskatalog, ed. TAKÁcs, Imre, Pannonhalma: Pannonhalmi Bencés Főapátság, 2001. 182; Abb. 51-52; German, Kinga: Sakramentnischen und Sakramenthäuser in Siebenbürgen. Die Verehrung des Corpus Christi, Petersberg: Michael Imhof Verlag, 2014. 94; TRIPPS 1998, (vgl. Anm. 13) 123.

94 JanotTA, A.: Die österreichisch-ungarische Monarchie in Wort und Bild, Band: Kärnten und Krain, Königliche Hof- und
Staatsdruckerei, Wien, 1891. 227; SCHWARZWEBER 1940, (vgl. Anm. 2) 43-44.

95 KROESEN: The Sepulchrum Domini 2000, (vgl. Anm. 2) 164.

${ }^{96}$ Annemarie Schwarzweber schloss bei den letzteren zwei Beispielen eben deswegen die Möglichkeit der Anbringung der geweihten Hostie aus und bestritt damit überhaupt die liturgische Funktion. Siehe: Schwarzweber 1940, (vgl. Anm. 2) 44.

97 SChWARZWEBer 1940, (vgl. Anm. 2) 43; Kroesen: The Sepulchrum Domini 2000, (vgl. Anm. 2) 106.

98 GLASER, Franz: Das monumentale Grabmal des Alboin (†975) in Möchling, Rudolfinum-Jahrbuch des Landesmuseums für Kärnten 2003. 101-106.

${ }_{99}$ Gallenstein, Ritter von: Steinwerk in der Pfarrkirche zu Möchling in Jaunthale in Kärnten, Mittheilungen der K.K. Central-Commission zur Erforschung und Erhaltung der Baudenkmale 1872. 38.

100 Gallenstein 1872, 37.

101 STADLER, Georg: Das Bürgerspital St. Blasius zu Salzburg, Salzburg: Druckhaus-Nonntal-Bücherdienst, 1985. 156.

102 STADLER 1985, 93.

103 STADLER 1985, 93.

104 Husty 2010, (vgl. Anm. 8) 183.

105 Steinauer, Verena Villiger: Ostergrab aus dem Kloster Magerau (kurz nach 1329), in Museum für Kunst und Geschichte Freiburg, 1999-2009/4.

106 JeZLER 1982, (vgl. Anm. 5) 236.

107 SCHMiddunser, Agathe: Körper der Passionen: Die lebensgroße Liegefigur des toten Christus vom Mittelalter bis zum spanischen Yacente des Frühbarock, Regensburg: Erhardi, 2008. 29.

108 Liber ordinarius 1260, Zürich, Zentralbibliothek. ms. C 8b. 51b: LOO, (vgl. Anm. 27) Teil 4. 767

${ }^{109}$ WeHKING, Sabine: Die Inschriften der Lüneburger Klöster Ebstorf, Isenhagen, Lüne, Medingen, Walsrode, Wienhausen, Wiesbaden, 2009. (Die Deutschen Inschriften Bd. 76) Nr. 44 - www.inschriften.net/index.php?id=687\# content

http://www.inschriften.net/lueneburg-kloester-ebstorf-isenhagen-luene-medingen-walsrode-wienhausen/inschrift/nr/ di076-0044.html\#content

110 Jezler 1982, (vgl. Anm. 5) 47-48; Hartwieg, Babette: Drei gefasste Holzskulpturen vom Ende des 13. Jahrhunderts in Kloster Wienhausen, Zeitschrift für Kunsttechnologie und Konservierung, Worms am Rhein: Wernersche Verlagsgesellschaft, 1988. 2:2. 193.

${ }^{111}$ HARTWIEG 1988, 191-192, 197-198.

112 Dauven-VAn KnipPenberG, Carla: Die Klosterfrauen von Wienhausen feiern Auferstehung, in Das Theater des Spätmittelalters und der Frühen Neuzeit. Kulturelle Verhandlungen in einer Zeit des Wandels, hrsg. von HuwiLER, Elke, Heidelberg: Sinchron, 2015. 74-75.

113 SCHMidDUNSER 2008, (vgl. Anm. 107) 28.

114 TAmEN, Silke: Ornamentgitter und Christuskörper, in Ornament: Motiv, Modus, Bild, hrsg. von BEYER, Vera - SPIES, Christian, München: Fink, 2012. 212-235.

115 SuCKALE, Robert: Arma Christi. Überlegungen zur Zeichenhaftigkeit mittelalterlicher Andachtsbilder, in Stil und Funktion: Ausgewählte Schriften zur Kunst des Mittelalters, hrsg. von SCHMid, Peters - Wedekind, Gregor von, München: Deutscher Kunstverlag, 2008. 38. (Ursprünglich: Städel-Jahrbuch. Neue Folge. - München: Prestel, Bd. 6. 1977. 177-208.)

116 GsCHwend 1965, (vgl. Anm. 16) 56 
117 SuCKAle 2008, (vgl. Anm. 115) 31.

118 Ehrstine, Glenn: Figuriertes Gedächtnis, in Text und Kultur. Mittelalterliche Literatur 1150-1450, hrsg. von PETERS, Ursula, Stuttgart-Weimar, 2001. 416-437; EHRSTINE, Glenn: Framing the Passion: Mansion Staging as Visual Mnemonic, in Visualizing Medieval Performance. Perspectives, Histories, Contexts, ed. Gertsman, Elina, Ashgate, 2008. 263-277.

119 EHRSTine 2001, (vgl. Anm. 118) 419.

${ }^{120}$ Ehrstine 2008, (vgl. Anm. 118) 265.

${ }^{121}$ EHRSTine 2001, (vgl. Anm. 118) 419

122 Ehrstine 2001, (vgl. Anm. 118) 427; Neumann, Bernd: Geistliches Schauspiel im Zeugnis der Zeit. Zur Aufführung mittelalterlicher religiöser Dramen im deutschen Sprachgebiet, München-Zürich: Artemis, 1987. 414-415.
123 „nunc vero eandem (circuitum) cum figuris passionem Christi repraesentantibus ad commovendum simplicium animos ad meditantionem passionis dominice perficere $\mathrm{cu}-$ perent..." und „... ad excitandas mentes Christi fidelium in memoriam ejusdem dominice passionis cum ceremoniis et solennitatibus alias consuetis celebrari et perfici valeat...".

${ }^{124}$ EHrStine 2008, (vgl. Anm. 118) 263.

125 Neumann 1987, (vgl. Anm. 122) 279. no. 1220

${ }^{126}$ LOO, (vgl. Anm. 27) Teil 3. 617; Tripps 1998, (vgl. Anm. 13) 140 .

127 GSCHWEND 1965, (vgl. Anm. 16) 91.

128 BROOKs 1921, (vgl. Anm. 4) 61.

129 AuERBACH, Erich: „Figura“, in Gesammelte Aufsätze zur romanischen Philologie, Bern-München: Francke, 1967. 55-92.

130 Belting 1981, (vgl. Anm. 58) 98-99. 